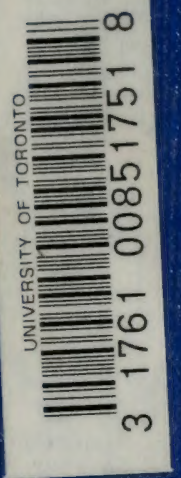



Digitized by the Internet Archive in 2008 with funding from Microsoft Corporation 





\section{THE FITNESS}

\section{OF THE ENVIRONMENT}




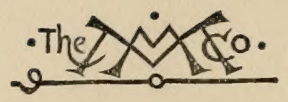

\section{THE MACMILLAN COMPANY NEW YORK - BOSTON - CHICAGO DALLAS - SAN FRANCISCO \\ MACMILLAN \& CO., Limited LONDON - BOMBAY - CALCUTTA MELBOURNE}

THE MACMILLAN CO, OF CANADA, LTD. TORONTO 


\section{THE FITNESS \\ OF THE ENVIRONMENT}

AN INQUIRY

INTO THE BIOLOGICAL SIGNIFICANCE OF THE PROPERTIES OF MATTER

BY

\section{LAWRENCE J. HENDERSON}

ASSISTANT PROFESSOR OF BIOLOGICAL CHEMISTRY IN HARVARD UNIVERSITY

IN PART DELIVERED AS LECTURES IN THE LOWELL INSTITUTE, FEBRUARY, 1913

Neros 19ork

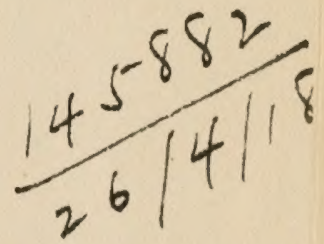

THE MACMILLAN COMPANY 


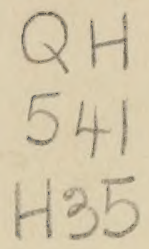

Copyright, 1918,

BY THE MACMILLAN COMPANY.

Set up and electrotyped. Published February, rgiz. 


\section{PREFACE}

Darwinian fitness is compounded of a mutual relationship between the organism and the environment. Of this, fitness of environment is quite as essêntial a component as the fitness which arises in the process of organic evolution; and in fundamental characteristics the actual environment is the fittest possible abode of life. Such is the thesis which the present volume seeks to establish. This is not a novel hypothesis. In rudimentary form it has already a long history behind it, and it was a familiar doctrine in the early nineteenth century. It presents itself anew as a result of the recent growth of the science of physical chemistry.

About fifteen years ago I first became interested in the connection between physical and chemical properties of simple substances and the organic functions which they serve. At that time the applications of the new physical chemistry to physiology were only just beginning, and the older speculations of natural theology upon such subjects had long since 
passed into oblivion. It was a time of very little interest in such matters, for many lines of development of natural science during the preceding quarter century had conspired to divert attention to other problems. The immediate occasion of my interest was, I well remember, the chance reading of Maly's important but almost forgotten papers upon the diffusion and dialysis of phosphates, recounting phenomena which, in the light of the modern theory of ionization, appeared simple enough, though to their discoverer they had been in some respects inexplicable. A series of researches have grown out of this interest, and since that time, whenever freedom has permitted, I have been occupied with various aspects of the problem of the neutrality or faint alkalinity of the organism. For it soon appeared that the key to the peculiar conditions of equilibrium between acids and bases in blood and protoplasm is to be found in such characteristics of phosphate solutions as Maly had observed, and in like behavior of similar solutions containing carbonic acid. When at length it became possible quantitatively to describe the chemical equilibra in such systems, it was at once clear that, of all known substances, phosphoric acid and carbonic acid possess the greatest power of automatic regu- 
lation of neutrality (the concentration of ionized hydrogen and hydroxyl at the neutral point).

One does not like to accept a fact of such far-reaching importance as mere chance, and yet no other explanation was at hand. For, after the briefest consideration, it was obvious that here, at least, natural selection could not be involved. But it was also certain that this is no unique instance of a property of a simple substance automatically serving a very useful purpose in the processes of life. Like every one who has received a chemical training, I was vaguely conscious of numerous other similar cases ; like every one who has any acquaintance with the general properties of matter, I knew that the remarkable thermal properties of water are of great importance to living organisms. However, in spite of the fact that I had been brought face to face with a definite problem whose solution now appears to be perfectly patent, so great is the natural inertia of the mind, and so firmly established was the belief that natural selection is, on the whole, quite adequate to account for biological fitness, that for a number of years I made no further progress.

Then, finally, after a long period of uncertainty, came the realization of the reciprocal 
character of Darwinian fitness, and at once the whole difficulty was resolved. On all sides instances of environmental fitness were manifest, and casual search brought many other cases to light. The forgotten literature of natural theology is crammed with illustrations, and the recent biological developments of physical chemistry have provided still others. It is, indeed, a very curious episode in the history of thought that these wellknown facts should have been so long forgotten or misconstrued. But, though forgotten, they have, so to speak, lain dormant in the minds of physical scientists, and I have found both chemists and physicists ready to accept them without hesitation. In the following pages an attempt has been made to collect and to interpret such facts, in so far as they arise among the compounds of carbon, hydrogen, and oxygen, especially in the cases of water and carbonic acid. This restriction has been adopted in order to facilitate the logical discussion, and it should be borne in mind that other phenomena, dependent upon the properties of other substances, such as the above-mentioned characteristics of phosphate solutions, belong in the same category.

The argument which has been thus developed is comparatively rigid and closely woven. 
That is, perhaps, in some respects unfortunate, because the impression which must be produced is unlike that of the facts themselves, and the argument is certainly very different from the mental process through which I have myself passed in reaching the conclusion. But it would be very difficult indeed in any other manner to set forth all the necessary considerations, so that they should be intelligible to any one but the physico-chemical biologist, and on the whole there seems to be no choice but to follow a logical rather than a descriptive method. The reader will find, however, that in the main Chapters III, IV, V, and VI are concerned with evidence alone. This taken together, as a whole, is the only true ground for a conclusion, and it is upon the general character of the evidence rather than upon an argument which only serves as a means to the end that I should wish to rest my case. To many, on the other hand, as to any biologist who may not care to examine the difficult facts of physics and chemistry, Chapters I, II, VII, and VIII will be sufficient to explain both the purpose of the book and the outcome of the investigation.

There has been a constant effort to restrict all discussions to the utmost, because at the present time encyclopædic handbooks covering all 
departments of science have so multiplied that hardly any facts or theories which come within the scope of this work are inaccessible to the general reader. On the other hand, it has been deemed necessary to explain every subject as it has arisen, for many of the readers of this volume will perhaps be unfamiliar even with the rudiments of all the departments of science which have necessarily been touched upon.

Much of the content of the following pages has already been set forth in lectures. The general conclusion was presented last February to the members of the Harvard Seminary of Logic; later in the academic year I delivered the substance of the book as part of a college course to my students of biological chemistry in Harvard College.

I am indebted to many of my colleagues in Harvard for valuable assistance, criticism, and expressions of opinion. Without such assurances that I have not fallen into gross blunders, and that the conclusions appear reasonable to experienced men of science, I should not have dared to undertake a task which overtaxes my knowledge, or positively to assert a proposition which is in conflict with much of the scientific thought of the last half century. Especial thanks are due to Professor 
Josiah Royce. His learning and generosity have in the past aided me to reach an understanding of the philosophical problems of science, and in the preparation of this book they have repeatedly guided me aright.

Seil Harbor, Maine, August, 1912. 



\section{CONTENTS}

\section{CHAPTER I}

PAGE

FITNESS • • • • • • • • •

I. Purpose and Order .

II. Fitness . . . . . . . • . 4

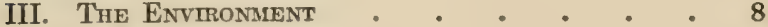

A. Matter . . . . . . . 8

B. Energy * • • • • . . 15

C. Space and Time . . . . . . 19

IV. The Organism • . . . . . . 21

A. Metabolism . . . . . . . 24

B. Organic Chemistry $\quad$ - . . . 28

C. The Characteristics of Life . . . . 30

V. The Problem .

\section{CHAPTER II}

\section{THE ENVIRONMENT}

I. Astronom • • • • • • • . 38

II. Possible Environatents • • • • • 49

III. Geophysics - • • • • • • 52

IV. The Atmosphere . • • • • • $\quad 55$

V. General Cosmographical Conclusions . 60

VI. The Prmary Constituents of tue EnvironMENT . . . . . . . . 61

VII. The Ulthite Problem . . • • . 63

VIII. The Method of Solution • . • • . 67 


\section{CHAPTER III}

PAGE WATER • • • • • • • • • • . 78

I. Thermal Properties . . . . . 80 A. Specific Heat . . . . . . 80

B. Latent Heat . . . . . . 92

C. Thermal Conductivity . . . . 106

D. Expansion before Freezing . . . 106

II. The Action of Water upon Other Substances 110

A. Water as a Solvent. . . . . . 111

B. Ionization . . . . . . 118

C. Surface Tension . . . . . 126

\section{CHAPTER IV}

CARBONIC ACID

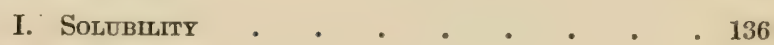

II. ACIDITY * . . . . . . . 140

\section{CHAPTER V}

THE OCEAN • • . . . . . . . 164

I. The Regulation of Physico-chemical Conditions 164

II. The Circulation of Water . • . . 180

III. The Ocean as Environment $\quad . \quad$. . . 183

\section{CHAPTER VI}

THE CHEMISTRY OF THE THREE ELEMENTS • 191

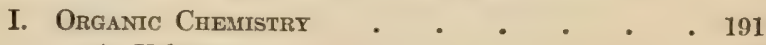

A. Valence . . . . . . . . 196

B. Hydrocarbons . . . . . . 197 
PAEE

C. Compounds of Carbon, Hydrogen, and Oxygen 202

D. Other Organic Compounds . . . . 208

E. The Characteristics of Organic Substances - 209

$F$. The Sugars . . . . . . . 222

G. Hydrolysis . . . . . . . 232

II. Inorganic Chemistry . . . . . . 237

III. Thermochemistry . . . . . . . 243

\section{CHAPTER VII}

THE ARGUMENT . . . . . • • . 249

I. Analysis of the Evidence - . . . . $\$ 50$

II. The Exhaustiveness of the Treatment * . 253

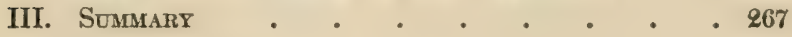

\section{CHAPTER VIII}

LIFE AND THE COSMOS . . . . . . 274

I. The Significance of Fitness . . . . 274

II. Vitalism . . . . . . . . 282

A. The Vitalism of Bergson . $\quad$. . . 293

B. Vitalism and Teleology . . . . . 298

III. Cosmic Evolution . . • • . . . 301

A. The Periodic System . . . . . 303

B. Teleology . . . . . . . 305 



\section{CHAPTER I}

\section{FITNESS}

\section{I}

\section{PURPOSE AND ORDER}

TDEAS of purpose and order are among 1 the first concepts regarding their environment which appear, as vague anticipations of philosophy and science, in the minds of men. In truth, when the manifold phenomena and experiences of daily life stored in the memory are critically scrutinized, purpose and order seem naturally to suggest themselves as explanations of the universe. Day and night, the changing but recurring seasons, the fertilizing sunshine and rain, the flight of birds, the powers of the human hand, and all the beauties and mysteries of nature cannot fail of such interpretation by the simple and untrained mind. Alike anthropology and the history of primitive civitizations bear witness to this natural tendency of thought. Such ideas pre- 
cede exact knowledge and civilization, and arise spontaneously among savage peoples. They are the solvent of the chaos, as which the outer world first presents itself to our. eyes and hands, and they are the fabric of all theologies.

As civilization has progressed, these early hypotheses have received endless criticism, and their definition has been continually sharpened. Meantime natural science has sought and provided ever more accurate accounts of the phenomena which first suggested them to man, and of countless other forms and transformations of matter and energy, and the discovery of laws of nature has steadily changed once quite mysterious order and purpose into the plainest of necessary results.

Upon the advent of modern science order speedily began to receive its true account when, after only a half century of progress, dynamics through Newton provided a formulation of the laws which govern the most striking of all the orderly phenomena of nature. ${ }^{1}$ Since Newton's day the explana-

1 “'Die Newton'schen Principien sind genügend, um ohne Hinzuziehung eines neuen Princips jeden praktisch vorkommenden mechanischen Fall, ob derselbe nun der Statik oder der Dynamik angehört, zu durchschauen. Wenn sich hierbei Schwierigkeiten ergeben, so sind dieselben immer nur mathe- 
tion of natural order as the automatic result of natural law has not ceased, and at length has become so nearly complete that the appearance of order under any circumstances is now taken as proof of the existence of a law.

The fate of the hypothesis of purpose in nature has been less simple, because the discovery of law, or even of the possibility of law, underlying adaptation and fitness was more difficult. Until the middle of the nineteenth century the countless adaptations of organisms to the environment and the manifest fitness of nature for the activities of living things seemed to many biologists only explicable as the result of some directing force. ${ }^{1}$ Even skeptics were nearly or quite

mathischer (formeller) und keineswegs mehr principieller Natur." - MACH, "Die Mechanik in Ihrer Entwickelung Historisch-Kritisch Dargestellt." Leipzig, 1897, 3l el., p. 257.

"Dann hat er auch die Aufstellung der heute angenommen Principien der Mechanik zu einem Abschluss gebracht."” - MACH, ibid. p. 181.

${ }^{1}$ See for example that remarkable series of works, the Bridgewater Treatises "On the Power, Wisdom, and Goodness of God, as manifested in the Creation; illustrating such work by all reasonable arguments, as for instance the variety and formation of God's creatures in the animal, vegetable, and mineral kingdoms; the effect of digestion, and thereby of conversion; the construction of the hand of man, and an infinite variety of other arguments; as also by discoveries ancient and modern, in arts, sciences, and the whole extent of literature."-Whewell, "Astronomy and General Phys- 
unable, however strong their desire, to account for the facts with a plausible theory. The dogma of final causes had led a thousand times to the truth by teaching the investigator that the true description of an organ or physiological process was to be found in its utility to the organism as a whole. Such considerations were far too numerous and too patent for science to shirk some explanation, and the only weighty explanation at hand seemed the teleological one.

\section{II}

\section{FITNESS}

With a suddenness which to many seemed catastrophic Darwin's hypothesis of natural selection changed the whole aspect of the problem. Law appeared as the basis of purpose just as it had appeared as the basis of order, and adaptations became, in the judgment of most men, the necessary results of an automatic process. To-day, after a half century, there is no longer room for doubt that the fitness of organic beings for their life in the world has been won in whole or in part

ics Considered with Reference to Natural Theology." London, 1834, 4th ed., p. ix.

To this series such men as Wherrell and Sir Charles Bell contributed. 
by an almost infinite series of adaptations of life to its environment, whereby, through a corresponding series of transformations, present complexity has grown out of former simplicity. ${ }^{1}$

The great and fruitful ideas which Darwin brought to the attention of the whole world have long since been incorporated into human thought. Not the least important among them is the new scientific concept of fitness, as it emerges from the discussion of natural selection. Before Darwin, this concept possessed all the vagueness of an idea which, though in part founded on observation, was not to be explained with the help of existing scientific theories. But although Darwin's fitness involves that which fits and that which is fitted, or more correctly a reciprocal relationship, it has been the habit of biologists since Darwin to consider only the adaptations of the living organism to the environment. ${ }^{2}$

${ }^{1}$ The ideas which are associated with the names of de Vries, as well as the very different hypotheses of Driesch, Bergson, and others are, of course, concerned with the manner, not with the fact of adaptation and organic evolution.

${ }^{2}$ Far different was the earlier point of view. An examination of Whewell's Bridgewater Treatise at once reveals important, if often fallacious, discussions of environmental fitness; e.g. "It has been shown in the preceding chapters that a great number of quantities and laws appear to have been selccted in the construction of the universe; and that by the 
For them, in fact, the environment, in its past, present, and future, has been an independent variable, and it has not entered into any of the modern speculations to consider if by chance the material universe also may be subjected to laws which are in the largest sense important in organic evolution. Yet fitness there must be, in environment as well as in the organism. How, for example,-could man adapt his civilization to water power if no water power existed within his reach?

adjustment to each other of the magnitudes and laws thus selected, the constitution of the world is what we find it, and is fitted for the support of vegetables and animals in a manner in which it could not have been, if the properties and quantities of the elements had been different from what they are. We shall here recapitulate the principal of the laws and magnitudes to which this conclusion has been shown to apply.

1. The Length of the Year, which depends on the force of the attraction of the sun, and its distance from the earth.

2. The Length of the Day.

3. The Mass of the Earth, which depends on its magnitude and density.

4. The Magnitude of the Ocean.

5. The Magnitude of the Atmosphere.

6. The Law and Rate of the Conducting Power of the Earth.

7. The Law and Rate of the Radiating Power of the Earth.

8. The Law and Rate of the Expansion of Water by Heat.

9. The Law and Rate of the Expansion of Water by Cold, below 40 degrees. 
At first sight it may well seem that inquiry into such a problem must end unsuccessfully in vague and unprofitable guesses. Indeed the past has brought forth no lack of such vain attempts, usually guided by a devotion to the doctrine of design in the service of theology. Yet other sciences have grown since 1859, and physical and chemical data in abundance are now at hand to aid in a reconsideration of the environment's fitness, if

10. The Law and Quantity of the Expansion of Water by Freezing.

11. The Quantity of Latent Heat absorbed in Tharwing.

12. The Quantity of Latent Heat absorbed in Evaporation. Heat.

13. The Law and Rate of Evaporation with regard to

14. The Law and Rate of the Expansion of Air by Heat.

15. The Quantity of Hicat absorbed in the Expansion of Air by Heat.

16. The Law and Rate of the Passage of Aqueous Vapor through Air.

17. The Laws of Electricity; its relations to $\mathrm{Air}$ and Moisture.

18. The Fluidity, Density, and Elasticity of the Air, by means of which its vibrations produce Sound.

19. The Fluidity, Density, and Elasticity of the Ether, by means of which its vibrations produce Light." - Wиеwell, "Astronomy and General Physies Considered with Reference to Natural Theology." London, 1834, 4th ed., pp. 141-143.

It is hard to understand how such ideas could have fallen into oblivion. 
such exist. Clearly it is well to seek among these data for a more precise formulation of the problem, which may then perchance lead to some more ambitious quest, or at least to new understanding of the old failure.

\section{III}

\section{THE ENVIRONMENT}

The world of our senses is a world of matter and energy, space and time. After centuries of philosophical and scientific study, these, the very logical elements of science, are no doubt still without a final description. None the less is there sound foundation for the belief that our preliminary accounts of all four possess completeness in some respects and for certain purposes. Nor are we to-day less confident of the finality of some of our ideas regarding the nature of life and the vital processes, as they exist in this world. But both of these conclusions call for further consideration.

MATTER

Many facts contribute to the belief, universal among chemists, that the known elements constitute by far the greatest part of 
a system of materials out of which the universe is formed, within which all chemical changes (except certain phenomena of radium and a few other anomalies, including perhaps unknown changes in the interiors of the celestial bodies) take place.

It is certain that nearly all the chemical transformations upon the earth consist of rearrangements of the atoms of the known elements. A century and a half of scientific chemistry guarantee that conclusion with a security rarely attained in descriptive science. And the testimony of the spectroscope is equally conclusive that the visible stars, like the sun itself, are made up almost or quite exclusively of the same chemical elements. Such facts, so familiar that they require no comment or explanation, might sufficiently justify the acceptance of the chemist's known elements as the only important matter in the universe. But even more weighty evidence is at hand; I mean the so-called periodic classification of the elements.

It has long been evident that simple relationships exist in some cases between the atomic weights of similar elements. For example, the atomic weights of bromine, strontium, and selenium are approximately equal 
to the means of the atomic weights of chlorine and iodine, of calcium and barium, and of sulphur and tellurium respectively. More general relationships between the atomic weights and properties of the elements were first pointed out by Newlands in 1864 and were extended by Mendeléeff and Lothar Meyer a little later. Out of these studies has arisen the law that the properties of the elements are periodic functions of their atomic weights.

The essential characteristics of this law are best illustrated by a consideration of the relative volumes occupied by atoms of the various elementary substances, the so-called atomic volumes, which may be expressed by dividing atomic weights by specific gravities. The facts are graphically represented upon the accompanying diagram, where atomic weights are plotted horizontally, atomic volumes vertically.

Beginning with lithium the volumes fall to boron and carbon, then rise irregularly to sodium. A second fall leads to aluminium, a second rise to potassium, and then the rises and falls of the curve are repeated until, among the elements of higher atomic weight, gaps break the continuity of the relationship. On the whole curve similar elements occupy 


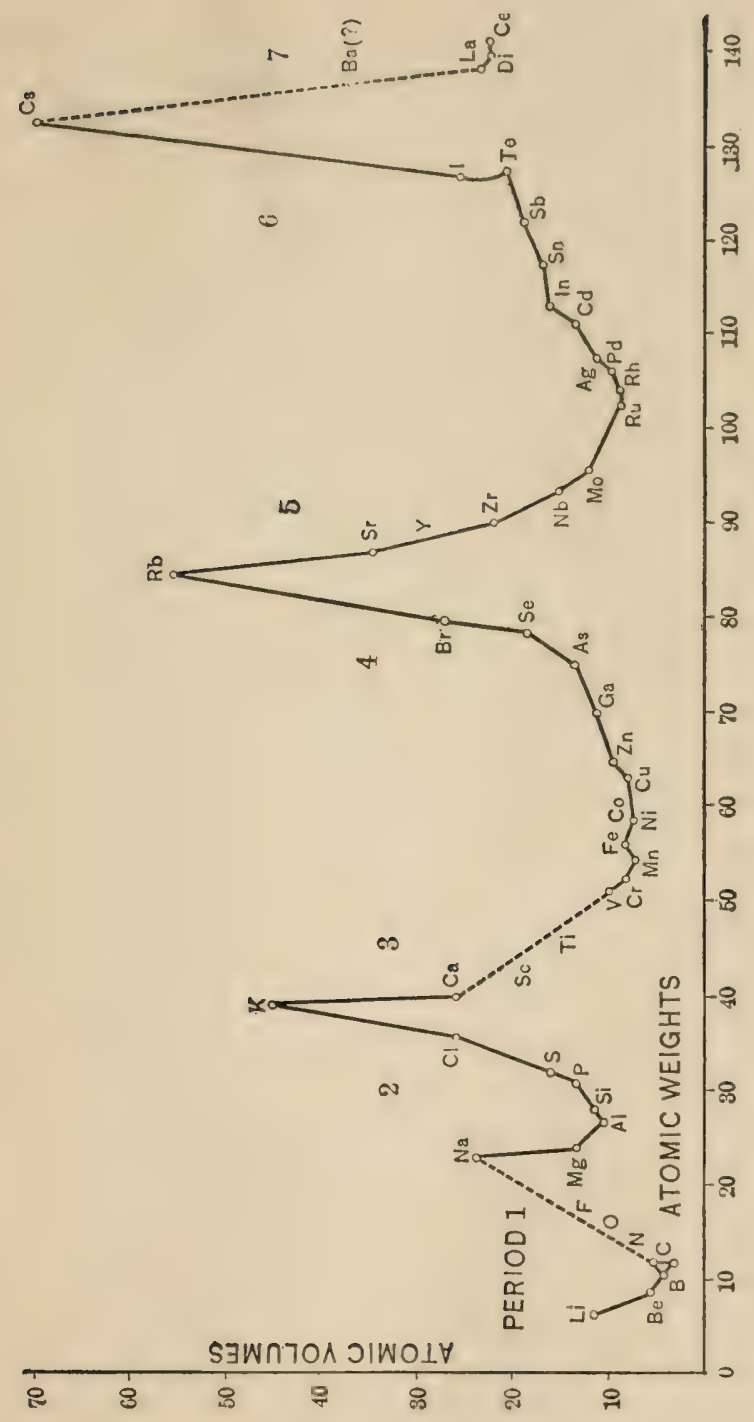


similar positions. Thus the alkali metals, lithium, sodium, potassium, rubidium, and cæsium, occupy the crests of the waves; the halogens, fluorine, chlorine, bromine, and iodine, fall about midway between crests and troughs, and a little further study discloses a host of other corresponding relationships.

Similar periodic variations may be shown to occur in other physical properties of the elements; - the melting points, the boiling points, the magnetic characteristics, etc. Even more striking are the periodic variations in chemical properties, including the general characteristics which first led to the idea of rational classification, and more specific qualities like the combining powers for hydrogen, oxygen, and other elements.

The clearest proof of the value of the periodic classification has been the prediction of "new" elements, and accurate foreknowledge of their properties. Thus when Mendeléeff first described the system, the element germanium, discovered by Winkler in 1886, was unknown; but from the properties of the elements surrounding a gap in the system the Russian chemist was able to predict its properties with almost incredible exactness, as the following table shows. 


\begin{tabular}{|c|c|c|c|c|c|}
\hline & & & & Prediction & OBgERVATION \\
\hline Atomic weight . & - . & . & - & 72.0 & 72.3 \\
\hline Specific gravity . & . . . & . & . . & 5.5 & 5.469 \\
\hline Atomic volume & . . . & . & - & 13 & 13.2 \\
\hline Formula of oxide & . . . & 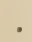 & . & $\mathrm{GeO}_{2}$ & $\mathrm{GeO}_{2}$ \\
\hline Specific gravity of & oxide . & - & . & 4.7 & 4.703 \\
\hline Formula of chloride & e . . & 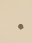 & - & $\mathrm{GeCl}_{4}$ & $\mathrm{GeCl}_{4}$ \\
\hline Boiling point of chl & loride . & ${ }^{\circ}$ & . & Less than $100^{\circ}$ & $86^{\circ}$ \\
\hline Specific gravity of & chloride & . & . & 1.9 & 1.9 \\
\hline Formula of fluoride & e . & & - & $\mathrm{GeFl}_{4}$ & $\mathrm{GeFl}_{4}$ \\
\hline Formula of ethyl ce & ompoun & & & $\mathrm{Ge}\left(\mathrm{C}_{2} \mathrm{H}_{5}\right)_{4}$ & $\mathrm{Ge}\left(\mathrm{C}_{2} \mathrm{H}_{5}\right)_{4}$ \\
\hline Specific gravity of & ethyl cor & $\mathrm{mr}$ & ound & 0.96 & Lower than water \\
\hline
\end{tabular}

Finally it is to be especially noted that, upon arranging the known elements in a table rationally constructed upon the basis of the above recorded facts, comparatively few spaces within the range of known atomic weights remain to be filled. The conclusion is obvious that very few elements now unknown are possible unless they possess very high atomic weights. But the apparent transmutation of radium into helium is a pretty clear indication that elements of very high atomic weight may be unstable. If they have existed in number and large quantity, they probably have long since ceased so to exist, except perhaps in the interior of celestial bodies, and they are not likely elsewhere to complicate natural phenomena by their unknown properties. 
14 THE FITNESS OF THE ENVIRONMENT

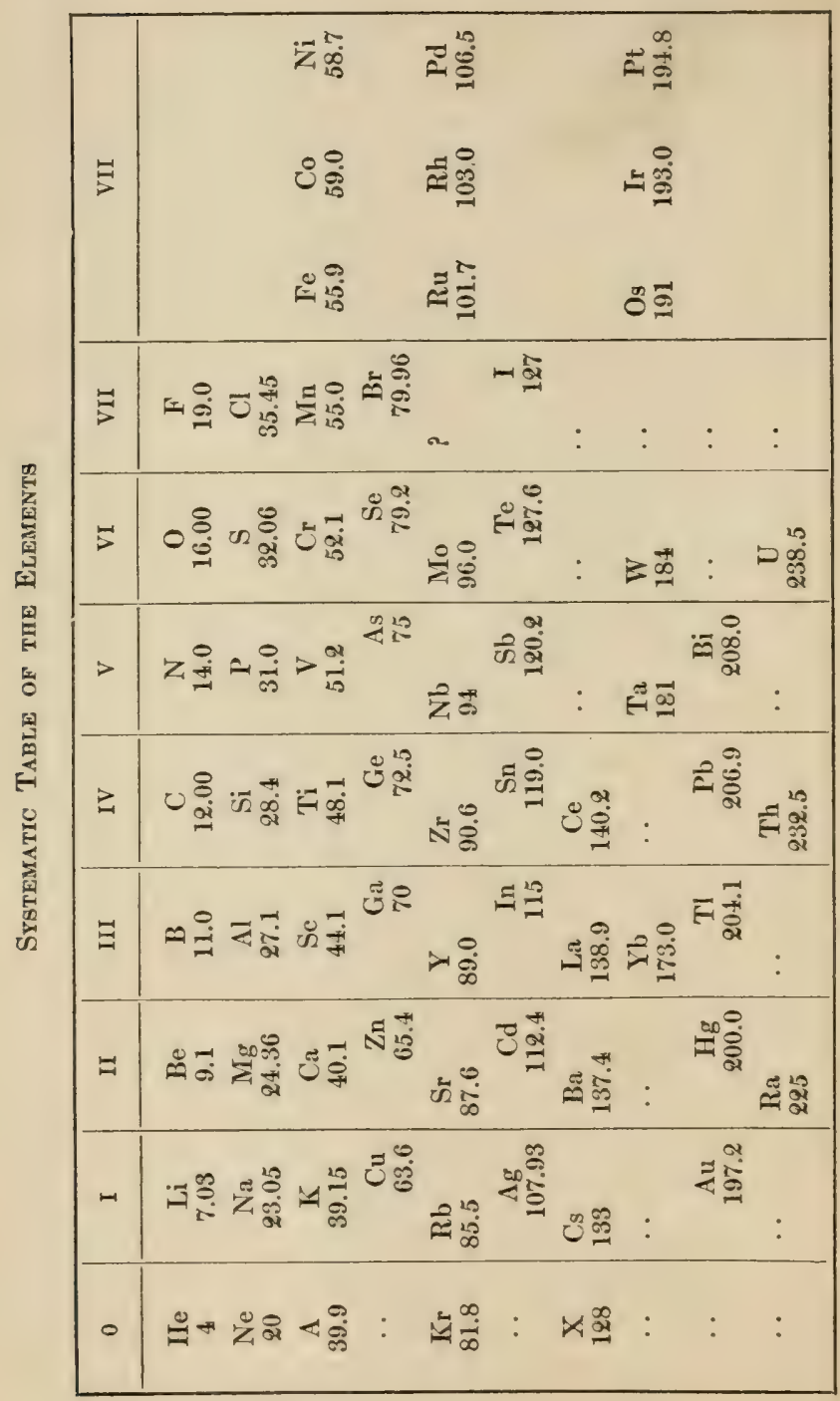


The behavior of radium and the classification itself suggest one further idea: the hypothesis that the elements are genetically related, that they have been evolved by some unknown process according to unknown laws. Certain it is that the properties of matter are no chance phenomena, and that transmutation has ceased to be merely a philosopher's dream.

All of these familiar facts of chemical science fully justify us in dealing with matter as a known factor in the study of life conditions in the universe. For, whatever may be the fate of present theories, our present practical knowledge of the behavior of matter cannot fail us in the future.

\section{$B$}

ENERGY

Contemporary with the work of Darwin and of Mendeléeff were the feats of Mayer, Joule, Helmholtz, Kelvin, and Clausius, whereby ideas of energy assumed their modern aspect. In the revolution wrought by these men imponderables and fluids vanished from this domain, and energy became that which, not being matter, is conserved. The new principles of the 'fifties have held their own until to-day. Meantime they have 
made of thermodynamics (the department of science which is especially concerned with the laws of energy transformation) a subject which few who cultivate the physical sciences may disregard. Countless developments and achievements of thermodynamics give very real ground for the belief that we may speculate about the transformations of energy in the universe with the same assurance that we have in discussing chemical changes.

Our reasons for confidence in the truth of current general notions of energy, and in their adequacy to account for any phenomena so far as energy is concerned, wherever life exists in the universe, are manifold, and not unlike those which have been reviewed in discussing the elements.

Centuries of search have revealed, in addition to that most obvious form which is studied in dynamics, a very small number of varieties or manifestations of energy, such as heat, electricity, magnetism, optical energy, and chemical energy. Such manifestations of energy are by no means confined to the earth or to the solar system. Indeed Newton first worked out the general laws of dynamics and erected them into a complete science with the aid, not of terrestrial, but of astro- 
nomical phenomena. ${ }^{1}$ And recent most remarkable studies of the stars have enabled astronomers to account for obscure events in far distant parts of the universe by the application of the principles of dynamics. Similarly light, heat, and chemical energy, as we know them, are unquestionably universal.

No doubt the manifestations of energy within the sun and stars, like the accompanying material phenomena there, can to-day only be surmised. For aught we know, these places may, as has been guessed, be the birthplace of elements and the seat of manifestations of energy quite different from

1 "What the Occasion of Sir Isaac Newton's leaving the Cartesian Philosophy, and of discovering his amazing Theory of Gravity was, I have heard him long ago, soon after my first Acquaintance with him, which was 1694, thus relate, and of which Dr. Pemberton gives the like Account, and somewhat more fully, in the Preface to his Explication of his Philosophy: It was this. An Inclination came into Sir Isaac's Mind to try, whether the same Power did not keep the Moon in her Orbit, notwithstanding her projectile Velocity, which he knew always tended to go along a strait Line the Tangent of that Orbit, which makes Stones and all heavy Bodies with us fall downward, and which we call Gravity? Taking this Postulatum, which had been thought of before, that such Power might decrease, in a duplicate Proportion of the Distances from the Earth's Center." - "Memoirs of the Life of Mr. William Whiston by Himself." London, 1749, Vol. I, pp. 35-38. Quoted by Ball. “An Essay on Newton's Principia." London, 1893, p. 8. 
what we have ever observed. But, however interesting and important such processes may be, it is not to be supposed that they are of direct moment in physiological processes. These conditions are far beyond the limits of our present investigation. Accordingly, everything that observation has taught confirms the belief that energy, like matter, is in general well known to us. Its manifestations are few, and they are universal. But just as the generalizations of science yield further assurance regarding matter, so they do not fail to confirm our conclusions in the study of energy. The law of the conservation of energy and the law of the degradation of energy, otherwise known as the first and second laws of thermodynamics, clearly indicate that the manifestations of energy are not accidental nor independent of one another. They are orderly, and they obey laws. Energy is one and indestructible.

Such are the apparently irrefragable conclusions of the brief half century of creative development, from the time when Young first used the word "energy" and Bolton and Watt first employed the idea of measuring energy in horse power, through the period of Carnot's brilliant intuition regarding the relation between heat and work, to the epoch 
of the foundation of thermodynamics. ${ }^{1}$ Today we know that just so much heat, neither more nor less, may be obtained by the complete conversion of a unit of electrical energy or by a given chemical process. We know, moreover, that not every conceivable change from one form of energy to another is possible. On the whole, energy can flow in but one direction; perpetual motion is impossible; and useful energy is steadily becoming degraded, dissipated, and useless.

Such laws are fully worthy of a place beside the periodic law, and they justify equal confidence in the adequacy of our current descriptions of matter and of energy for the purposes of biology.

\section{C}

\section{SPACE AND TIME}

Since Kant revolutionized modern philosophy, the whole world has steadily realized that between matter and energy on the one hand, and space and time on the other, there is a real and highly significant difference. ${ }^{2}$

${ }^{1}$ An excellent account of this period may be found in Merz's "History of European Thought in the Nineteenth Century," Vol. II, Chap. VII, "On the Physical View of Nature."

${ }^{2}$ For a brief statement of Kant's argument see Royce, “The Spirit of Modern Philosophy,” pp. 121-125. 
But, however important such distinctions may be for the philosopher, the man of science in his practical task is obliged to put them aside and to make the best of whatever evidence experience, observation, and experiment may supply. Out of such studies space and time have emerged, usefully defined by mathematical criticism as substantial parts of the edifice of science. ${ }^{1}$

There is no small difficulty in the exposition of modern critical results regarding space and time, but fortunately there is little need of considering them on the present occasion. For in spite of all assaults of philosophers and mathematicians space remains for practical purposes more certainly than ever the Euclidian space of the ancients, only it has become somewhat richer in characteristics. And time is now and forever that which flows equably, wholly independent of all else, though almost all else is dependent upon time. It is Euclidian space in which the earth moves and describes its ellipse, parallel rays of light never do meet in our practical experience, and our crystals

${ }^{1}$ The works of Poincaré, "La Science et l'Hypothèse," "La Valeur de la Science," and "Science et Méthode," published by Flammarion, may be consulted for a popular statement of such mathematical studies. 
are in form the figures of Euclidian geometry. Our time flows ever in proportion to the swings of a pendulum, the propagation of light and the progress of a chemical change. Time and space are thus bound to matter amel energy by experience, and for practical mimoses we accept all four as science at prescnt knows them. ${ }^{1}$ We cannot doubt ha! knowledge of them will increase and illea of them change. But we can scarcely think that our present ideas are inadequate for our present purposes, or that, for life, muller will ever be other than the elements of the periodic classification, energy that set of yruntities to which we apply the laws of thermodynamics, and time and space the concepts which were familiar to Galileo and Euclid.

\section{IV}

\section{THE ORGANISM}

Thus the growth of physical science has morided the speculative biologist with a V(r) accurate and extensive description of tive physico-chemical structure of the materiel universe and with a well-founded con-

in the present work we need have no concern for the so-ci iled principle of relativity. 
fidence in his right to make use of the description in investigating the relationship between life and the environment.

The biologist studies living organisms as inhabitants of this world, and by holding fast to physics and chemistry he has created modern physiology, a science which unites many, indeed nearly all, of the departments of physics and chemistry in the task of describing the processes of life.

That task has proved an arduous one, even in comparison with the other enterprises of science, and it must be confessed that few of the departments of physiology wear an aspect of finality which has long been familiar in such sciences as mechanics and crystallography, for example. Yet, as time has passed, and the nature of the material basis of life and the conspicuous features of the mechanism which the organism presents for study have become more familiar, assurance has steadily grown of the possibility of deciding upon fundamental and essential characteristics of the life process. No doubt opinions have fluctuated, and in different periods of the history of science particular phenomena of living organisms have been examined, criticized, and then well-nigh forgotten. But gradually ideas, ever more and more precise, have arisen and been accepted. 
Until very recent times, however, the main interest has centered upon morphological problems and upon the processes of growth and development. The ancient controversies regarding types and homologous parts, the question of spontaneous generation and the whole science of embryology, and inquiries into the nature of fermentation und the rôlc of microörganisms are examples of the older tendencies. Such interests have, it noed hardly be said, lost none of their imIn) rince, but they scarcely touch the physicochernical problem of the nature of living things. Yet there is in these subjects one noint of view, a favorite of Cuvier's, now, thuugh still familiar, less often emphasized, which states a most important characteristic of live in terms of matter and energy, space and time. ${ }^{1}$ Living things preserve, or tend

1 La vie est donc un tourbillon plus ou moins rapide, n. 1 ou moins compliqué, dont la direction est constante,

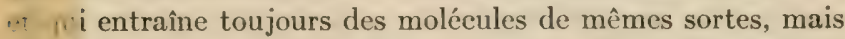
wi) $s$ molécules individuelles entrent et d'où elles sôrtent (....) nuellement, de manière que la forme du corps vivant hi.i st plus essentielle que la matière." ("Règne animal," i. ' ;, etc.) "Il vient sans cesse des éléments du dehors en (1. ns: il s'en échappe du dedans en dehors: toutes les par$\therefore \quad$ ont dans un tourbillon continuel, qui est une condition. tielle du phénomène, et que nous ne pouvons suspendre lauciemps sans l'arrêter pour jamais. Les branches les plus s) Iles de l'histoire naturelle participent déjà à cette compli- 
to preserve, an ideal form, while through them flows a steady stream of energy and matter which is ever changing, yet momentarily molded by life; organized, in short. This idea, to which we must later return, could not possess in the early nineteenth century the significance and value which now attach to it. It needed the explanation which the study of metabolism has at length provided.

\section{A}

\section{METABOLISM}

Metabolism is the term applied to the inflow and outflow of matter and energy and their intermediary transformations within the organism. Its serious investigation began with Lavoisier, the principal founder of mod-

cation et a ce mouvement perpétuel, qui rendent si difficile l'application des sciences générales." ("Rapport," p. 150, etc.) "Dans les corps vivans chaque partie a sa composition propre et distincte; aucune de leurs molécules ne reste en place; toutes entrent et sortent successivement: la vie est un tourbillon continuel, dont la direction, toute compliquée qu'elle, est, demeure constante, ainsi que l'espèce des molécules qui y sont entraînées, mais non les molécules individuelles ellesmêmes. ... Ainsi la forme de ces corps leur est plus essentielle que leur matière," etc. (Ibid. p. 200.) - " Eloges historiques," Vol. I, p. 200. Quoted by Merz, "A History of European Thought in the Nineteenth Century," Vol. I, p. 129. Edinburgh and London, 1898. 
ern chemistry, who by ingenious experiments discovered that the essential feature of the chemical process in the animal is combustion or oxidation, and that the amount of oxygen required by such combustion is not much less than that needed to burn substances which resemble the foods in the air. The problems which thus arose have been studied by a host of later investigator's, notably by Liebig and Voit, and gradually a vast array of facts concerning the turnover of matter and energy in the body have been accumulated. Among other achievements is the proof that the principle of the conservation of energy applies to the living organism. These have been chemical investigations, carried out by chemists, and for that reason, until quite recently, they have not received their due in general biology.

Meantime, as knowledge of the balance sheet of the body, the total metabolism socalled, has been perfected, more and more interest has developed in the changes which attend the passage of matter and energy in their various stages through the organism. Such problems at once demand a physicochemical description of protoplasm as a necessary basis for their solution. The same demand has also arisen in other quarters. 
Thus the microscope, with all its brilliant contributions to knowledge of the form and more gross structural elements of the cell, hardly at all contributes to knowledge of its physico-chemical organization as a mechanism. Out of such needs a preliminary, if very imperfect, rational description of protoplasm has arisen, and gradually the physical and chemical laws governing protoplasm, its form, composition, and stability, its constituent parts and their mode of action, and the physical and chemical changes within it are being discovered. ${ }^{1}$ The idea of durable form in matter and energy that change can now be applied to the cell with greater advantage, in that descriptions of the form and of the change are now at hand, though as yet all too imperfect.

Another profoundly important contribution of the science of metabolism to our knowledge of the characteristics of life is the discovery of the cycle of matter through plants and animals. ${ }^{2}$ The plant takes up carbonic acid and water and a few other simple substances from air and soil, and

1 This subject is extensively treated by Höber, "Physikalische Chemie der Zelle und der Gewebe." Leipzig, 1911, $3 \mathrm{~d}$ ed.

${ }^{2}$ This was originally clearly stated by Lavoisier. 
transforms them into oxygen, which renews the air, and sugar, starch, and other substances, which are the food of the animal. ${ }^{1}$ These products the animal burns, thereby forming once more carbonic acid and water, which return to the plant and so pass through the cycle again and again. The changes in energy which accompany this process are quite different from the chemical changes. Starch and sugar and oxygen, formed in the leaf of the plant, are compounded of carbonic acid, water, and sunshine. This sunshine, or solar energy, when changed into the chemical energy of the carbohydrate, is preserved and transmitted to the animal. ${ }^{2}$ In his body it is set free as muscular force and heat, and then dissipated. Accordingly, when carbonic acid and water are combined to form sugar and oxygen in the leaf, it is always a new store of solar energy which they bear, and while matter goes round and round, energy is being constantly degraded and lost. The one process is cyclic, the other moves steadily in one direction from

${ }^{1}$ Our knowledge of photosynthesis is largely based upon the classical work of N. T." de Satrssure, "Recherches Chimiques sur la Vegetation." Paris, 1804.

${ }^{2}$ Only after the establishment of the principle of the conservation of energy was it possible to gain a clear conception of the energetics of metabolism. 
sunshine to the waste heat of the animal body. ${ }^{1}$

ORGANIC CHEMISTRY

Independent alike of general biology and of the science of metabolism there has grown up still another department of natural science, organic chemistry, which contributes very materially to the description and comprehension of living things. During a large part of the nineteenth century the efforts of chemists were mainly directed to the cultivation of this subject, which seeks to describe the molecular constitution of all the compounds of carbon, including nearly all the individual substances which make up animals and plants. Gradually, as organic chemistry has progressed, very complete descriptions of the atomic groupings within the molecules of fats, ${ }^{2}$ carbohydrates, ${ }^{3}$ and pro-

${ }^{1}$ Here, as in so many other cases, it is not the conservation of matter and energy, but the conservation of matter and the degradation of energy which are important. For an extensive development of this important difference see B. Brunhes, “La Dégradation de l'Énergie." Paris, 1909.

${ }^{2}$ Chevreul, "Recherches Chimiques sur les Corps Gras." Paris, 1823.

${ }^{3}$ E. Fischer, "Untersuchungen über Kohlenhydrate und Fermente." Berlin, 1909. 
teins, ${ }^{1}$ the chicf of such things, and most of the other biologically important substances have been obtained, and we are at length in possession of exccedingly clear and reliable ideas as to the chemical constitution of living matter. In fact, the nature and laws of the chemical composition of protoplasm are actually more certain than the nature and laws of its physical structure. ${ }^{2}$

In this manner, by slow degrees, the description of living things has progressed, and gradually the characteristics of life have become less obscure and their aspects more simple. It cannot be denied that many traits like consciousness and inheritance are, at least for the present, beyond the scope of description in terms of matter and energy, and the fundamental riddle shares this detachment. ${ }^{3}$ But the physico-chemical basis

${ }^{1}$ E. Fischer, "Untersuchungen über Aminosäuren, Polypeptide und Proteine." Berlin, 1906.

${ }^{2}$ Substantial progress in the latter field is nearly all of very recent date, almost wholly since the sudden rise of physical chemistry.

3 "But now, having confessed that Life as a principle of activity is unknown and unknowable - that while its phenomena are accessible to thought the implied noumenon is inaccessible - that only the manifestations come within the range of our intelligence while that which is manifested lies beyond it; we may resume the conclusions reached in the preceding chapters. Our surface knowledge continues to be 
of life is firmly established in the world of our senses. On the whole the composition of living matter, its physical structure, the changes of matter and energy which constitute the metabolic process, together with the totality of such changes, which make up the fundamental economic process of that largest community which consists of all living beings, are all clearly defined.

THE CHARACTERISTICS OF LIFE

Under the circumstances it is certainly no rash enterprise to seek a definition of some of the essential characteristics of life. Al-

a knowledge of its kind, after recognizing the truth that it is only a surface knowledge.

"For the conclusions we lately reached and the definition emerging from them, concern the order existing among the actions which living things exhibit; and this order remains the same whether we know or do not know the nature of that from which the actions originate. We found a distinguishing trait of Life to be that its changes display a correspondence with coexistences and sequences in the environment; and this remains a distinguishing trait, though the thing which changes remains inscrutable. The statement that the continuous adjustment of internal relations to external relations constitute Life as cognizable by us, is not invalidated by the admission that the reality in which these relations inhere is incognizable."-Herbert Spencer, "The Principles of Biology." New York and London, 1909, Vol. I. Revised and enlarged edition, pp. 122-123. 
though it is probably far beyond our present power to make a complete study of the problem, I feel sure that a brief analysis will justify certain very definite conclusions. Life. as we know it is a physico-chemical mechanism, and it is probably inconceivable that it should be otherwise. ${ }^{1}$ As such, it possesses, and, we may well conclude, must ever possess, a high degree of complexity, - physically, chemically, and physiologically; that is to say, structurally and functionally. We cannot imagine life which is no more complex than a sphere, or salt, or the fall of rain, and, as we know it, it is in fact a very great deal more complex than such simple things. Next, living things, still more the community of living things, are durable. But complexity and durability of mechanism are only possible if internal and external conditions are stable. Hence, automatic regulations of the environment and the possibility of regulation of conditions within the organism are essential to life. It is not possible to specify a large number of conditions which must be regulated, but certain it is from our present experience that at least rough regulation of

${ }^{1}$ I mean, of course, for the purposes of physical and chemical study. With such qualifications the statement is probably no longer open to objection from any quarter. 
temperature, pressure, and chemical constitution of environment and organism are really essential to life, and that there is great advantage in many other regulations and in finer regulations. Finally, a living being must be active, hence its metabolism must be fed with matter and energy, and accordingly there must always be exchange of matter and energy with the environment.

Returning to the concept of the organism as a durable form through which flow matter and energy, it is now possible to make these ideas more vivid. The complex structure of the living being is relatively stable, alike in the chemical composition of its individual constituent molecules, in their proportions and amounts, in their aggregation into the invisible structural elements of protoplasm, in the visible parts of the cell, in the organs and tissues, and finally in toto, as a man or a tree. Similarly stable are the physical conditions within this structure: temperature, pressure, alkalinity, and osmotic pressure. Finally, that which surrounds it, the immediate environment, possesses also a high degree of stability, or if the organism be very complex, it may be that it has an efficient protection against change of environment; a skin which insulates, for instance. But in this case 
it has also acquired an environment, a milieu intéricur for its cells, - like the blood and lymph, - which serves the same purpose as stability of the external environment, and exercises the further function of supplying food.

It is through this structure, in the process of metabolism, that matter and energy flow. Entering in various forms and quantities, they are temporarily shaped exactly to the form and condition of the organism; they conform to the characteristics of the kingdom, class, order, family, genus, species, and variety to which it belongs, and they assume even the characteristics of the individual itself. ${ }^{1}$ Then they depart through the various channels of excretion.

When these ideas are reduced to their very simplest forms, it appears that life must be highly complex in structure and function; that the conditions of the environment must be regulated, and that there must be very exact regulation of conditions, both structural and functional within the organism, and finally, that, while life is active, there must be exchange of both matter and energy with the environment. Complexity, regulation, and food are essential to life as we know it, and

${ }^{1}$ Science is, of course, still at a loss for an adequate general explanation of such processes. 
in truth we cannot otherwise conceive of life, or indeed of any other durable mechanism. For my part I do not doubt that these postulates are quite as true of the world of our senses as are the fundamental laws of matter and energy, space and time.

Obviously these few conclusions can make no claim to completeness. Fully to describe life, the discovery of many other fundamental characteristics is necessary, including such as are related to inheritance, variation, evolution, consciousness, and a host of other things. But in the formation and logical development of such ideas there is danger of fallacy at every step, and since the present list will suffice for the present purpose, further considerations of this sort are best dispensed with. This subject should not be put aside, however, without clear emphasis that the postulates which have been adopted above are extremely meager. The only motives for abandoning further search are the economy and the security which are thus insured, and the very great difficulty of extending the list. Any one who is familiar with similar efforts to elucidate the essential characteristics of life, such as that of Wallace, ${ }^{1}$ cannot, I fear, fail to perceive the extreme limitations

${ }^{1}$ A. R. Wallace, "Man's Place in the Universe." New 
which are imposed upon inquiry by assuming complexity, regulation, and metabolism exclusively. Perhaps in reality these postulates are only two. Metabolism might without difficulty be included under regulation, but the consideration of such purely logical questions is beside the present purposc. However, these are probably the characteristics of the organism which are best fitted for discussion in relation to the physico-chemical phenomena of matter and energy, and it is barely possible that no others bear the same simple relations to the outside world.

York, 1903, Chaps. X and XI, especially the following statement :-

"The physical conditions on the surface of our earth which appear to be necessary for the development and maintenance of living organisms may be dealt with under the following headings :

"1. Regularity of heat supply, resulting in a limited range of temperature.

" 2 . A sufficient amount of solar light and heat.

" 3 . Water in great abundance, and universally distributed.

"4. An atmosphere of sufficient density, and consisting of the gases which are essential for vegetable and animal life. These are Oxygen, Carbonic-acid gas, Aqueous vapor, Nitrogen, and Ammonia. These must all be present in suitable proportions.

"5. Alternations of day and night."

It must be remembered, however, that such conclusions depend upon reasoning from analogy, a dangerous proceeding. 


\section{V \\ THE PROBLEM}

We may now return to the problem of the fitness of the environment. So long as ideas of the nature of living things remain vague and ill-defined, it is clearly impossible, as a rule, to distinguish between an adaptation of the organism to the environment and a case of fitness of the environment for life, in the very most general sense. No doubt there are clear instances of both phenomena which require no close analysis for their interpretation. Thus the hand is surely an instance of adaptation, and the anomalous expansion of water on cooling near its freezing point an instance of environmental fitness. But how much weight is to be assigned to adaptation and how much to fitness in discussing the relations between marine organisms and the ocean? Evidently to answer such questions we must possess clear and precise ideas and definitions of living things. Life must by arbitrary process of logic be changed from the varying thing which it is into an independent variable or an invariant, shorn of many of its most interesting qualities to be sure, but no longer inviting fallacy through our 
inability to perceive clearly the questions involved.

Such is the purpose, and the justification, for setting up the postulates of complexity, regulation, and metabolism as inherent in that mechanism which is called the living organism. With them, at length, we face the problem which awaits us. To what extent do the characteristics of matter and energy and the cosmic processes favor the existence of mechanisms which must be complex, highly regulated, and provided with suitable matter and energy as food? If it shall appear that the fitness of the environment to fulfill these demands of life is great, we may then ask whether it is so great that we cannot reasonably assume it to be accidental, and finally we may inquire what manner of law is capable of explaining such fitness of the very nature of things. 


\section{CHAPTER II}

\section{THE ENVIRONMENT}

\section{I}

ASTRONOMY

A $N$ examination of the relationship beA tween life and the environment, in which by means of the simplifying postulates previously developed life is arbitrarity taken as an invariant, should, if it is to be quite general, rest upon a physico-chemical description of the whole universe. We require to know the form and structure of stars and of interstellar space, of nebulæ and of solar systems, and the conditions and changes which accompany such aggregations of matter. Evidently this requirement can be but imperfectly fulfilled, and yet one need not be too apologetic in venturing the attempt. In the end, to be sure, we shall found our argument upon the safe basis of terrestrial phenomena, but meantime it will be an advantage to consider conditions far and wide. 
The science of cosmography is probably the earliest of all the natural sciences, and cosmological speculation appears to accompany it from the outset. Long before the dawn of history the Chaldeans possessed much accurate information about the stars, and the zodiac was known to the Egyptians not less than fifteen centuries before our era. Always pursued with great interest, such studies received their first provisional systematic formulation at the hands of Hipparchus in the second century в.c. He, the greatest of the astronomers of antiquity, succeeded in bringing the apparent movements of the sun, moon, and planets into an arbitrary scheme which was nearly perfect for the sun, though less so for the other movable celestial bodies. He also measured and catalogued the positions of a large number of fixed stars. Upon this secure foundation of quantitative observations modern astronomy has built. At the beginning of the modern period Copernicus, Tycho Brahe, Kepler, Galileo, and Newton reduced the phenomena of the solar system to law. At a later day speculations based upon their results and upon growing knowledge of physics and chemistry led Thomas Wright, Kant, and finally Laplace to a rational, if somewhat imperfect, cosmological 
theory of the solar system. Finally, ever more accurate observations and the marvelous fertility of spectroscopical investigations have brought the stars within our reach.

The whole universe now appears to be not unlike our part of it, both chemically and physically. The same forms of matter, the same material aggregates, the same manifestations of energy, and similar movements are everywhere present. The stars are no longer changeless, but violently active bodies; they are no longer permanent, but evolving systems; they are born, they grow, age, and die; and throughout their evolution they obey laws, which, though as yet imperfectly known, appear to be common to all. Meantime the study of nebulæ, comets, and meteorites has kept pace with other departments of the science, and our interpretation of the results of stellar astronomy ${ }^{1}$ constantly gains from ever increasing knowledge of the physical and chemical processes in the sun.

The universe which thus gradually has been revealed to the astronomer is made up of a relatively small number of types of material

${ }^{1}$ A description of such facts from the physico-chemical point of view may be found in Arrhenius's "Lehrbuch der kosmichen Physik." Leipzig, 1903. A brief popular account of some of the facts in the same author's "Worlds in the Making," translated by Borns. New York and London, 1908. 
aggregation. These include luminous dense bodies like the sun and stars; ron-luminous dense bodies like the earth, the moon, the planets, and invisible partners of certain stars ; nebulæ, comets, and meteorites. The larger of these bodies are separated by vast extents of space which contain only rare meteorites, perhaps minute traces of gaseous material, and cosmic dust. There can be little doubt that other types of bodies do not commonly occur in that portion of the universe which is open to astronomical investigation. Both the enormous collections of astronomical data which are now at hand and the beginnings of clear knowledge of cosmic processes justify this belief. Of what may lie beyond the visible stars we can, of course, know nothing.

The nature of the stars is revealed to us chiefly by study of their spectra, according to which they have been roughly classified, by Vogel $^{1}$ for example, quite simply into three principal types.

I. White stars in which there is marked evidence of the presence of hydrogen, or, in some instances, helium. The stars of this class undoubtedly are extremely hot, the helium stars probably especially so. Their atmospheres seem to be very dense and to

1 See Arrhenius's “Lehrbuch," pp. 23-27. 
consist of hydrogen or helium or a mixture of the two gases. There is evidence that some of these stars possess very high rotational velocities.

II. Yellow stars, including the sun, whose spectra indicate the presence of hydrogen and numerous metals, - sodium, iron, calcium, magnesium, etc. The lines which show the presence of hydrogen in the stars of this type vary in intensity. The current belief is that those stars which appear to possess more hydrogen are the hottest. The stars of this type are less hot than those of type I.

III. Reddish stars whose spectra show little or no sign of the presence of hydrogen, but indicate that of chemical compounds, including hydrocarbons. The presence in these spectra of the lines of sodium, iron, calcium, and magnesium is clearly established. Stars of this type are evidently the coolest of luminous dense bodies.

This classification is, of course, provisional and unsatisfactory, and probably sometimes results in bringing together relatively unlike stars and in separating such as are very much akin. Moreover, subdivisions in the classification are necessary and hard to make. Other better but more complex classifications appear to exist, but they suffer only in less degree 
from like defects. In short all the known facts can best be explained by the assumpfion that the stars represent different stages of development of suns. ${ }^{1}$ In that case this

1 "Bei Durchmusterung der Specktra der verschiedenen Sterne kann man sich nicht des Gedankens erwehren, dass die verschiedenen Sterngruppen verschiedenen Entwicklungsstadien entsprechen. Die jüngsten und wärmsten aller Sterne wïren (nach der allgemeinen Ansicht, vgl. weiter unten Kap. Kosmogonie) diejenigen der ersten Gruppe. Das kontinuierliche Licht, welches ron dem eigentlichen Sternkörper ausstrahlt, rührt haupstächlich von Kondensationen, wolkenartigen Bildungen in der Atmosphäre der Sterne, zum geringeren Teil von den stark verdichteten Metalldämpfen im Inneren des Sterns her. In den höheren Schichten dieser Atmosphäre finden sich die leichten Gase, Wasserstoff oder Helium oder alle beide, weiter unten Metalldämpfe. Bei den Sternen erster Klasse ist die Atmosphäre der leichten Gase so dick und heiss, dass die für uns sichtbaren Kondensationen beinahe alle in diesen oberen Schichten vor sich gehen. Wir sehen deshalb keine oder nur schwache Metallinien, dagegen sehr starke Wasserstoff- oder Heliumlinien. Bisweilen ist die Menge und Temperatur der leichten Gase genügend, um helle Umkehrungen dieser Linien zu verursachen. Bei dem zweiten Spektraltypus ist die Abkiilllung weiter fortgeschritten, so dass Kondensationen nicht nur in den höchsten Schichten der $\Lambda$ tmosphäre, sondern auch innerhalb der Metallatmosphäre vorkommen. Man sicht dann die dunklen Metalllinien scharf hervortreten. Das Zurücktreten des violetten Endes des Spektrums und einige schwache Bänder im roten Teil deuten auf niedrigere Temperatur hin. Bei den rötlichen Sternen treten tiefe Temperatur andeutende Erscheinungen noch mehr hervor. Die bei denselben gewöhnlich vorkommende Veränderlichtkeit liisst auf das Vorkommen von kälteren und wärmeren Perioden 
development or evolution must be a continuous process through which every sun slowly passes, and on the whole all suns must be much alike. Certainly we have the best of evidence to justify the assumption that most stars, inetuding the sun, have very much the same chemical composition, and that differences in spectra are due to the slowly progressing physico-chemical changes which have accompanied the process of coeling-

Needless to say, the chemical composition of the sun itself is far better known than that of the stars. Particularly prominent among his constituent elements are those above mentioned: hydrogen, sodium, calcium, mag-

schliessen, wie solche in geringerem Maasstab bei unserer Sonne durch die Fleckenperiode sich kundgeben. Zuletzt wird die Leuchtkraft der Sterne sehr schwach und das Licht ausgeprägtrot, der relativ niedrigen Temperatur entsprechend. Nach diesem Stadium kommt dasjenige, worin die dunklen ultraroten Strahlen allein herrschen, der Stern ist in einen nichtleuchtenenden Himmelskörper Ubergegangen (vgl. weiter unten Kap. Kosmogonie).

Im Grossen und Ganzen zeigen die Sterne dieselbe chemische zusammensetzung wie die Sonne. Die hervorragende Rolle des Wasserstoffs und Heliums, sowei des Eisens, Natriums, Calciums und Magnesiums, macht sich überall bemerkbar. Es ist dann kein Zweifel, dass unsere Sonne mit den Fixsternen sehr nahe verwandt ist, und zwar ist sie als ein Fixstern der ersten Abteilung in der zweiten Klasse anzusehen." - Arrhenius, "Kosmische Physik." Leipzig, 1903 , p. 27. 
nesium, and iron. Also some others, which because of their low density are concentrated near the surface, are known to occur. The elements which have not yet been discovered are those like the metalloids which do not under ordinary circumstances give well-marked spectra, and those like gold, platinum, and mercury, whose higher specific gravities may be supposed to cause their accumulation in the interior. Carbon is certainly present, and almost certainly oxygen as well. Indeed it is only reasonable to conclude, as Kirchhoff originally suggested, ${ }^{1}$ that all the elements

1 "Diese Vorstellung von der Beschaffenheit der Sonne stimmt mit der von Laplace begrindeten Hypothese über die Bildung unseres Planetensystems uberein. Wenn die Masse, die jetzt in den einzelnen Körpern dieses Systems verdichtet ist, in fruheren Zeiten einen zusammenhängenden Nebel von ungeheurer Ausdehnung bildete, durch dessen Zusammenziehung Sonne, Planeten und Monde entstanden sind, so mussten alle diese Körper bei ihrer Bildung im wesentlichen von ähnlicher chemischer Zusammensetzung sein. Die Geologie hat gelehrt, dass die Erde einst in gliihend fliussigem Zustande sich befunden hat; man muss annehmen, dass auch die anderen Körper unseres Systems einmal in einem solchen gewesen sind. Die Abkühlung, die infolge der Ausstrahlung der Wärme bei allen eingetreten ist, hat aber bei ihnen sehr verschiedene grade erlangt; und während der Mond kälter als die Erdegeworden ist, ist die Temperatur des Sonnenkörpers noch nicht unter die Weissglühhitze gesunken. Die irdische Atmosphäre, die jetzt nur wenige Elemente enthält, musste, als die Erde noch glïhte, eine viel mannigfaltigere Zusammensetzung haben; alle in der Glüh- 
are present in the sun, and very often, at least, in the stars. Exceptions may arise, but probably they will hardly suffice to invalidate the rule.

The large, dark, dense bodies which are directly known to us are the planets and their satellites. There are, however, many indications that the heavens are occupied by great numbers of "dead" suns, incrusted and therefore no longer luminous. Such appear to be the only conclusions which can be drawn from a study of the energetics of solar evolution, for sooner or later a sun must cool from loss of energy until at length a crust forms, and, barring catastrophe, it must then endure forever. Moreover, as we have seen, the varying aspects of the stars seem to disclose suns in all stages of such a process.

More nearly direct is the evidence furnished by study of variable stars of the Algol type. Algol itself ( $\beta$ Persei) is a star of second magnitude with a period of $\mathcal{Q}$ days, 20 hours, 48 minutes, 53.8 seconds. During each period

hitze flüchtigen Stoffe mussten in ihr vorkommen. Eine entsprechende Beschaffenheit muss heute noch die Atmosphäre der Sonne besitzen." - G. KrRchноғF, - "Untersuchungen uber das Sonnenspektrum und die Spektren der Chemischen Elemente." Abhandlungen der Königlichen Akademie der Wissenschaften zu Berlin, 1861. Zweite, durch einen Anhang vermehrte Ausgabe. Berlin, 1862. 
for about $2 \frac{1}{2}$ days it shines with constant intensity; thereupon it begins to decline and in approximately $4 \frac{1}{2}$ hours sinks to its minimum of brightness; then it becomes gradually brighter until after $4 \frac{1}{2}$ hours more it has reattained its full brilliancy. This behavior is explained by the supposition that Algol is accompanied by a dark star and that their movements are such that a partial eclipse occurs every 69 hours. Pickering has succeeded in calculating, upon the assumption that the dark star as a whole intercepts the rays of Algol, the approximate sizes, velocities, and orbits of these two stars, one of which is quite invisible. Many similar phenomena lead to similar conclusions regarding other variable stars.

It is apparent that such dark bodies, whether extinct suns or planets, represent another stage in celestial evolution. Their past histories may be various, for there is still room for much doubt as to the manner of formation and origin of planets, but at any rate all are probably derived from luminous stars or planets through the process of cooling, with its accompanying crust formation. Like their earlier forms, they must therefore be made up of matter as we know it, since when a heavenly body puts on a crust, it does not change the 
matter of which it is composed. Finally terrestrial chemistry completes the evidence regarding the composition of such astronomical bodies; geophysics that regarding their state. The number of extinct suns is probably very great; Arrhenius thinks it not unlikely that they may be one hundred times more numerous than the luminous stars. ${ }^{1}$

It is more difficult to gain a clear idea of the nebulæ, for such aggregations of matter are very diverse in appearance, and none lie near enough to the earth for us to study them as we study the solar system. However, investigation of new stars, of the spiral forms of many nebulæ, of the so-called star rifts which appear to be due to the movement of a large body through a nebula, sweeping up smaller bodies and leaving a channel behind, and a variety of considerations dependent upon the modern development of the sciences of physics and chemistry, all contribute to a growing belief that nebulæ may often, and sometimes at least do certainly arise from collisions between dense bodies. Further, the nature of the processes by which stars may be formed out of nebulæ becomes constantly better understood, and while there is small ground to regard our present science of nebulæ 1 "Worlds in the Making," p. 151. 
as final, there is none at all for the belief that anything essentially inexplicable either physico-chemically or genetically will be discovered in their organization.

Putting aside all contentious matters, it is abundantly clear that nebulæ, however they may vary among themselves, are made up of vast extents of gaseous material and dust which are exceedingly rare and at very low temperature, and that they may contain all kinds of foci of condensation, from stars to meteorites, in great variety of forms and conditions.

On the whole the common-sense judgment that the solar system may be taken as a fair sample of the universe, and that its probable evolution is in the main typical of cosmic evolution in general seems to be well founded. Any other hypothesis does violence to a host of facts, and to the larger generalizations of modern science.

\section{II}

\section{POSSIBLE ENVIRONMENTS}

If now we seek to make the best of existing astronomical knowledge, as hastily sketched, in the study of our biological problem, certain considerations at once present themselves. 
Obviously it is not everywhere in such a universe that life can exist. The visible stars, like the sun, certainly cannot support life. Throughout such bodies durable and complex arrangements of matter are impossible, for if formed, they must be at once dissipated by catastrophes far greater than any which can occur upon the earth's crust. The enormous intensity of heat, even in the most superficial parts of suns, must effectually preclude any state of matter but the gaseous, and thus prevent the existence there of anything of the nature of a mechanism. Such bodies, apart only from continuous variation from center to periphery, in the proportions of the elements, in density, and in the nature of the chemical unions between the elements, must be essentially homogeneous. They can scarcely possess relatively as much structure as the earth's atmosphere. In truth the sun itself seems to be the one and only durable solar mechanism.

Not less evident is the impossibility of active life in interstellar space or in nebulæ. Dormant life (panspermia) may indeed be possible universally, except only in the neighborhood of suns. But if life is to be fed, if there is to be active metabolism, including exchange of matter with the environment, something more 
nourishing than the rare molecules of a nebula, or the still rarer particles of interstellar space, must be provided.

We may safely conclude, therefore, on the basis of our reliable knowledge of the universe, that active life can exist probably only upon a dense, crusted body ${ }^{1}$; for, of course, the intcrior of the earth is no better suited to life than is the interior of the sun.

We have perhaps taken a long road to arrive at so familiar an idea. But our task involves the consideration of every conceivable form of life, not merely that relatively anthropomorphic kind which we commonly think of when speculating loosely regarding life in other worlds.

It is indeed possible that the common-sense judgment of the universe which declares our solar system to be on the whole, in its fundamental characteristics, typical of every such system may turn out to be in some respects unjustified. For the present, however, so long as we use it only as an indication of the direction in which we are to turn our attention, there is certainly no risk whatever in following this hypothesis in the later discussion.

${ }^{1}$ For an interesting discussion of the necessary conditions of existence see P. Lowell, "Mars as the Abode of Life." The Macmillan Company, New York, 1908. 


\section{III}

\section{GEOPHYSICS}

Let us, accordingly, now examine such phenomena as are likely to occur upon the surfaces of bodies which in the course of cosmic evolution have acquired a solid crust. In faithfully carrying out such a plan, the sciences of geology and meteorology must be brought under contribution, and climatic conditions must receive especial attention. Not, to be sure, that our globe in every respect can fairly be taken as meteorologically typical of all incrusted bodies. On the contrary, there are a large number of phenomena which are unquestionably of highest significance in favoring the existence of life on this particular planet which appear to be accidental and probably somewhat uncommon. ${ }^{1}$ Such are the

1 These also have been favorite subjects in the works on natural theology. The Bridgewater Treatises of Whewell and of Prout are replete with illustrations, those of Whewell often moderately expounded, while Prout's are, as a rule, most curious and antiquated.

"Lastly, who will venture to assert that the distribution of sea and of land, as they now exist, though apparently so disproportionate, is not actually necessary as the world is at present constituted? What would be the result, for instance, if the Pacific or the Atlantic oceans were to be converted into continents? Would not the climates of the exist- 
size of the sun taken in relation with its distance from the earth; the size of the earth, which enables it to retain its present atmosphere; the eccentricity of its orbit and the inclination of the ecliptic; the relative amounts of land and sea, and a host of other factors. Together these probably make of the earth, in comparison with other bodies, an extremely favorable abode for the living organism. Yet it cannot be denied that in detailed chemical constitution the earth is certainly more or less typical of all similar bodies. Moreover the earth's crust and its atmosphere, being formed in accordance with

ing continents, as formerly observed, be completely changed by such an addition to the land, and the whole of their fertile regions be reduced to arid deserts? Now, this distribution of sea and of land, so wonderfully adapted as it appears to be to the present state of things, depends of course in a great measure upon the absolute quantity of water in the world. While, on the other hand, the relative gravity of water, as compared with that of the earth, keeps the ocean within its destined limits, notwithstanding its incessant motion. Thus Laplace has shown that the world would have been constantly liable to have been deluged from the slightest causes, had the mean density of the ocean exceeded that of the earth! Hence the adjustment of the quantity of water and of its density, as compared with that of the earth, afford some of the most marked and beautiful instances of design." - Prout, The Bridgewater Treatises, Treatise VIII, "Chemistry, Meteorology, and the Function of Digestion." London, 1834, pp. 186-187. 
general laws, are likewise typical or at all events were so at the time of their origin.

Neither can the change in crust and atmosphere which time has wrought be wholly unique, though here a possible exception may again arise in the action of life itself. Since we do not at present positively know of the existence of life elsewhere and certainly have no detailed knowledge of its nature, we cannot feel sure that the conversion of atmospheric carbonic acid into oxygen and coal is either a universal or a common occurrence. In details of the geological process indeed there may well be marked differences. Probably the greatest variation will occur in the relative duration of conditions like those which we now enjoy on the earth, the length or brevity of the period from the full establishment of the circulation of water by evaporation, cloud formation, rainfall, with the flow of lakes and streams, until its extinction by cold. Thus there is more liability of error in an analyis of the general characteristics of those spontaneous changes which must occur upon the surface of a body after the formation of a crust than there is in the attempt to discover the general characteristics of stellar evolution. But here again our knowledge is not based upon terrestrial phenomena alone. 
With greater or less completeness and accuracy the atmospheres of the moon, of Mars, and of other planets have been studied and accounted for.

\section{IV}

\section{THE ATMOSPHERE}

Even at the earliest period in the evolution of a typical star there appears to be a progressive variation in chemical composition from center to periphery. Theoretically it seems inevitable that the heaviest elements should be concentrated in the interior and that those of lowest atomic weight should be present in greatest amount near the surface. Actually, as above stated, spectroscopic investigation fully confirms this view. Thus the spectra of typical hot stars show that hydrogen is an invariable constituent of their superficial parts. Indeed the universal presence of hydrogen under such circumstances is undoubtedly one of the most clearly established facts of stellar astronomy. As stars cool and become red the spectral changes quite as unmistakably point to the presence of carbon. Accordingly we possess the best of evidence and the best of reasons for the belief that large quantities of hy- 
drogen and carbon must exist at or near the surface when a crust forms upon a cooling star.

The nature of the chemical combinations into which these elements at first enter is perhaps open to some question. But as the temperature falls in the cooling of a sun or planet the affinities of carbon and hydrogen for oxygen increase, so that carbonic acid and water must normally result. For oxygen is almost certainly present in the sun; it is found in meteorites, and the vast store of it in the earth's atmosphere and crust (roughly one half of their total mass) justifies the belief that it is everywhere one of the commonest of elements. Hence an atmosphere containing water and carbonic acid appears to be a normal envelope of a new crust upon a cooling body. Even were not these substances at first present in such an atmosphere, volcanoes must soon belch them forth in enormous quantities to relieve the pressure which inevitable chemical processes set up.

It is clear that no one can give an exhaustive description of the formation of the earth's atmosphere and the changes which underlie vulcanism, so long as the theoretical considerations involved remain often more obscure than the facts. However, be the process what it 
may, it is at least automatic, and must repeat itself in other similar circumstances.

There is, moreover, direct evidence in support of the above conclusions. Spectroscopic investigation has proved the presence of water vapor in the atmospheres of Mars, Venus, Jupiter, and Saturn, and nobody has suggested what the snowcaps of Mars may be unless they are real snow (hoarfrost) or, improbably, carbonic acid. Lowell and Arrhenius agree in considering them snowcaps. ${ }^{1}$

In the earth's atmosphere carbonic acid has been very largely converted into oxygen and vegetable matter, which later has been turned into enormous quantities of coal. It is, in fact, possible, in accordance with the suggestion of Koene, that all the oxygen of the atmosphere has been thus formed from carbon dioxide, and that therefore coal, peat, and other similar substances within the earth are chemically equivalent to the oxygen now free.

If a typical atmosphere must contain water and carbon dioxide, its evolution must obviously be in part conditioned by the presence of these substances. Hence terrestrial meteorology, no less than terrestrial geology, must be in greater or less degree a special case of a

${ }^{1}$ Arrhenius, "Kosmische Physik," p. 173; Lowell, "Mars as the Abode of Life," p. 81. 
general process, and meteorological conditions on the earth cannot be perfectly unique.

A number of circumstances, however, cause far greater variations in meteorological processes than in most other phenomena which have yet been discussed. For instance, on small astronomical bodies with weak gravitational attractions atmospheres cannot long endure. Like the moon these bodies must gradually lose nearly all their gases to space. Such loss has almost certainly occurred from the earth itself, and probably accounts for the absence of hydrogen and helium from the air. These gases, being very light, are not attracted with sufficient force to the earth, and gradually rise to the upper level of the atmosphere and fly away. Again, in the absence of a near-by sun which steadily provides energy to balance loss by radiation, the period during which water and carbonic acid can remain in an atmosphere must be relatively short. Gradually, but in a time wholly inconsiderable in comparison with the duration of the terrestrial atmosphere, the gases surrounding bodies so placed must condense and then solidify. Finally, a body which constantly turns one face to a sun must slowly condense its whole atmosphere upon its dark, 
cold surface, and so no less certainly be deprived of a gaseous envelope and of oceans.

Accordingly it appears safe to say that really durable atmospheric conditions depend upon sufficient size of the planet, the presence of a sun, and rotation. ${ }^{1}$ No doubt a host of other factors which exist in the case of the earth are only less important. In any event, all such phenomena, though varied by chance, are of automatic origin, and whatever may be the peculiarities of our solar system there is no reason to suppose that like conditions are not of frequent occurrence. Throughout space there must be thousands of planets which, like the earth and Mars, are enveloped in an atmosphere that endures through countless centuries, and that contains great quantities of water and carbon dioxide.

1 All such atmospheres must in greater or less degree manifest general meteorological phenomena. There must be winds and clouds, rain and snow and ice, the formation of oceans and ocean currents, streams and lakes, all interrelated by complex cyclic processes which endure. Tides, too, and magnetic and electrical phenomena cannot be absent, while

${ }^{1}$ A full discussion of all such problems will be found in the "Lehrbuch" of Arrhenius and in S. Giinther's "Handbuch der Geophysik." Two volumes, Stuttgart, 1897-1898. 
the action of water through long ages must accomplish its gigantic work of disintegration and sedimentation. Soil must be formed, and water must penetrate it. In short a possible abode of life not unlike the earth apparently must be a frequent occurrence in space.

\section{V}

\section{GENERAL COSMOGRAPHICAL CONCLUSIONS}

Such, in the present state of knowledge, are the general cosmographical views which naturally suggest themselves to one who considers the possibility of life throughout the universe. The solar system appears to be, in its most general traits, a fair sample of the whole; the sun is a typical star; the planets are certainly members of a large class of similar bodies. These various types of material aggregation are a good deal alike wherever they occur. They are formed of the same matter, probably in very much the same proportions. They are actuated by the same manifestations of the same energy, and their evolutionary histories are similar. One and all are likely to possess, for a longer or shorter time, climates which make life possible. On the other hand, it is already obvious that 
the solar system, and especially the earth among planets, are very favorable for life, partly through apparently accidental circumstances. Putting aside, therefore, the biological fitness of the special climates of the earth both as a familiar fact, and as possibly in no small degree accidental, we may more advantageously give our attention at once to other phenomena which appear to be of a far more general character, - the occurrence of large quantities of water and carbon dioxide in the atmosphere, and the fundamental meteorological processes which their presence involves. Nitrogen and various other substances automatically find a place beside water and carbonic acid, but it will be convenient to pass them by or to postpone the consideration until other aspects of the subject have been more fully developed.

\section{VI}

\section{THE PRIMARY CONSTITUENTS OF THE} ENVIRONMENT

Of course a consideration of the properties of water and carbonic acid might be approached from a study of terrestrial processes exclusively. But since the assumption that such phenomena are common occur- 
rences throughout the universe, and that they are the normal result of cosmic evolution, does not in any way modify the subsequent course of the inquiry, there appears to be no loss of logical security from its introduction. Meanwhile the evidence that the special phenomena under discussion are probably the nowise exceptional outcome of the operation of general laws, and not merely sporadic, cannot fail to lend weight to whatever conclusions may ultimately be reached.

Obviously it is in the physical and chemical attributes of these two compounds and their constituent elements that we find very many of the conditions which make life possible upon the earth. They are material, provided and mobilized automatically, out of which living things undoubtedly can be formed. Moreover if we limit our study to the physicochemical properties of water and carbonic acid, and to the compounds of carbon, hydrogen, and oxygen, we shall greatly simplify our problem. It cannot be denied that this restriction, no less than the earlier decision to restrict the postulated characteristics of life to complexity, regulation, and metabolism, is sure to limit the inquiry, often perhaps in a very unwelcome manner. On the other hand, the gain in economy and security is once 
more of great importance, and at present is perhaps essential to clear thinking. Such a procedure manifestly influences not at all the validity of any conclusions which may be reached; only it must not be forgotten that the conclusions apply directly to our limited field of inquiry alone.

\section{VII}

\section{THE ULTIMATE PROBLEM}

Such is the outcome of a preliminary glance at the many departments of science which are necessarily involved in the question of fitness of the environment. Living things permit themselves to be simplified into mechanisms which are complex, regulated, and provided with a metabolism; the environment, by a series of eliminations, is reduced to water and carbonic acid. These are simplifications counseled solely by expediency. Neither logical process is necessary; each involves a disregard for many circumstances which might be of weight in the present inquiry. But in the end there stands out a perfectly simple problem which is undoubtedly soluble. That problem may be stated as follows: In what degree are the physical, chemical, and general meteorological char- 
acteristics of water and carbon dioxide and of the compounds of carbon, hydrogen, and oxygen favorable to a mechanism which must be physically, chemically, and physiologically complex, which must be itself well regulated in a well-regulated environment, and which must carry on an active exchange of matter and energy with that environment?

The first step in seeking a solution must be to review the data of physics and chemistry which describe the properties of water and carbonic acid, having due regard to their meteorological significance. Such data of the highest accuracy exist in great profusion, for almost every conceivable property of these substances has been studied with patient care. Next, the properties of the compounds of carbon, hydrogen, and oxygen must be considered, and some of the characteristics of the chemical reactions into which they enter must be discussed. For this examination the unparalleled development of the science of organic chemistry provides ample material. All of these things must be scrutinized quantitatively as well as qualitatively, and here again there is no lack of necessary information.

Immediately one advantage of the method here proposed becomes evident. We can deal with the familiar abstractions of physical 
science, - specific heat, coefficient of expansion, solubility, heat of reaction, etc., - and thereby we shall gain all the advantages of the most exact sciences. No qualifications, no doubtful or contentious matter, no imperfect descriptions need enter.

In this manner it will be easy to estimate the absolute biological fitness in certain respects of water and carbonic acid, and at once a host of automatic results of their properties will become evident. Many of these results, such as the nearly constant temperature of the ocean, the ample rainfall, the freezing of water upon the surface, the great variety of carbon compounds, are familiar subjects of speculation, though since Darwin little interest has been manifested in them; others, only recently brought to light by the growth of physical science, are nearly or quite unknown in this connection. All deserve to receive more serious attention from biologists than is at present vouchsafed them, for they constitute a part of the very foundation of general biology, and they cause many of the phenomena with which man is concerned in his struggle for mastery of the environment. Yet the mere exposition of such facts and relationships cannot suffice in a discussion of the fitness of the environment. In the first 
place these are in the main familiar ideas, and if they were altogether conclusive to prove the existence of really significant fitness, if they could be regarded as alone adequate to establish the necessity of putting fitness by the side of adaptation as a coördinate factor in causing the marvels of life, it is hard to believe that they would have been so long neglected. In the second place there is nothing comparative about such information. Water is indeed a wonderful substance which fills its place in nature most satisfactorily, but would not another substance do as well? Is not ammonia, for example, a possible substitute? And are there not many other chemical bodies which might, in a very different world, serve equally useful purposes? Perhaps, too, the great variety of carbon compounds which are known to the chemist are known only because the vital processes furnish an abundance of material with which to experiment. Is it not possible, therefore, that another element, silicon, for instance, may enter into even greater varieties of compounds? It is such questions, ever present in the minds of men of science, yet never carefully scrutinized to see if an answer be possible, which, I suspect, have long deflected attention from this subject.

Clearly, therefore, it will be necessary to 
compare the properties of water and carbonic acid and of the carbon compounds with those of other substances. It will be necessary to find out whether these substances are not only fit but fittest, - and this no doubt is a task of a very different sort. It may even seem at first sight an impossible one, but I hope to show that this is not the case, and that in spite of the incompleteness of our physical and chemical knowledge, it may be pressed to a satisfactory issue. A few remarks may now indicate the general line of thought we shall pursue, and then the actual study must provide the proof.

\section{VIII}

\section{THE METHOD OF SOLUTION}

The very constant temperature of the ocean is a most important factor in the economy of nature. It constitutes, for example, a vital regulation of the environment of a large proportion of all the living organisms of the world, and it has many other important "functions." This constancy of temperature is in large part due to the magnitude of the specific heat of water. Other things being equal, the greater the specific heat of water, the more constant must be the temperature of the ocean. If, 
then, the specific heat of water, as is actually the case, be nearly or quite a maximum among all specific heats, it follows that the fitness of water in this respect is nearly maximal.

Again the ocean contains an astonishing variety of substances in solution, and they are present often in large quantities. In this manner a very great supply of food in very great variety is offered marine organisms. Of course such richness of the environment is an exceedingly favorable circumstance for the organism, and it is due principally to the ability of water to dissolve a multitude of things in large quantities. It is not to be supposed that the substances present in sea water are all of use to every organism. This need not be the case at all; but a variety of supplies which may be adapted to special requirements as they arise, here iodine, there copper, for instance, is a very genuine advantage. Further, the vast utility of the solvent action of water in blood, lymph, and all the body fluids is too patent to call for comment. If, now, it can be shown that the efficiency of water is nearly or quite a maximum, as it really is, among all known solvents, then it must be evident that in another respect the fitness of water is nearly or quite maximal.

Again the amount of energy that is re- 
quired to tear apart molecules of water, and to liberate hydrogen and oxygen, is very great indeed, and when hydrogen and oxygen recombine to form water, this energy must reappear, - under ordinary circumstances as heat. This fact, too, is very favorable for the organism, because almost all compounds which contain hydrogen yield a great deal of energy when they are burned; they are, in short, great reservoirs of energy which can be tapped in the process of metabolism. If, therefore, the heat of combustion of hydrogen be nearly or quite a maximum, as it is, among all substances, it is clear that water is again, in another respect, most wonderfully fitted for life.

Finally, if it be true, and such is the case, that very few of the substances which share the fitness of water in one of these characteristics also share or approach its fitness in either of the others, and that none possesses all these qualifications in a degree that merits consideration, it must, I conceive, be admitted that so far as the investigation has proceeded water is the only possible fit substance.

A criticism may here be made; are there not other substances which possess other groups of qualifications which water lacks? And that is a difficulty which is even harder to meet. But in the first place it is evident 
that there are not an infinity of important physical properties; in fact there are very few. And in the second place it is evident, both from centuries of experience in physical science and from the postulates above adopted regarding life, which undoubtedly do in the main describe its physico-chemical characteristics, that very few properties indeed are of importance in the least comparable with those which I have mentioned.

Finally, it is in the highest degree probable that we are acquainted with most of the truly essential physical properties, and know them as biologically important, when they are so; and I think we shall find it possible to consider them all, and thus to make the argument complete.

Meanwhile it should be noted that there are two different ways of illustrating the fitness of a physical property. Properly employed, both are free from fallacy, and it will be desirable for us to employ both. Thus it may be shown, as in the case of the temperature of the ocean, that a particular property of water, its high specific heat, automatically produces a maximum of something which is favorable to life. Or again, as in the case of the regulation of the temperature of the human body by the process of perspiration, it may be shown that a particular property of water, its high 
heat of vaporization, has been utilized through adaptation of the organism to secure very high efficiency in a physiological process.

Such is the method which must be followed in order to decide the question of the fitness of the environment. The physico-chemical characteristics of water, carbonic acid, and the carbon compounds are to be taken up one by one, and their absolute and relative magnitudes considered. The possible utility of such properties, both automatically and through process of organic adaptation, must then be estimated, bearing in mind the fundamental characteristics of the living organism which have been arbitrarily postulated. Finally the various favorable qualities of water, carbonic acid, and the carbon compounds must be grouped together in order to see if they constitute a unique ensemble of fitness, among all possible chemical substances, for a living organism which must be complex, regulated, and engaged in active metabolism.

At length the problem of fitness appears in a simple form. The road to a solution is open, and we may now proceed to an untrammeled discussion of unexceptionable data and well-known laws of physics, chemistry, meteorology, and physiology. Without further hypothetical difficulties, these must lead to the goal. 


\section{CHAPTER III}

\section{WATER \\ GENERAL CONSIDERATIONS}

T $\mathrm{T}$ was assuredly not chance that led Thales 1 to found philosophy and science with the assertion that water is the origin of all things. Whether his belief was most influenced by the wetness of animal tissues and fluids, or by early poetic cosmogonies, or by the ever present importance of the sea to the Ionians, ${ }^{1}$ however vague his conception of water may, indeed must, have been, he at least expressed a conclusion which proceeded from experience and serious reflection. Later, when positive knowledge had already grown to be a substantial basis for speculation, both meteorological and chemical views contributed to the decision of Empedocles and Aristotle to include water among the elements. ${ }^{2}$ And it is especially worthy of note that of earth, air,

1 Windelband, "Handbuch der Altertumswissenschaft," V. 1. 139. Nördlingen, 1888.

${ }^{2}$ Windelband, l.c.; S. Günther, "Geschichte der Naturwissenschaften." Reclam, Leipzig, Vol. I, p.19. 
fire, and water the last is the only one which happens to be an individual chemical compound. From that day to this the unique position of water has never been shaken. It remains the most familiar and the most important of all things.

Within a comparatively recent time, to be sure, it has definitely lost its claim to be a true element, in the modern sense, but meanwhile almost every great development of science has but contributed to make its importance more clear. In physics, in chemistry, in geology, in meteorology, and in biology nothing else threatens its preëminence. The physicist has perforce chosen it to define his standards of density, of heat capacity, etc., and as a means to obtain fixed points in thermometry. The chemist has often been almost exclusively concerned with reactions which take place in aqueous solution, and the unique chemical properties of water are of fundamental significance in most of the departments of his science. In geology neptunism has at length won a certain though incomplete truimph over plutonism, and the action of water now appears to be far the most momentous factor in geological evolution. ${ }^{1}$ The meteorologist perceives

1 " Of all geological agencies water is the most obvious and apparently the greatest, though its efficiency is conditioned 


\section{THE FITNESS OF THE ENVIRONMENT}

that the incomparable mobility of water, which depends upon its peculiar physical properties and upon its existence in vast quantities in all three states of solid, liquid, and gas, is the chief factor among the properties of matter to determine the nature of the phenom-

upon the presence of the atmosphere, upon the relief of the land, and upon the radiant energy of the sun. Through the agency of rainfall, of surface streams, of underground waters, and of wave action, the hydrosphere is constantly modifying the surface of the lithosphere, while at the same time it is bearing into the various basins the wash of the land and depositing it in stratified beds. It thereby becomes the great agency for the degradation of the land and the building up of the basin bottoms. It works upon the land partly by dissolving soluble portions of the rock substance, and partly by mechanical action. The solution of the soluble part usually loosens the insoluble, and renders it an easy prey of the surface waters. These transport the loosened material to the valleys and at length to the great basins, meanwhile rolling and grinding it and thus reducing it to rounder forms and a finer state, until at length it reaches the still waters or the low gradients of the basins and comes to rest. The hydrosphere is, therefore, both destructive and constructive in its action. As the beds of sediment which it lays down follow one another in orderly succession, each later one lying above each earlier one, they form a time record. And as relics of the life of each age become more or less imbedded in these sediments, they furnish the means of following the history of life from age to age. The historical record of geology is, therefore, very largely dependent upon the fact that the waters have thus buried in systematic order the successive life of the ages." - Chamberlin and Salisbury, "Geology." New York, 1904, Vol. I, p. 8. 
ena which he studies; ${ }^{1}$ and the physiologist has found that water is invariably the prin-

1"Of all the terrestrial agents by which the surface of the earth is geologically modified, by far the most important is water. We have already seen, when following hypogene changes, how large a share is taken by water in the phenomena of volcanoes and in other subterranean processes. Returning to the surface of the earth and watching the operations of the atmosphere, we soon learn how important a part of these is sustained by the aqueous vapor that pervades the atmosphere.

"The substance which we term water exists on the earth in three well-known forms: (1) gascous, as invisible vapor; (2) liquid, as water; and (3) solid, as ice. The gascous form has already been noticed as one of the characteristic ingredients of the atmosphere. Vast quantities of vapor are continually rising from the surface of the seas, rivers, lakes, snow fields, and glaciers of the world. This vapor remains invisible until the air containing it is cooled down below its dewpoint, or point of saturation, - a result which follows upon the union or collision of two aërial currents of different temperatures, or the rise of the air into the upper cold regions of the atmosphere, where it is chilled by expansion, by radiation, or by contact with cold mountains. Condensation appears only to take place on free surfaces, and the formation of cloud and mist is explained by condensation upon the fine microscopic dust of which the atmosphere is full. At first minute particles of water vapor appear, which either remain in the liquid condition, or, if the temperature is sufficiently low, are frozen into ice. As these changes take place over considerable spaces of the sky, they give rise to the phenomena of clouds. Further condensation augments the size of the cloud particles, and at last they fall to the surface of the earth, if still liquid, as rain; if solid, as snow or hail; if partly solid and partly liquid, as sleet. As the vapor is largely raised from the ocean surface, so in great 


\section{cipal constituent of active living organisms. ${ }^{1}$ Water is ingested in greater amounts than all}

measure it falls back again directly into the ocean. A considerable proportion, however, descends upon the land, and it is this part of the condensed vapor which we have now to follow. Upon the higher elevations it falls as snow, and gathers there into snow fields, which, by means of glaciers, send their drainage towards the valleys and plains. Elsewhere it falls chiefly as rain, some of which sinks underground to gush forth again in springs, while the rest pours down the slopes of the land, swelling the brooks and torrents which, fed both by springs and rains, gather into broader and yet broader rivers that bear the accumulated drainage of the land out to sea. Thence once more the vapor rises, condensing into clouds and rain to feed the innumerable water channels by which the land is furrowed from mountain top to seashore.

"In this vast system of circulation, ceaselessly renewed, there is not a drop of water that is not busy with its allotted task of changing the face of the earth. When the vapor ascends into the air, it is, comparatively speaking, chemically pure. But when, after being condensed into visible form, and working its way over or under the surface of the land, it once more enters the sea, it is no longer pure, but more or less loaded with material taken by it out of the air, rocks, or soils through which it has traveled. Day by day the process is advancing. So far as we can tell, it has never ceased since the first shower of rain fell upon the earth. We may well believe, therefore, that it must have worked marvels upon the surface of our planet in past time, and that it may effect transformation in the future." - Geirie, "Textbook of Geology." London, 1903, 4th ed., Vol. I, pp. 447, 448.

${ }^{1}$ Thus water makes up from 70 to 85 per cent of fishes, about 87 per cent of oysters, 85 per cent of apples, 78 per cent of potatoes, 95 per cent of the edible portion of lettuce, etc. 
other substances combined, and it is no less the chief excretion. It is the vehicle of the principal foods and excretory products, for most of these are dissolved as they enter or leave the body. ${ }^{1}$ Indeed, as clearer ideas of the physico-chemical organization of protoplasm have developed it has become evident that the organism itself is essentially an aqueous solution in which are spread out colloidal substances of vast complexity. ${ }^{2}$ As a result of these conditions there is hardly a physiological process in which water is not of fundamental importance.

All of these circumstances, which completely justify the interest in water which Thales and Aristotle, and nearly all later students of nature have manifested, depend in great part upon the quantity of water which is present outside the earth's crust, and upon its often unique physical and chemical properties.

${ }^{1}$ Properly speaking, the entrance of the foods into the body is across the wall of the intestine; at this point the foods have all undergone digestion and are almost exclusively in solution. In like manner excretion takes place across the renal epithelium, or the epithelium of the lungs, or across that of the sweat glands; these too are traversed only by substances in solution.

2 "Der Organismus, Pflanze wie Tier, ist ein Gefäss voll wässeriger Lösung, in dem sich als disperse Phase verschiedenartige Kolloide befinden." - BEcruold, "Die Kolloide in Biologie und Medizin." Dresden, 1912. 
Such properties are our present concern. Doubtless if it were not for the enormous quantity of water which exists upon our planet, all its physical properties would be of little avail to bring about its universal importance in nature. This, however, as has been above explained, appears to be neither an accidental nor an uncommon phenomenon.

Of the total extent of the earth's surface the oceans make up about three fourths, and they contain an amount of water sufficient, if the earth were a perfect sphere, to cover the whole area to a depth of between two and three miles. This corresponds to about 0.2 per cent of the volume of the globe. The occurrence of water is, moreover, not less important and hardly less general upon the land. In addition to lakes and streams, water is almost everywhere present in large quantities in the soil, retained there mainly by capillary action, and often at greater depths. The atmosphere also contains an abundance of water as aqueous vapor and as clouds. Now the very occurrence of water upon the earth, and especially its permanent presence, is due in no small degree to its chemical stability in the existing physical and chemical conditions. This stability is of great moment in the various inorganic and organic processes 
in which water plays so large a part. In the first place the chemical reactions in which it is concerned during the process of geological evolution, though they are no doubt in the total of great magnitude, are both slow and far from violent. Long since any very active changes of this sort, so far as the superficial part of the crust is concerned, have run their course. In the second place water is really, at the temperature of the earth and in comparison with most other chemical substances, an extremely inert body, for the union of hydrogen with oxygen is so firm that it is not readily dissolved.

Thus water exists as a singularly inert constituent of the atmosphere, as a liquid nearly inactive in chemical processes on the surface and in the soil, and everywhere as a mild solvent which does not easily attack the substances which in great variety dissolve in it. The chemical changes which do follow upon solution are not such as to produce substantial chemical transformations, and most substances can pass through water unscathed. The nature of water, then, is a great factor in the chemical stability, which, no less than the physical stability of the environment, is essential to the living mechanism. But it may be questioned if such stability would not 
necessarily be ultimately attained in greater or less degree with almost any other substance, as a result of the general tendency of chemical processes to reach a condition of equilibrium, and it will therefore be well to turn to more secure fields of inquiry.

\section{I}

\section{THERMAL PROPERTIES}

The most familiar among such are certain characteristics of water which have been long known, and which, as the Bridgewater Treatises and other works on natural theology testify, were formerly favorite subjects of metaphysical speculation, - the thermal properties. These characteristics of water were recognized at an early stage in the development of modern science, and in many cases their special importance in meteorology and in other departments of the sciences of nature is almost self-evident.

\section{A}

SPECIFIC HEAT

First among these is the heat capacity or, as it is more commonly termed, the specific heat of water. This quantity has the value of 
1.000 for the interval between $0^{\circ}$ and $1^{\circ}$ centigrade, a number which is due to the choice of water in defining the calorie or fundamental unit of heat. The calorie, small calorie, or gram calorie is that quantity of heat which is required to raise the temperature of one gram of water through $1^{\circ}$ centigrade, and it varies slightly with the temperature, having the relative values 1.000 for the interval from $0^{\circ}$ to $1^{\circ}, 0.998$ for the interval from $4^{\circ}$ to $5^{\circ}, 0.992$ for the interval from $15^{\circ}$ to $16^{\circ}$, and its mean value for the interval from $0^{\circ}$ to $100^{\circ}$ is 1.004 . The heat capacity of water is then 1.000 , in that 1.000 calorie is required to raise the temperature of 1.000 gram of water through 1.000 degree centigrade.

The approximate specific heats of a variety of important substances are as follows:-

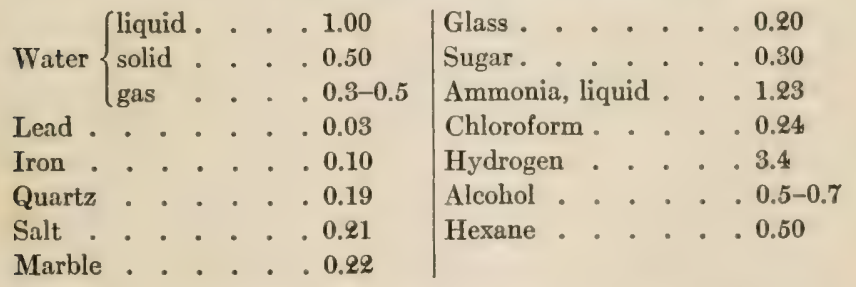

It is unnecessary to enter upon an elaborate analysis of the data concerning specific heats, for the magnitude of the specific heat of a substance is dependent upon its chemical nature, as was first made clear by Dulong 
and Petit in 1819. The law which bears their name consists of the statement that in the case of elementary substances the product of specific heat and atomic weight is a constant, — roughly, 6.4. Certainly this so-called law is a mere approximation, and some elements, notably carbon, silicon, and boron, at the ordinary temperature, depart widely from its requirements, but in the main the approximation holds good. Later the researches of Neumann, Garnier, Cannizaro, and especially of Kopp made possible an extension of the law to compounds.

It is evident that the law of Dulong and Petit amounts to the statement that for all elementary substances the quantity of heat which is required to change the temperature of every atom, regardless of its nature, is a constant. A brief discussion will serve to make this plain. According to the law the specific heat of an element varies inversely as its atomic weight, diminishing as the atomic weight increases, so that the product of the two quantities remains constant. But of course the number of atoms per gram of substance also varies inversely as the atomic weight. Hence the specific heats of elementary substances and the number of atoms per gram are always roughly proportional, which 
can only be the case if all atoms, no matter of what element, require a constant amount of heat to raise their temperatures one degree. That is to say, in all elementary substances the heat capacity of the atom is constant, and independent of the nature of the element (with the qualifications above noted).

The study of compounds has shown that this same generalization is also true of them. This means that in all substances the heat capacity of every atom is nearly constant and is independent of its nature and of that of the compound in which it finds itself.

Accordingly the law of Dulong and Petit may be formulated as follows; - the specific heat of a substance multiplied by the average of the atomic weights of all the constitutent atoms in the molecule is often equal to about 6.4 , and is always not very different from this number. This conclusion may be tested with the data above recorded.

\begin{tabular}{|c|c|c|c|c|c|}
\hline Substance & $\begin{array}{c}\text { Molecular } \\
\text { Weigrt }\end{array}$ & $\begin{array}{l}\text { NOMBER } \\
\text { OF } \\
\text { AtoMs }\end{array}$ & $\begin{array}{l}\text { Average } \\
\text { Atomic } \\
\text { Weight }\end{array}$ & $\begin{array}{c}\text { SPECIFIC } \\
\text { HEAT }\end{array}$ & $\begin{array}{c}\text { Specific Heat } \\
\times \\
\text { Atomic Weight }\end{array}$ \\
\hline Water & 18 & 3 & 6 & 1.0 & 6.0 \\
\hline Ammonia & 17 & 4 & 4 & 1.2 & 4.8 \\
\hline Quartz . & 60 & 3 & 20 & 0.2 & 4.0 \\
\hline Salt . & 58 & 2 & 29 & 0.2 & 5.8 \\
\hline Sugar. . & 342 & 45 & 8 & 0.3 & 2.4 \\
\hline Hexane . & 86 & 20 & 4 & 0.5 & 2.0 \\
\hline
\end{tabular}


It must be confessed that such data are not a brilliant confirmation of the law. A series of numbers which vary from 2.0 to 6.0 is something quite different from constancy, and every one of these numbers is less than 6.4. It is, however, certain that these quantities are uniformly of the same order of magnitude, and this is all that is of importance for our present purpose. For accordingly they prove that unless the average atomic weight of a substance be very low its specific heat cannot be very high. Of course only compounds which are largely made up of hydrogen can possess very low average atomic weights, and among such those will be lowest in this respect which contain a relatively small number of atoms of another element of low atomic weight, like carbon, nitrogen, oxygen, etc. Of such substances the hydrocarbons make up the only numerous group, and for the most part their specific heats appear to be, like that of elementary carbon itself, considerably lower even than would be predicted by the rule. So it is that the conclusion is warranted that water shares the characteristic of very high specific heat with a very small number of substances, among which hydrogen and ammonia are probably the only important chemical individuals. From this conclusion another 
follows directly; namely, that water possesses certain nearly unique qualifications which are largely responsible for making the earth habitable, or at least very favorable as a habitation for living organisms.

It need hardly be pointed out that this importance of the high heat capacity of water is a very well-known fact. Even in the early decades of the nineteenth century, when natural theology and argument from design were the subject of lively controversy, especially in England, such subjects were very familiar, and an excellent temperate discussion from the theologian's side will be found in Whewell's Bridgewater Treatise. ${ }^{1}$ At that time, before a clear formulation of the concept of adaptation existed, it was of course impossible to disentangle such natural fitness from the results of the organic evolutionary process. In the more modern period since the publication of "The Origin of Species," the late Professor J. P. Cooke of Harvard has dwelt upon this and other properties of water and sought to show that, lying wholly apart from the new ideas, such phenomena remain

${ }^{1}$ Chapter IX of this work deals with "The Laws of Heat with Respect to Water." Although the ideas are somewhat vague, the importance of the capacity of water to absorb heat is clearly brought out. 
unexplained and inexplicable by our present laws of natural science. He, too, endeavored to employ such facts as theological arguments but, in spite of many sound contentions, with less success in a more skeptical age. ${ }^{1}$

The most obvious effect of the high specific heat of water is the tendency of the ocean and of all lakes and streams to maintain a nearly constant temperature. This phenomenon is of course not due to the high specific heat of water alone, being also dependent upon evaporation, freezing, and a variety of circumstances which automatically mix and stir water. But in the long run the effect of high specific heat is of primary importance. It will be convenient to postpone consideration of the regulation and importance of the constant temperature of the ocean until the other properties of water which contribute thereto have been discussed.

A second effect of the high specific heat of

1 "Assume that the variations preserved by natural selection are all accidental, a point on which naturalists greatly differ, still what is the result? An adaptation to the environment. According to the theory, then, the conditions of the environment are a determining cause; and unless we believe that all nature was the result of a fortuitous concourse of atoms, we can find in these conditions abundant opportunities where intelligent causation can act." - Josiah Parsons Cooke, "The Credentials of Science." New York, 1888, p. 251. 
water is the moderation of both summer and winter temperatures of the earth. It is not easy to estimate the total magnitude of this effect, but the manner in which it comes about is well illustrated by the differences between seaboard and inland climates or between the climate of a large part of the United States, which is a continental climate, and that of Western Europe, which is essentially an insular climate. In the most extreme form such moderation of climate is to be observed on the high seas and upon small islands. There are found the smallest known differences between the mean temperatures of different months of the year and of different hours of the day, and the least tendency to violent changes of temperature. The calculation of Zenker regarding normal temperatures may

\begin{tabular}{c|r|r|r}
\hline \hline Latitude & Continental Climate & Marine Climate & Difference \\
\cline { 2 - 3 } Degrees & Degrees & Degrees & Degrees \\
0 & 34.6 & 26.1 & -8.5 \\
10 & 33.5 & 25.3 & -8.2 \\
20 & 30.0 & 22.7 & -7.3 \\
30 & 24.1 & 18.8 & -5.3 \\
40 & 15.7 & 13.4 & -2.3 \\
50 & 5.0 & 7.1 & 2.1 \\
60 & -7.7 & 0.3 & 8.0 \\
70 & -19.0 & -5.2 & 13.8 \\
80 & -24.9 & -8.2 & 16.7 \\
90 & -26.1 & -8.7 & 17.4 \\
\hline
\end{tabular}


be cited as a good illustration of the nature of the case. ${ }^{1}$

It is unnecessary to discuss the effects upon living organisms of the equable temperature of the ocean and of the moderation of climate, for obviously we are here confronted by a true instance of regulation of the environment.

The high heat capacity of water operates in still another manner to regulate temperature upon the land and at the same time to increase the mobility of the environment of marine organisms. For directly or indirectly it is involved in the formation and duration of ocean currents, especially the movement of water in the depths from the polar to the tropical seas, and it determines the amount of heat carried by such currents. A similar and even more important "function" is the direct promotion of winds, with the resulting distribution of aqueous vapor throughout the atmosphere, a primary factor in the dissemination of water by means of the rainfall. Here the essential thing is the existence of a vast warm reservoir in the tropics and of two similar cold reservoirs at the poles. Under

${ }^{1}$ A discussion of Zenker's work will be found in Hann's "Handbook of Climatology," translated by Ward, pp. 210215. 
these circumstances the circulation of winds, bearing away water vapor from the tropical oceans, is inevitable, and the process is intensified by the high specific heat of water.

The living organism itself is directly favored by this same property of its principal constituent, because a given quantity of heat produces as little change as possible in the temperature of its body. Man is an excellent case in point. An adult weighing 75 kilograms (165 pounds) when at rest produces daily about 2400 great calories, which is an amount of heat actually sufficient to raise the temperature of his body more than $32^{\circ}$ centigrade. But if the heat capacity of his body corresponded to that of most substances, the same quantity of heat would be sufficient to raise his temperature between $100^{\circ}$ and $150^{\circ}$. In these conditions the elimination of heat would become a matter of far greater difficulty, and the accurate regulation of the temperature of the interior portion of his body, especially during periods of great muscular activity, well-nigh impossible. Extreme constancy of the body temperature is, of course, a matter of vital importance, at least for all highly organized beings, and it is hardly conceivable that it should be otherwise. In 
the first place marked influence of change of temperature upon chemical reaction is almost universal, and as a rule an increase of $10^{\circ}$. centigrade in temperature will more than double the rate of a chemical change. ${ }^{1}$ Secondly all living organisms contain both chemical substances and physico-chemical structures or systems which begin to be altered, and usually irreversibly altered, at a temperature which is very little above that of the human body. ${ }^{2}$ It is perhaps imaginable that

${ }^{1}$ If the velocity of a chemical reaction be represented by a coefficient, $k$, the increase in its magnitude with rising temperature is unlike that of ordinary physical coefficients, and in many cases amounts to a two or threefold rise for a temperature increase of $10^{\circ}$ centigrade. The well-known data concerning the transformation of dibromsuccinnic acid into brommaleic acid and hydrobromic acid in aqueous solution illustrate a typical case.

\begin{tabular}{cl}
$t$ & \multicolumn{1}{c}{$k$} \\
$15^{\circ}$ & 0.00000967 \\
$40^{\circ}$ & 0.0000863 \\
$50^{\circ}$ & 0.000249 \\
$60.2^{\circ}$ & 0.000654 \\
$70.1^{\circ}$ & 0.00169 \\
$80^{\circ}$ & 0.0046 \\
$89.4^{\circ}$ & 0.0156 \\
$101^{\circ}$ & 0.0318
\end{tabular}

${ }^{2}$ This is attested not only by the low temperature at which many proteins coagulate, but also by the action of temperatures between $50^{\circ}$ and $60^{\circ}$ to inactivate enzymes, and 
conditions might be otherwise in beings of a very different kind, but to-day every chemist well knows that if he is to control a chemical process, almost the first desideratum is rigid regulation of the temperature at which the process takes place. ${ }^{1}$

It is therefore incontestable that the unusually high specific heat of water tends automatically and in most marked degree to regulate the temperature of the whole environment, of both air and water, land and sea, and that of the living organism itself. Likewise the same property favors the circulation of water by facilitating the production of winds, besides contributing to the formation of ocean currents. Here is a striking instance of natural fitness, which in like degree is unattainable with any other substance except ammonia.

to produce alterations in many of the complex substances that are involved in the phenomena of immunity and other similar things.

${ }^{1}$ Almost the most conspicuous change in the equipment of modern chemical laboratories, as a result of the growth of physical chemistry, is the introduction everywhere of thermostats. 


\section{$B$}

\section{LATENT HEAT}

Very different from specific heat in their relationship to the chemical constitution of a substance, but not unlike it in biological importance, are the so-called latent heats of melting and of evaporation.

The latent heat of melting is expressed as the number of calories which are required to convert one gram of solid at the freezing point into one gram of liquid at the same temperature. For water its value is approximately 80 , which indicates that the same quantity of heat must be employed to melt ice as to raise the temperature of the resulting icewater to $80^{\circ}$ centigrade.

The latent heat of evaporation is similarly defined as the number of calories required to change one gram of liquid into vapor. Its magnitude depends upon the temperature at which the process takes place. The latent heat of evaporation of water is approximately 536. There is required, accordingly, as much heat to boil away one gram of water as to raise the temperature of 536 grams through $1^{\circ}$ centigrade.

There are a number of important effects of 
the high latent heats of fusion and evaporation of water upon the meteorological processes. When, for example, a body of water becomes cooled to its freezing point, the further abstraction of heat cannot lower its temperature below that point, which, to be sure, is somewhat variable in the case of salt water. And so long as water and ice exist in contact, the system constitutes a thermostat, a very accurate one if the water be fresh, which changes only in respect to the quantities of ice and water as heat is added or removed. ${ }^{1}$ Heating serves merely to melt the ice, cooling to freeze the water. Accordingly, as long as the earth shall remain habitable the cooling of its oceans and seas will remain rigidly limited by their freezing point. However inclement the atmosphere, the ocean can always support life until the final extinction of water by cold. It is worthy of note that the freezing point of water, though to man with his carefully regulated body temperature apparently low, is in reality very high indeed compared with that of any like substances, - perhaps $100^{\circ}$ centigrade above the average.

${ }^{1}$ In fact, there is no better means of obtaining a constant temperature in the chemical laboratory than by mixing pure ice with pure water. 


\section{Table of Melting Points}

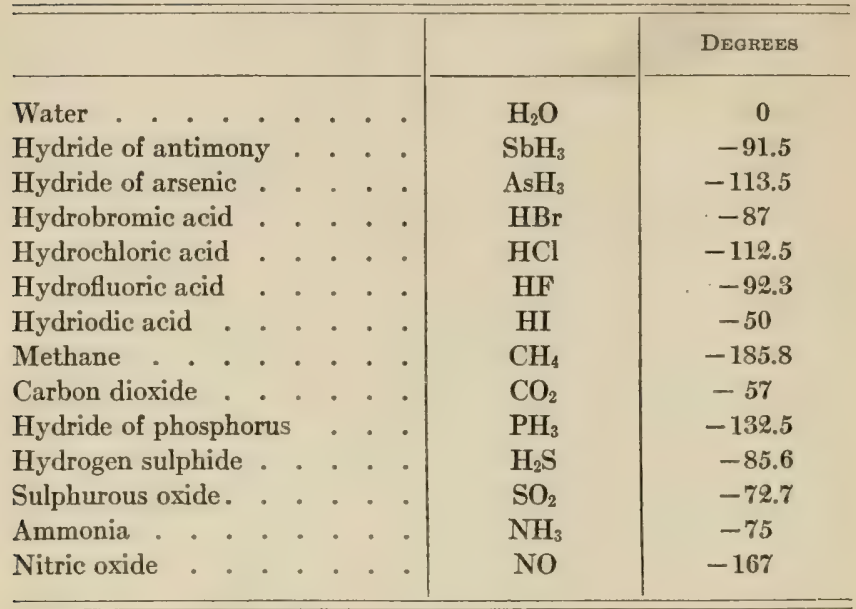

This is, no doubt, one of the most important facts with which we are concerned, for while a very large number of chemical processes take place quite freely at $0^{\circ}$, the conditions are very different at the freezing point of ammonia, for instance. At that temperature the velocity of most chemical processes is but a fraction of one per cent of their velocity at $0^{\circ}$, and a large part of the chemical activity which is familiar to us ceases.

The result of the unusually high freezing point of water and of the phenomenon of latent heat is felt, however, not merely in the avoidance of an excessive fall in the temperature of lakes and seas. As above explained, 
whenever the ocean comes in contact with climates of very low temperature it tends to moderate them, the more effectively the greater the disparity between the temperature of the air and that of the water, and here latent heat is quite as important a factor, though indirectly, as specific heat.

It remains to point out that the latent heat of melting of water is nearly the greatest which has yet been discovered, being exceeded, in fact, by that of ammonia alone.

\section{Table of Latent Heats of Melting}

\begin{tabular}{|c|c|c|c|c|c|c|c|c|c|}
\hline \multicolumn{6}{|c|}{ SUBstance } & \multirow{2}{*}{$\frac{\text { Formula }}{\mathrm{Pb}}$} & \multirow{2}{*}{$\frac{\begin{array}{c}\text { Meliting } \\
\text { Point }\end{array}}{326^{\circ}}$} & \multicolumn{2}{|c|}{$\begin{array}{c}\text { Tuatent Heat } \\
\text { of Fugion }\end{array}$} \\
\hline Lead . & . & . & - & . & - & & & 5.4 & Calories \\
\hline Bromine & - & - & - & . & - & $\mathrm{Br}$ & -7.3 & 16.2 & \\
\hline Cadmium . & - & - & - & - & - & $\mathrm{Cd}$ & 321 & 13.7 & \\
\hline Iron. . & - & - & - & - & - & $\mathrm{Fe}$ & & 23-33 & \\
\hline Gallium & - & - & - & - & - & $\mathrm{Ga}$ & 13 & 19.1 & \\
\hline Iodine. & . & . & - & - & - & I & & 11.7 & \\
\hline Potassium & . & - & - & - & - & $\mathbf{K}$ & 58 & 15.7 & \\
\hline Copper. & - & - & - & - & - & $\mathrm{Cu}$ & & 43 & \\
\hline Sodium & . & . & . & - & - & $\mathrm{Na}$ & 96.5 & 31.7 & \\
\hline Nickel. & - & - & - & . & . & $\mathrm{Ni}$ & & 4.64 & \\
\hline Palladium. & . & - & . & & . & $\mathbf{P d}$ & & 36.3 & \\
\hline Phosphorus & & - & - & - & - & $\mathbf{P}$ & 27.35 & 4.7 & \\
\hline Platinum & $\therefore$ & - & - & - & - & Pt & 1779 & 27.18 & \\
\hline Mercury & - & - & - & - & - & $\mathrm{Hg}$ & & 2.82 & \\
\hline Sulphur & - & - & - & . & - & $\mathrm{S}$ & 115 & 9.37 & \\
\hline Silver. & - & - & . & . & - & $\mathrm{Ag}$ & 999 & 21.07 & \\
\hline Bismuth & - & - & - & - & - & $\mathrm{Bi}$ & 266.8 & 12.64 & \\
\hline Zinc. & - & - & - & - & - & $\mathrm{Zn}$ & 415 & 28.13 & \\
\hline Tin. & - & . & . & . & . & Sn & 233 & 14.25 & \\
\hline
\end{tabular}




\begin{tabular}{|c|c|c|c|}
\hline Substance & ForMULA & $\begin{array}{l}\text { Melting } \\
\text { Point }\end{array}$ & $\begin{array}{c}\text { Latent Heat } \\
\text { of FUSION }\end{array}$ \\
\hline Water . . . . & $\mathrm{H}_{2} \mathrm{O}$ & $0^{\circ}$ & 80 Calories \\
\hline Ammonia . . . & $\mathrm{NH}_{3}$ & -75 & 108 \\
\hline Antimony chloride. & $\mathrm{SbCl}_{3}$ & 73 & 13.4 \\
\hline Antimony bromide. & $\mathrm{SbBr}_{3}$ & 94 & 9.7 \\
\hline Lead chloride . . & $\mathrm{PbCl}_{2}$ & 485 & 20.9 \\
\hline Calcium chloride & $\mathrm{CaCl}_{2} \cdot 6 \mathrm{H}_{2} \mathrm{O}$ & 28.5 & 40.7 \\
\hline Potassium nitrate & $\mathrm{KNO}_{3}$ & 339 & 47.4 \\
\hline Sodium nitrate . & $\mathrm{NaNO}_{3}$ & 310.5 & 63 \\
\hline Phosphoric acid & $\mathrm{H}_{3} \mathrm{PO}_{4}$ & 18 & 25.7 \\
\hline Nitric acid . . & $\mathrm{HNO}_{3}$ & $-47^{\circ}$ & 9.5 \\
\hline Sulphuric acid . & $\mathrm{H}_{2} \mathrm{SO}_{4}$ & 10.3 & 24. \\
\hline Sulphuric oxide. & $\mathrm{SO}_{3}$ & & 76.7 \\
\hline Ethylene bromide . & $\mathrm{C}_{2} \mathrm{H}_{4} \mathrm{Br}_{2}$ & 8 & 13 \\
\hline Formic acid . & H.COOH & -7.5 & 57.4 \\
\hline Chloral hydrate & $\mathrm{C}_{2} \mathrm{H}_{3} \mathrm{Cl}_{3} \mathrm{O}_{2}$ & 46 & 33.2 \\
\hline Dimethyl oxalate & $\mathrm{C}_{2} \mathrm{O}_{4}\left(\mathrm{CH}_{3}\right)_{2}$ & 49.5 & 42.6 \\
\hline Acetic acid . . & $\mathrm{CH}_{3} \mathrm{COOH}$ & & 43.7 \\
\hline Glycerine . . & $\mathrm{C}_{3} \mathrm{H}_{8} \mathrm{O}_{3}$ & 13 & 42.5 \\
\hline Stearic acid . . & $\mathrm{C}_{18} \mathrm{H}_{36} \mathrm{O}_{2}$ & 64 & 47.6 \\
\hline Benzene . & $\mathrm{C}_{6} \mathrm{H}_{6}$ & 5.3 & 30.1 \\
\hline Nitrobenzene . & $\mathrm{C}_{6} \mathrm{H}_{5} \mathrm{NO}_{2}$ & -9.21 & 22.3 \\
\hline Di-chlorbenzene & $\mathrm{C}_{6} \mathrm{H}_{4} \mathrm{Cl}_{2}$ & 52.5 & 29.9 \\
\hline$p$-Toluidine . & $\mathrm{C}_{7} \mathrm{H}_{9} \mathrm{~N}$ & & 35.8 \\
\hline Phenol - . & $\mathrm{C}_{6} \mathrm{H}_{5} \mathrm{OH}$ & 25.4 & 24.9 \\
\hline Menthol . . . & $\mathrm{C}_{10} \mathrm{H}_{20} \mathrm{O}$ & 42 & 18.9 \\
\hline Phenylhydrazine & $\mathrm{C}_{6} \mathrm{H}_{5}$. NH.NH $\mathrm{NH}_{2}$ & & 24.5 \\
\hline Phenylacetic acid & $\mathrm{C}_{6} \mathrm{H}_{5} \cdot \mathrm{CH}_{2} \cdot \mathrm{COOH}$ & 75 & 25.4 \\
\hline Naphthaline . . & $\mathrm{C}_{10} \mathrm{H}_{8}$ & 80 & 35.7 \\
\hline
\end{tabular}

Accordingly, the processes above described possess nearly the highest possible efficiency. A very large amount of heat must be abstracted from a body of water before it can be solidified; after a given amount of cool- 
ing a very large quantity of water must remain liquid; a body of water at $0^{\circ}$ centigrade can warm up a very large amount of colder air with the formation of a very small quantity of ice. Thus the permanency of the ocean, and the moderating effect of water upon cold climates are very nearly maximal. These are also facts, directly dependent upon the physico-chemical nature of water, which are remarkably favorable to the organism.

Still more important is the latent heat of evaporation of water. Wherever water is in contact with the air, evaporation must take place until, if the system be of small dimensions, equilibrium is established between aqueous vapor and the liquid; in short until the air is saturated with water. Unlike freezing, which occurs only at one particular temperature, this process goes on continuously throughout all ranges of temperature at which liquid water can exist, and even upon ice at low temperatures. It is always accompanied by the conversion of heat, in the amount measured by the latent heat of evaporation, into other forms of energy; the heat becomes latent. And since air in contact with water is rarely saturated with aqueous vapor, owing to the constant movement of the atmosphere, the process of evaporation, with the accompany- 
ing conversion of heat into latent heat, is a continuous process. The phenomenon is a variable one, however, for while at high temperature, both because of the greater supply of heat and because of the greater amount of water vapor that the air can hold, the process is very important and active, at low temperature it is far less considerable. This in itself is no doubt a benefit because it tends especially to restrict the upward march of temperature when the temperature is high, but is of minor importance when the temperature is low.

In view of the other favorable qualities of water it is perhaps not surprising to find that its latent heat of evaporation is by far the highest known. So great, in truth, is this quantity and so important the process that the latent heat of evaporation is one of the most important regulatory factors at present known to meteorologists.

When the sun shines upon a body of water, only a small part of the energy which the water receives contributes to the elevation of its temperature. Thus Fitzgerald has concluded from his studies of Lough Derg in Ireland during clear hot summer weather ${ }^{1}$

${ }^{1}$ See Hann, "Handbook of Climatology," translated by Ward, p. 131. 
WATER

Table of Latent Heats of Evaporation

\begin{tabular}{|c|c|c|c|c|}
\hline SUb : tance & & FORMULA & $\begin{array}{l}\text { TEMPER- } \\
\text { ATURE OF } \\
\text { VAPOR- } \\
\text { IZATION }\end{array}$ & $\begin{array}{c}\text { Latent Heat of } \\
\text { Vaporization }\end{array}$ \\
\hline Water. . . & . & $\mathrm{H}_{2} \mathrm{O}$ & $100^{\circ}$ & 536 Calories \\
\hline Ammonia . . & . & $\mathrm{NH}_{3}$ & & 295 \\
\hline Bromine . . & . & $\mathrm{Br}_{2}$ & 61.5 & 43.7 \\
\hline Chlorine . . & . & $\mathrm{Cl}_{2}$ & -22 & 67.4 \\
\hline Iodine . . . & . & $\mathbf{I}_{2}$ & 174 & 23.9 \\
\hline Hydrofluoric acid & . & HF & & 360 \\
\hline Oxygen . . & . & $\mathrm{O}_{2}$ & -188 & 58 \\
\hline Nitrogen . . & - & $\mathrm{N}_{2}$ & & 49.8 \\
\hline Phosphorus . . & . & $\mathbf{P}$ & 287 & 130.4 \\
\hline Mercury . . & . & $\mathrm{Hg}$ & 350 & 62 \\
\hline Sulphur . . . & . & $\mathrm{S}_{2}$ & 316 & 362 \\
\hline Nitrous oxide & . & $\mathrm{N}_{2} \mathrm{O}$ & & 100.6 \\
\hline Nitric acid . & . & $\mathrm{HNO}_{3}$ & & 115 \\
\hline Sulphurous oxide & - & $\mathrm{SO}_{2}$ & 0 & 91.2 \\
\hline Sulphuric oxide . & . & $\mathrm{SO}_{3}$ & 18 & 147.5 \\
\hline Sulphuric acid . & . & $\mathrm{H}_{2} \mathrm{SO}_{4}$ & 326 & 122.1 \\
\hline Thionylchloride & . & $\mathrm{SOCl}_{2}$ & 82 & 54.5 \\
\hline Arsenic chloride & . . & $\mathrm{AsCl}_{3}$ & & $69.7^{*}$ \\
\hline Phosphorus trichlo & oride & $\mathrm{PCl}_{3}$ & & $67.2^{*}$ \\
\hline Stannic chloride & . . & $\mathrm{SnCl}_{4}$ & & $46.8^{*}$ \\
\hline Silicon chloride. & . & $\mathrm{SiCl}_{4}$ & & 37.3 \\
\hline Carbon dioxide. & . & $\mathrm{CO}_{2}$ & & 72.2 \\
\hline Carbon disulphide & $\therefore$ & $\mathrm{CS}_{2}$ & 0 & 90 \\
\hline Carbon tetrachlori & ide . & $\mathrm{CCl}_{4}$ & 0 & 52 \\
\hline Cyanogen. : & . . & $(\mathrm{CN})_{2}$ & 0 & 103 \\
\hline Hydrocyanic acid & . & HCN & 20 & $211^{*}$ \\
\hline Methyl alcohol . & . & $\mathrm{CH}_{3} \mathrm{OH}$ & $0^{\circ}$ & 289.2 \\
\hline Ethyl alcohol . & - & $\mathrm{C}_{2} \mathrm{H}_{5} \mathrm{OH}$ & 0 & 236.5 \\
\hline Amyl alcohol . & . . & $\mathrm{C}_{5} \mathrm{H}_{11} \mathrm{OH}$ & 131 & 120 \\
\hline Cetyl alcohol . & . . & $\mathrm{C}_{16} \mathrm{H}_{33} \mathrm{OH}$ & & 58.5 \\
\hline Hexane $\cdot$. & . & $\mathrm{C}_{6} \mathrm{H}_{14}$ & 68 & 79.4 \\
\hline Methyl chloride & . . & $\mathrm{CH}_{3} \mathrm{Cl}$ & 0 & 96.9 \\
\hline
\end{tabular}

* Total heat of vaporization. 


\begin{tabular}{|c|c|c|c|c|c|}
\hline \multicolumn{3}{|l|}{ SUbSTANCE } & \multirow{2}{*}{$\begin{array}{l}\text { ForMULA } \\
\mathrm{C}_{2} \mathrm{H}_{5} \mathrm{Br}\end{array}$} & \multirow{2}{*}{$\begin{array}{c}\text { TEMPER- } \\
\text { ATURE OF } \\
\text { VAPOR- } \\
\text { IZATION }\end{array}$} & \multirow{2}{*}{$\begin{array}{c}\begin{array}{c}\text { LATENT HEAT OF } \\
\text { VAPORIZATION }\end{array} \\
\text { 60.4 Calories }\end{array}$} \\
\hline Ethyl bromide . & . & . & & & \\
\hline Amyl iodide. . & . . & . & $\mathrm{C}_{5} \mathrm{H}_{11} \mathrm{I}$ & & 47.5 \\
\hline Aldehyde. . & . & . & $\mathrm{CH}_{3} \cdot \mathrm{CHO}$ & & 136.4 \\
\hline Chloroform . & . . & . & $\mathrm{CHCl}_{3}$ & 0 & 67 \\
\hline Ether . . . & . & . & $\left(\mathrm{C}_{2} \mathrm{H}_{5}\right)_{2} \mathrm{O}$ & 34.9 & 90.4 \\
\hline Acetone . . & . & . & $\mathrm{CH}_{3} \cdot \mathrm{CO} . \mathrm{CH}_{3}$ & 56.6 & 125.3 \\
\hline Formic acid . & . & . & НСOOH & & 103.7 \\
\hline Acetic acid . . & . & - & $\mathrm{CH}_{3} \mathrm{COOH}$ & 118 & 84.9 \\
\hline Acetic anhydride & e . & . & $\left(\mathrm{CH}_{3} \mathrm{CO}\right)_{2} \mathrm{O}$ & 137 & 66.1 \\
\hline Dichlor-acetic ac & cid & . & $\mathrm{CHCl}_{2} \mathrm{COOH}$ & 138.4 & 79.1 \\
\hline Valerianic acid . & - . & . & $\mathrm{C}_{5} \mathrm{H}_{10} \mathrm{O}_{2}$ & & 103.5 \\
\hline Ethyl acetate . & . & . & $\mathrm{C}_{4} \mathrm{H}_{7} \mathrm{O}_{2}$ & & 105.8 \\
\hline Acetyl chloride. & . & . & $\mathrm{CH}_{3} \mathrm{COCl}$ & & 78.9 \\
\hline Acetonitrite . & . & . & $\mathrm{CH}_{3} \mathrm{CN}$ & 81.5 & 170.6 \\
\hline Ethyl amine. & • & . & $\mathrm{C}_{2} \mathrm{H}_{5} \mathrm{NH}_{2}$ & & 146.2 \\
\hline Benzene . . & . & . & $\mathrm{C}_{6} \mathrm{H}_{6}$ & 0 & 109 \\
\hline Toluene . . & . & . & $\mathrm{C}_{6} \mathrm{H}_{5} \mathrm{CH}_{3}$ & 111 & 83.5 \\
\hline Nitro-benzene & . & . & $\mathrm{C}_{6} \mathrm{H}_{5} \mathrm{NO}_{2}$ & 151.5 & 79.1 \\
\hline Aniline . . & . & . & $\mathrm{C}_{6} \mathrm{H}_{5} \mathrm{NH}_{2}$ & & 93.3 \\
\hline Acetophenone & - & . & $\mathrm{C}_{6} \mathrm{H}_{5} \mathrm{COCH}_{3}$ & 203.7 & 77.2 \\
\hline Benzonitrite. & . & - & $\mathrm{C}_{6} \mathrm{H}_{5} \mathrm{CN}$ & 191 & 87.7 \\
\hline Piperidine . . & . & . & $\mathrm{C}_{5} \mathrm{H}_{11} \mathrm{~N}$ & 105.8 & 88.9 \\
\hline Pyridine . . & . & . & $\mathrm{C}_{5} \mathrm{H}_{5} \mathrm{~N}$ & 115.5 & 101.4 \\
\hline
\end{tabular}

that in the morning the surface temperature rises about $0.6^{\circ}$ per hour. This, however, appears to account for but a small fraction of the solar heat which the lake had taken up; the rest must have been expended in evaporation. Another element of great importance is the transparency of water. As a result the rays of the sun are not absorbed 
by the mere surface alone, but a considerable layer of water near the surface receives the heat.

At the equator the evaporation of the ocean appears to be about 2.3 meters per year, ${ }^{1}$ which involves more than $1,000,000,000,000$,000 calories of latent heat per square kilometer. The amount of heat which is employed in evaporating water from 100 square kilometers of the tropical ocean is accordingly vastly more than all the energy employed in the metabolism of the total population of the United States, and it amounts to more than $100,000,000$ horse power. This is equivalent to more than one horse power per square meter day and night throughout the year. To a greater or less extent all over the earth this same process goes on, and as a result the water vapor in the air probably averages between 15 and 20 kilograms per square meter of the earth's surface, an ample supply for the formation of rain. The effect of this enormous evaporation to moderate the temperature of the tropics is very considerable; but the heat which thus disappears is not lost. Rendered latent at the place of evaporation, it is turned back into actual heat at

${ }^{1}$ This and other similar facts will also be found in the work of Hann. 
the point of condensation, and thus serves to warm another and cooler locality.

This process, so vast that all the water power of the globe may be regarded as its secondary by-product, possesses, in respect to its tendency to moderate and equalize the temperature of ocean, of lakes, and of the climates of all the earth, a maximal value. No other liquid could, during the evaporation of a given quantity of material, bind so much heat; no other vapor could yield so much heat upon condensation.

Quite as important to man as this great power of meteorological regulation is the corresponding physiological activity, evaporation of water from the skin and lungs. In an animal like man, whose metabolism is very intense, heat is a most prominent excretory product, which has constantly to be eliminated in great amounts, and to this end only three important means are available: conduction, radiation, and the evaporation of water. The relative usefulness of these three methods varies with the temperature of the environment. At a low temperature there is little evaporation of water, but at body temperature or above there can be no loss of heat at all by conduction and radiation, and the whole burden is therefore thrown upon 
evaporation. The manner in which evaporation becomes important in temperature regulation is well illustrated by the following calculation from a chart of Rubner's. ${ }^{1}$ The experiments upon which the chart is based were made upon the dog, an animal which lacks man's apparatus of sweat glands. The values of the table are only approximate.

\section{TEMPERATURE \\ Degrees}

9

11

13

15

17

19

21

23

27

29

31

33

35

\section{Heat Logs by Evaporation} Per Cent

16

19

22

25

27

30

32

32

36

42

58

64

79

In plants evaporation is even more important than in animals. Evidently such adaptation of the physiological processes to the conditions of the environment is enormously favored by the high latent heat of evaporation. ${ }^{2}$

${ }^{1}$ Lusk, "The Science of Nutrition," p. 99.

${ }^{2} \mathrm{~A}$ full discussion of this subject will be found in the work of Lusk (see above), Chap. III, especially pp. 98-100. 
There is still another beneficial result of this property: the great variation in the vapor tension of water which accompanies variation in temperature. Vapor tension measures the amount of vapor which is present in the atmosphere when it is in contact with a liquid and after it has become saturated with the liquid's vapor. Now, according to a wellknown law, the rate of increase of vapor tension, or in other words the amount of vapor which the air can hold, is greater the greater the latent heat of vaporization. ${ }^{1}$ Hence, degree by degree there is more variation in the vapor tension of water than there could be if the latent heat were lower. Such great variability in the quantity of water which the air can hold is in meteorology the most important characteristic of aqueous vapor. ${ }^{2}$ The relationship between vapor tension and temperature (centigrade) is shown in the accompanying table.

${ }^{1}$ Near the freezing point an increase of $10^{\circ}$ in temperature doubles the amount of water which the air can hold. The increase is proportional to the latent heat of vaporization according to the formulæ

$$
2.3025 \log \frac{p_{1}}{p_{0}}=\frac{18 \cdot W}{1.99}\left(\frac{T_{1}-T_{0}}{T_{0} T_{1}}\right)
$$

where $\mathrm{W}$ stands for the latent heat of vaporization, $\mathrm{p}$ for vapor tension, and $\mathrm{T}$ for temperature.

2 Arrhenius, "Kosmische Physik," p. 612. 
Temperature

Degrees

0

10

20

30

40

50

80

90

100
VAPOR TENSHON

Millimeters

4.58

9.18

17.41

31.55

54.97

92.17

355.47

526.00

760.00

These variations are what make possible both the evaporation of water and its precipitation as rain and as dew in the meteorological cycle. And therefore the high latent heat of vaporization of water is in still another manner a most favorable circumstance in its effect upon the organisms.

To sum up, this property appears to possess a threefold importance. First, it operates powerfully to equalize and to moderate the temperature of the earth; secondly, it makes possible very effective regulation of the temperature of the living organism; and thirdly, it favors the meteorological cycle. All of these effects are true maxima, for no other substance can in this respect compare with water. $^{1}$

${ }^{1}$ This conclusion may be contrasted with that of Whewell (Bridgewater Treatise, p. 142). He includes the expansion of water by heat, the expansion of water by cold below $40^{\circ}$, the expansion of wate. in freezing, the latent heats of melting and 
THERMAL CONDUCTIVITY

The heat conduction of water is also a maximum among ordinary liquids, and, though very low compared with good conductors like metals, must favor the equalization of temperature within the living cells whose structure hinders the establishment of convection currents.

\section{Table of Heat Conductivities}

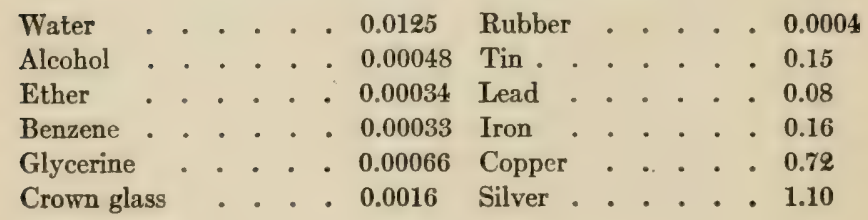

\section{D}

EXPANSION BEFORE FREEZING

A final thermal property of water remains to be considered; namely, its anomalous expansion when cooled at temperatures near the freezing point. The facts are illustrated by the accompanying table.

evaporation, and the rate of evaporation of water. It will be seen that eighty years ago it was already possible to make out a strong case for the fitness of water; but it should not be forgotten that at that time ideas were in some respects still very vague, and comparative data few. 


\begin{tabular}{r|c|c}
\hline Temperature & Density OF WATER & Expansion From $4^{\circ}$ \\
\hline & & Per cent \\
\hline 1 & 0.99987 & 0.013 \\
2 & 0.99993 & 0.007 \\
3 & 0.99997 & 0.003 \\
4 & 0.99999 & 0.001 \\
5 & 1.00000 & 0.000 \\
6 & 0.99999 & 0.001 \\
7 & 0.99997 & 0.003 \\
8 & 0.99993 & 0.007 \\
9 & 0.99988 & 0.012 \\
10 & 0.99981 & 0.019 \\
20 & 0.99973 & 0.027 \\
30 & 0.99824 & 0.176 \\
40 & 0.99567 & 0.44 \\
50 & 0.99233 & 0.77 \\
100 & 0.98813 & 1.19 \\
& 0.95934 & 4.07 \\
\hline
\end{tabular}

This unique property of water is the most familiar instance of striking natural fitness of the environment, although its importance has perhaps been overestimated. ${ }^{1}$ If, however, water, like all other common substances,

${ }^{1}$ It scarcely merits the curious rhapsody of Prout, for instance: "The above anomalous properties of the expansion of water and its consequences have always struck us as presenting the most remarkable instances of design in the whole order of nature - an instance of something done expressly, and almost (could we indeed conceive such a thing of the Deity), at second thought, to accomplish a particular object."-Prout, Bridgewater Treatise, "Chemical Meteorology and the Function of Digestion." London, 1834, pp. 249-250. 
steadily contracted on cooling, so that its point of maximum density fell at the freezing point, it is impossible to say how great would be the disadvantage for living organisms. Certain it is that life upon the earth would be thereby very greatly restricted. For this property, together with the by no means unique phenomenon of expansion upon solidification, ${ }^{1}$ is very largely responsible for the permanence in liquid state of many bodies of water in cold climates. In salt water the anomalous contraction disappears, and the lack of paleocrystic ice is due to the density of ice and to the great mass of the ocean and the movement of its waters. ${ }^{2}$

There is an old experiment of Rumford's which well illustrates what conditions must have been had the contraction of water been normal and ice denser than water. ${ }^{3} \mathrm{He}$ found that in a vessel filled with water, which contains ice confined at the bottom, it is possible to heat and even boil the superficial portion of the water without melting the ice. And so it would be with lakes, streams, and oceans were it not for the anomaly and the

1 The density of ice at the melting point is 0.91674 .

${ }^{2} \mathrm{~A}$ full discussion of this subject will be found in $\mathrm{S}$. Günther's "Handbuch der Geophysik."

${ }^{3}$ See Whewell's Bridgewater Treatise. 
buoyancy of ice. The coldest water would continually sink to the bottom and there freeze. The ice, once formed, could not be melted, because the warmer water would stay at the surface. Year after year the ice would increase in winter and persist through the summer, until eventually all or much of the body of water, according to the locality, would be turned to ice. As it is, the temperature of the bottom of a body of fresh water cannot be below the point of maximum density; on cooling further the water rises; and ice forms only on the surface. In this way the liquid water below is effectually protected from further cooling, and the body of water persists. In the spring the first warm weather melts the ice, and at the earliest possible moment all ice vanishes.

Such are the important thermal properties of water, and in briefest outline their unique fitness for the living mechanism. No other known substance could be substituted for water as the material out of which oceans, lakes, and rivers are formed, and as the substance which passes through the meteorological cycle, without radical sacrifice of some of the most vital features of existing conditions. Ammonia in these respects is the only substance now known which approaches the 
fitness of water. But not only is it almost inconceivable that ammonia should ever occur in sufficiently vast quantities upon a planet's surface, but it is evident as well that ammonia wholly lacks the qualification of anomalous expansion, and also in some of the most important of the other thermal properties falls far short of water; while in latent heat of melting and in specific heat its advantage over water is inconsiderable.

It is obvious that upon a body like the earth the state of the oceans and the meteorological phenomena are of the utmost importance to all living things. Unless these be favorable, human experience and reflection alike agree that life could not widely exist. It seems, therefore, almost safe to say, on the basis of its thermal properties alone, that water is the one fit substance for its place in the process of universal evolution, when we regard that process biocentrically.

\section{II}

THE ACTION OF WATER UPON OTHER SUBSTANCES

Although the thermal properties of water make up the classical subject-matter for discussions of the fitness of the natural en- 
vironment, other no less important physical properties exist. Such especially are those characteristics of liquid water which in no small measure determine the nature of the resulting physico-chemical systems when other substances, whether soluble or insoluble, crystalline or colloidal, are brought into contact with it; I mean the solvent power, the dielectric constant, together with the related ionizing power, and the surface tension.

WATER AS A SOLVENT

As a solvent there is literally nothing to compare with water. In truth its qualifications are on this point so unique and obvious that nobody seems to have taken the trouble to gather together the evidence, and, accordingly, beyond the bare assertion, a brief statement of the facts is not easy. ${ }^{1}$ In the first place the solubility in water of acids, bases, and salts, the most familiar classes of inorganic substances, is almost universal.

${ }^{1}$ Nearly the whole science of chemistry has been built around water and aqueous solutions. A reference to any textbook will at once reveal the truth of this statement. At first sight such a condition appears to be a matter of chance, but, as one becomes more familiar with the true character of the science, realization of a rational justification for the historical fact steadily grows. 
Relatively few of these bodies are highly insoluble; very many are exceedingly soluble in water. Apart from their electrolytic dissociation and hydrolysis, which will be later discussed, the chemical changes wrought upon such dissolved substances in solution are commonly very unimportant. For chemical inertness, depending upon great stability, is a most significant characteristic of water, and undoubtedly a highly advantageous one as well.

On the whole the best evidence for the efficiency of water as a solvent of inorganic substances is to be found in the data of geology. Of all geological agents water appears to have been by far the most active within the periods of which investigation is made possible by the geological record. ${ }^{1}$ Rainfall, the movement of surface streams and of water beneath the ground, and wave action, all contribute to the work of disintegration, sedimentation, etc., partly by dissolution of soluble material, partly by mechanical action. But mechanical action is itself much increased by the loosening which earlier dissolution has caused. In this manner the great solvent power of water throughout its meteorological cycle largely contributes to the mobil-

${ }^{1}$ Geikie, "Textbook of Geology," pp. 447-597. 
ization of many materials which could not otherwise be brought to the organisms which need them.

It has been calculated by Murray ${ }^{1}$ that the total yearly run off of all the rivers of the earth is about 6500 cubic miles, carrying nearly $5,000,000,000$ tons of dissolved mineral matter and prodigious quantities of sediment. The average composition of such water has been estimated as follows:-

Parts per Million

Potassium as $\mathrm{K}_{2} \mathrm{O}$. . . . . . . . . . . . . $\mathbf{2 . 4 0}$

Sodium as $\mathrm{Na}_{2} \mathrm{O}$. . . . . . . . . . . . 7.10

Lithium as $\mathrm{Li}_{2} \mathrm{O}$. . . . . . . . . . . . . . 0.20

Calcium as $\mathrm{CaO}$. . . . . . . . . . . 43.20

Magnesium as $\mathrm{MgO}$. . . . . . . . . . . 14.70

Manganese as $\mathrm{Mn}_{3} \mathrm{O}_{4}$. . . . . . . . . . . . . 1.20

Iron as $\mathrm{FeO}$. . . . . . . . . . . . . . 2.80

Aluminium as $\mathrm{Al}_{2} \mathrm{O}_{3}$. . . . . . . . . . . . 3.10

Silicon as $\mathrm{SiO}_{2}$. . . . . . . . . . . . . . . . 16.40

Carbonic acid as $\mathrm{CO}_{2}$. . . . . . . . . . . . . 46

Phosphorus as $\mathrm{P}_{2} \mathrm{O}_{5}$. . . . . . . . . . . . . . 0.30

Nitric acid as $\mathrm{N}_{2} \mathrm{O}_{5}$. . . . . . . . . . . 3.80

Sulphuric acid as $\mathrm{SO}_{3}$. . . . . . . . . . . . . 8

Chlorine as $\mathrm{Cl}$. . . . . . . . . . 3.70

Ammonia as $\mathrm{NH}_{3}$. . . . . . . . . . . . . 0.07

Total mineral matter . . . . . . . . . 152.97

It is, of course, almost exclusively to these constant accessions that the ocean owes its salinity, which in the course of time has reached well-nigh inconceivable magnitude. The common salt alone in the oceans of all

${ }^{1}$ Russell, "Rivers of North America," p. 80. 


\section{THE FITNESS OF THE ENVIRONMENT}

the earth amounts to not less than 35,000,000,$000,000,000$ tons. Quite as significant of the solvent power of water is the variety of elements whose presence in sea water can be demonstrated, thus proving that the total store of them is in any case enormous. They include hydrogen, oxygen, nitrogen, carbon, chlorine, sodium, magnesium, sulphur, phosphorus, which, are easily demonstrated; further, arsenic, cæsium, gold, lithium, rubidium, barium, lead, boron, fluorine, iron, iodine, bromine, potassium, cobalt, copper, manganese, nickel, silver, silicon, zinc, aluminium, calcium, and strontium. ${ }^{1}$

Equally striking is the evidence in regard to the first stages of this geological process. Under the action of water, aided, to be sure, in many cases by dissolved carbonic acid, every species of rock suffers slow destruction. All substances yield in situ to the solvent work of water, and the dissolved parts may all be found in the great final reservoir, the ocean. It has been proved that nearly every one of the substances which are thus set in motion upon the face of the earth are placed under contribution by life, for biochemical analysis reveals them as constituents of living organisms, absorbed either

${ }^{1}$ Arrhenius, "Kosmische Physil.." 
on their way down from the mountain tops to the ocean or by the marine flora and fauna.

Not less valuable to the community of living things than the dissolution of the rocks, is the disintegration and transport of solid material, largely dependent thereon, which among its many results includes the preliminary steps of soil formation. By these familiar and enduring geological means chemical substances are mobilized in the greatest variety of forms and conditions, and thus rendered available for the living organism. It is clearly evident from the chemist's long experience with solvents that no other fluid could permanently carry on this process with such acceptable regularity and efficiency. For no other chemically inert solvent can compare with water in the number of things which it can dissolve, nor in the amounts of them which it can hold in solution; and of course any chemically active solvent must sooner or later exhaust itself by its chemical action, when the cycle must cease. Here, then, is a fitness of water which is open to no doubt.

Let us turn for further proof to the organism itself, taking blood serum as a source of information. The composition of this sub- 
stance (in the case of the cow) is roughly as follows: ${ }^{1}$ -

Parts per 1000

Water

Protein

Sugar

Cholesterine

Lecithine

Fat

Organic phosphoric acid

$\mathrm{Na}_{2} \mathrm{O}$

$\mathrm{K}_{2} \mathrm{O}$

$\mathrm{CaO}$

$\mathrm{MgO}$

$\mathrm{Cl}$

$\mathrm{P}_{2} \mathrm{O}_{5}$ 913.6

72.5

Most of these substances are in solution, and unquestionably a host of others are present with them, in small and varying amounts. Among these may be mentioned iodine, bromine, iron, sulphates, urea, ammonia, benzoic acid, amino-acids, etc. But indeed all substances found in urine (see below) also occur in blood. It cannot be doubted that if the vehicle of the blood were other than water, the dissolved substances would be greatly restricted in variety and in quantity, nor that such restriction must needs be accompanied by a corresponding restriction of the life processes.

${ }^{1}$ A full discussion of the following data may be found in such works as those of Hammarsten and Abderhalden on physiological chemistry. 
The composition of the urine provides another excellent illustration of the utility of the solvent power of water. In the course of its complex chemical processes a higher organism produces a host of end products which must be removed, and also finds itself accidentally in possession of a great variety of other useless substances which require excretion. The solvent power of water is one of the great factors in facilitating this task. Human urine has been reported to contain in solution the following substances: urea, carbamic acid, creatinine, creatine, uric acid, xanthine, guanine, hypoxanthine, adenine, paraxanthine, heteroxanthine, episarkine, epiguanine, oxalic acid, allantoine, hippuric acid, phenaceturic acid, benzoic acid, phenolsulphuric acid, skatoxylsulphuric acid, paraoxyphenylacetic acid, homogentisic acid, urobiline, urochrome, uroerythrine, glucose, levulose, lactose, numerous compounds of glycuronic acid, glycine, alanine, leucine, tyrosine, and other amino-acids, various enzymes, putrescine, cadavarine, and countless other organic substances, chlorides, bromides, and iodides, phosphates and sulphates, potassium, sodium, ammonia, calcium, magnesium, iron, carbonic acid, nitrogen, argon, etc.

Here again it is sure that such variety could 
not be attained with another solvent. It is no exaggeration to say that except atmospheric oxygen and carbonic acid, nearly all the food of living organisms is water borne, and all material in its passage into the body, through the body, and out of the body nearly always employs the same vehicle. Certainly no other form of transport would be so efficient and so economical.

\section{$B$}

\section{IONIZATION}

If, therefore, aqueous solutions are, apparently of necessity, the very basis of the life processes, the state of substances when in this condition, and also when in contact with water, is of vital importance. Here two properties of water, the dielectric constant and the surface tension, exert a cardinal influence.

Among the phenomena of solution those which are related to electrolytic dissociation, as suggested by the hypothesis of Arrhenius, have deservedly received a great deal of attention since the secure establishment of the new science of physical chemistry in the eighties of the last century. In the course of time the belief that in aqueous solution the molecules of all acids, bases, and salts are more or less split into particles which bear 
electrical charges has been universally accepted. These so-called ions are the source of nearly all the electrical phenomena of solution, whether in batteries, in the manifestations of animal electricity, or in simple conduction through an aqueous solution. But the more familiar electrochemical processes are by no means the only results of ionization. An infinite number of chemical interactions between dissociated bodies follow inevitably. These changes are not, to be sure, decisive and irreversible, but balanced actions, which, however, vastly increase the variety of substances that exist in water.

Let us consider, for example, a system which has been made by dissolving in water the simple salts sodium chloride, $\mathrm{NaCl}$, potassium bromide, $\mathrm{KBr}$, and lithium iodide, LiI. According to the ionization hypothesis, more than half of the molecules of every one of these salts will at once dissociate into ions as follows:

$$
\begin{aligned}
\mathrm{NaCl} & =\stackrel{+}{\mathrm{Na}}+\overline{\mathrm{C}} \mathrm{l} \\
\mathrm{KBr} & =\stackrel{+}{\mathrm{K}}+\overline{\mathrm{Br}} \\
\mathrm{LiI} & =\stackrel{+}{\mathrm{L}^{+}}+\overline{\mathrm{I}}
\end{aligned}
$$

These reactions are balanced, and it is confidently believed that the ions are con- 
stantly recombining to form molecules and the molecules constantly dissociating once more to form ions. At the same time, nothing hinders the union of sodium ions with bromine ions, or of any other pair of positive and negative ions. Accordingly, the solution at once contains not only the three original salts and the six different varieties of ions, but also the following new molecules:sodium bromide, $\mathrm{NaBr}$, sodium iodide, $\mathrm{NaI}$, potassium chloride, $\mathrm{KCl}$, potassium iodide, $\mathrm{KI}$, lithium chloride, $\mathrm{LiCl}$, and lithium bromide, $\mathrm{LiBr}$. All nine varieties of molecules and all six of ions are concerned in a complicated system of chemical reactions which are now well understood, the state of equilibrium depending upon known conditions. For instance, if the solution be a moderately dilute one and the original substances be present in chemically equivalent quantities, about 90 per cent of the material will be in the ionic state, each variety of ions making up about 15 per cent of the total, and about 10 per cent will be in the form of molecules, each variety constituting about 1.1 per cent.

There can be no doubt that ionization plays a great part in determining the characteristics of solutions of acids, bases, and salts, and in bringing about the reactions which 
occur among them, and between them and other substances.

Such, then, is the process to which are due most of the electrical phenomena and many of the chemical phenomena of solutions, and it is certain that the extent and variety of ionization in water far surpass what is possible in any other solvent. One reason for this is most simple. The ionizing substances are so very much more often soluble in water than in any other solvent, and when soluble are in general so much more highly soluble, that the opportunity for ionization in water is quite unparalleled. Further, ionization in solution unquestionably depends upon the dielectric constant of the solvent, in accordance with the principle first stated by Nernst that the greater the dielectric capacity of the solvent, the greater is the degree of electrolytic dissociation of substances dissolved in it, when the conditions are otherwise the same. ${ }^{1}$

1 "The following consideration will make this principle clearer: The positively and negatively charged ions would unite to form electrically neutral molecules because of the electrostatic attraction which exists between them if it were not for the action of another and opposing force, the nature of which is as yet unknown. The equilibrium between these two forces gives rise to the equilibrium between the ions and the undissociated molecules, or determines the degree of dissociation. When the diclectric constant is increased, the 
This is the case because the tendency of the electrically charged ions to reunite and form electrically neutral molecules must be less the greater the dielectric constant of the solvent. Now the dielectric constant of water is nearly the highest at present known, and therefore ionization in water is on that account also more extensive than in almost any other solvent.

Finally, for reasons that are not yet understood, the process of ionization in other solvents than water is a much more complex affair, and there can be no doubt that such complexity limits the phenomena which are dependent upon ionization. ${ }^{1}$

electrostatic attraction between the ions is alone weakened, and hence the degree of dissociation is increased." $-L_{E}$ Blanc, "A Textbook of Electro-Chemistry." New York, 1907, p. 147.

1 "It would be natural to expect that the conceptions which have been found serviceable in the case of solutions in water could be applied directly to solutions in other solvents, keeping in mind that, according to the individual nature of any given solvent, the degree of dissociation, the migration velocity of the ions, and consequently the conductivity of a solution of a given concentration would be different. It is a noteworthy fact, however, that the behavior of non-aqueous is much more complicated than that of aqueous solutions. This is shown especially by the investigation of the conductivity of solutions of various substances in liquid sulfur dioxide made by Walden and Centnerszwer. Neither the law of the independent migration of the ions, nor the law that by increas- 
Physiologically, as researches of the last twenty years clearly prove, the action of ions is of fundamental significance. The brilliant investigations of $\mathrm{J}$. Loeb, and the long series of studies by various other physiologists of the influence of electrolytes upon colloids form perhaps the most telling evidence for this belief. ${ }^{1}$ At all events there is no question that the simple equilibria between acids and bases and salts are of extreme importance in physiological processes. They lie at the very basis of the structure of all protoplasm,

ing dilution the conductance approaches a maximum value, nor, finally, the dilution law, was found to hold. Molecular weight determinations carried out at the same time by the boiling-point method gave normal values for non-electrolytes, and abnormally large values for electrolytes, whereas abnormally small values would be expected. This indicates that association has taken place, to a considerable extent, which in all probability takes place not only between molecules of dissolved substance, but also between these molecules and those of the solvent. Considering these circumstances, it is very fortunate for the advance of the sciences of chemistry and electro-chemistry that such complications are generally, although not always, absent in the case of aqueous solutions. It is due to this fact that it has been possible to deduce simple laws from a study of such solutions." - LE BLANc, "A Textbook of Electro-Chemistry." New York, 1907, pp. 142-143.

${ }^{1}$ Full discussion of such subjects will be found in the "Dynamics of Living Matter," by Loeb, and in his contribution to Oppenheimer's "Handbuch der Biochemie," as well as in Höber's "Physikalische Chemie der Zelle und der Gewebe." 
and the sure and definite relations between such bodies provide, as it were, a secure foundation for the more complex organic structures.

More obvious is the value of ions as sources of electricity. If the older electro-physiology of the third quarter of the nineteenth century has proved in some respects a sterile field, there can yet be no doubt that more subtly, and quite apart from the nervous impulse and the peculiar phenomena of electrical fishes, electrical phenomena are everywhere involved in the most intimate of the physiological processes.

Even without further discussion of a subject that must soon lead into difficult and highly technical considerations, I feel sure that the existence of another important fitness of water is patent. For ions are evidently a real contribution to the richness of the environment. They enhance the variety of chemical substances and of chemical reactions ; they constitute a group of singularly mobile chemical agents; they provide electricity; and, finally, aqueous solutions are by far the best source of ions.

It must be pointed out before leaving this subject that the dielectric constant, hence the ionizing power, is somehow related to various other properties of the solvent. In 
the accompanying table $K_{D}$ stands for the dielectric constant, $H_{V}$ for the latent heat of vaporization, and $K_{H}$ for the absolute conductivity for heat. It is to be observed that on the whole all three quantities decrease simultaneously. These properties are also related to the critical pressure, to the van der Waals constant $a$, and to the molecular volume at the boiling point.

\begin{tabular}{|c|c|c|c|c|c|c|c|c|c|}
\hline Solvent & & & & & & & $K_{D}$ & $H_{V}$ & $K_{H}$ \\
\hline Water, $\mathrm{H}_{2} \mathrm{O} \ldots$ & . & . & - & . & & & 81.7 & 536.5 & 0.154 \\
\hline Methyl alcohol, $\mathrm{CH}_{3} \mathrm{OII}$ & . & . & - & . & & & 32.5 & 267.5 & 0.0495 \\
\hline Ethyl alcohol, $\mathrm{C}_{2} \mathrm{H}_{6} \mathrm{OH}$ & - & . & . & - & $\cdot$ & & 21.7 & 205 & 0.0423 \\
\hline Formic acid, H · COOH & . & . & . & . & & & 57.0 & 103.7 & 0.0648 \\
\hline Acetic acid, $\mathrm{CH}_{3} \cdot \mathrm{COOH}$ & & • & . & - & & & 6.5 & 89.8 & 0.0472 \\
\hline Ammonia, $\mathrm{NH}_{3} \ldots$ & - & - & . & - & * & & 16 & 329 & \\
\hline Methylamine, $\mathrm{CH}_{3} \cdot \mathrm{NH}_{2}$ & & . & - & - & & & $<10.5$ & 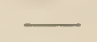 & \\
\hline Sulphurous oxide, $\mathrm{SO}_{2}$ & . & - & . & . & & & 14 & 92.5 & \\
\hline Acetone, $\mathrm{CH}_{3} \cdot \mathrm{CO} \cdot \mathrm{CH}_{3}$ & . & - & - & - & & & 20.7 & 125.3 & \\
\hline Ethylacetate, $\mathrm{CH}_{3} \cdot \mathrm{CO}$. & $\mathrm{O}$ & & ${ }_{2} \mathrm{H}_{5}$ & . & & & 5.85 & 86.7 & 0.0318 \\
\hline Benzene, $\mathrm{C}_{6} \mathrm{H}_{6} \ldots$ & - & ${ }^{\circ}$ & . & - & & & 2.26 & 93.5 & 0.0333 \\
\hline Toluene, $\mathrm{C}_{6} \mathrm{H}_{5} \cdot \mathrm{CH}_{3}$ & - & - & . & - & & & 2.31 & 83.6 & 0.0307 \\
\hline Ether, $\left(\mathrm{C}_{2} \mathrm{H}_{5}\right)_{2} \mathrm{O}$ & - & . & - & - & & & 4.36 & 84.5 & 0.0303 \\
\hline Chloroform, $\mathrm{CHCl}_{3}$ & . & - & . & . & & & 4.95 & 58.5 & 0.0288 \\
\hline Tetrachlormethane, $\mathrm{CCl}_{4}$ & & - & - & - & & & 2.18 & 46.35 & 0.0252 \\
\hline Stannic chloride, $\mathrm{SnCl}_{4}$ & . & . & - & - & $\cdot$ & & 3.2 & 30.53 & \\
\hline
\end{tabular}

Such evidence clearly suggests that some of the manifold fitnesses of water proceed from a single cause or group of causes. For the present, however, these relationships are 
obscure, and in any case there seems to be no immediate hope of bringing them into connection with the science of biology.

\section{C}

SURFACE TENSION:

Of all common liquids, except mercury, water has the greatest surface tension.

\section{Table of Surface Tensions}

Water

Carbonic acid . . . . . . . . . 18

Ammonia . . . . . . . . . 41.8

Mercury . . . . . . . . 436

Benzene . . . . . . . . . 28.8

Methyl alcohol . . . . . . . . 23

Ethyl alcohol . . . . . . . . . . 22

Ether . . . . . . . 16.5

Glycerine . . . . . . . 65

Acetone . . . . . . . . . . 23

Formic acid . . . . . . . . 37.1

Acetic acid . . . . . . . . . . 23.5

Chloroform . . . . . . . 26

This fact is of enormous moment in biology, most obviously perhaps in its influence upon the soil. For surface tension and density determine the height to which a liquid will rise in a capillary system, and thus it comes about that the principal factor in bringing water within reach of plants is the exceptional surface tension of water. The nature of the case is clearly explained by Hilgard. "The 
liquid water held in the pores of the soil, in the form of surface films representing the curved surface seen in capillary tubes, and therefore tending to cause the water to move upwards, as well as in all other directions, until uniformity of tension is established, is of vastly higher importance to plant growth than hygroscopic moisture. It not only serves normally as the vehicle of all plant food absorbed during the growth of the usual crops, but also, as a rule, to sustain the enormous evaporation by which the plant maintains, during the heat of the day, a temperature sufficiently low to permit of the proper operation of the processes of assimilation and building of cell tissue." 1

The rise of water in capillary systems resembling soil, under the action of surface tension, may be as much as ten feet. In soil itself the highest rise under the usual circumstances is unquestionably as much as four or five feet; but if the surface tension of water were like that of most liquids it could be, under similar conditions, but two or three feet. There seems to be little doubt that the rise of fluids in tall plants is also in large part due to the action of surface tension, and accordingly it must be much favored by the

${ }^{1}$ Hilgard, "Soils." New York, 1907, p. 201. 
magnitude of that quantity in the case of water.

Finally, surface tension is of great importance, indeed in simple cases is the one effective agent, in the phenomenon called adsorption. ${ }^{1}$ On the basis of thermodynamical considerations first developed by Willard Gibbs, it is easy to show that whenever the dissolution of a substance changes the surface tension of a solvent, the distribution of the dissolved substance will not be strictly homogeneous. If the solution has a lower surface $<$ tension than the solvent, the surface of the solution will become more concentrated than the interior; or if the surface tension of the solution be greater than that of the solvent, the surface of the solution will become less concentrated than the interior. This result, quite insignificant in simple solutions, becomes a matter of much moment when, as in the case of suspensions of fine particles like animal charcoal, in emulsions, jellies, or any other system of like disperse heterogeneity of physical constitution, there occurs very great increase of surface area. Then it is

${ }^{1}$ A familiar example of adsorption is the use of boneblack to decolorize sirup in the process of sugar refining. The colored matters are almost completely removed from solution, and cling to the surface of the charcoal. 
that adsorption becomes a factor of the greatest weight; for, other things being equal, the total force of surface tension in a system is proportional to the area of surface. Under these circumstances dissolved substances are no longer distributed with any approach to equality or regularity in the system, but they collect at the surface in very great quantities, and in the most irregular manner.

Now of all known physical structures there is none which rivals protoplasm in its fine complexity, and adsorption is therefore unquestionably a prominent agent in deciding its physico-chemical constitution. Moreover, adsorption influences and complicates almost every process of chemical physiology, for no product of life is without its colloids, i.e. substances which are finely divided and therefore endowed with great surface areas. In truth colloids are probably quite essential to fine complexity, and so to every conceivable form of life. ${ }^{1}$

The evidence for this universal importance

1 "Eines aber möchte ich behaupten, welches auch immer die stoffliche Zusammensetzung jener Lebewesen (living organisms in another world) sein mag: es müssen Kolloide sein. ... Welcher andere Zustand, ausser dem Kolloiden, könnte derart veränderliche, derart plastische Formen bilden und wäre doch im stande, diese Formen, wenn nötig, unveränderlich zu wahren." - BECHHOLd, l.c., p. 194. 
of adsorption in biology is not to be briefly presented, but it may be found in almost endless profusion in such works as those of Freundlich and Bechhold. ${ }^{1}$

It must not be supposed that the phenomena of adsorption in biology are simple and exactly understood. What is certain is that they are universal, and that surface tension lies at the root of the matter. This is because all living things are colloidal, and I am inclined to think that most physiologists will admit that life without colloids is probably unthinkable, even in a world very differently constituted from our own. Colloidal structures are, in fact, the first and greatest factors in physical complexity of organization, and the principal force, unless it be in exceptional cases an electrical charge due to ions, which operates upon the colloidal structures is surface tension. This, then, is another striking fitness of water above all other things.

Such are the facts which I have been able to discover regarding the fitness of water for the organism. The following properties appear to be extraordinarily, often uniquely,

${ }^{1}$ Freundlich, "Kapillarchemie." Leipzig, 1909. Bechhold, "Die Kolloide in Biologie und Medizin." Dresden, 1911. 
suited to a mechanism which must be complex, durable, and dependent upon a constant metabolism: heat capacity, heat conductivity, expansion on cooling ncar the freezing point, density of ice, heat of fusion, heat of vaporization, vapor tension, freezing point, solvent power, dielectric constant and ionizing power, and surface tension. ${ }^{1}$

In no case do the advantages which these properties confer seem to be trivial; commonly they are of the greatest moment; and I cannot doubt, even after allowances have been made for the probability of occasional fallacies in the development of an argument which, though simple, is beset with many pitfalls, that they are decisive. Water, of its very nature, as it occurs automatically in the process of cosmic evolution, is fit, with a fitness no less marvelous and varied than that fitness of the organism which has been won by the process of adaptation in the course of organic evolution.

If doubts remain, let a search be made for

${ }^{1}$ Contrasting this statement with that of Whewell in his Bridgewater Treatise, it is evident that while the progress of science has provided much novel information, and eliminated many false views, the present situation differs from the earlier one only in the better definition of the issue, and in our modern freedom from metaphysical and theological associations. 


\section{THE FITNESS OF THE ENVIRONMENT}

any other substance which, however slightly, can claim to rival water as the milieu ${ }^{1}$ of simple organisms, as the milieu intérieur of all living things, or in any other of the countless physiological functions which it performs either automatically or as a result of adaptation.

In truth Darwinian fitness is a perfectly reciprocal relationship. In the world of modern science a fit organism inhabits a fit environment.

${ }^{1}$ Here and elsewhere the word "milieu" has been employed when it is desired to express only that part of the conception of environment which is involved in the literal meaning of the word, leaving to environment the added significance of that which provides food. 


\section{CHAPTER IV}

\section{CARBONIC ACID}

TTWO chemical individuals stand alone in 1 importance for the great biological cycle upon the earth. The one is water, the other carbon dioxide. The one, for reasons which we have just reviewed, is the most familiar of all the varieties of matter. The other rarely is seen except by chance, and without scientific research never could have been known for what it is in value to living things. Yet these two simple substances are the common source of every one of the complicated substances which are produced by living beings, and they are the common end products of the wearing away of all the constituents of protoplasm, and of the destruction of those materials which yield energy to the body. ${ }^{1}$

${ }^{1} \mathrm{~A}$ man weighing $60-70$ kilograms excretes daily the following quantities of material :-

Water . . . . 2500-3500 grams

Carbon dioxide . . . 750-900 grams

All other substances . . 60-125 grams 
Once perhaps the atmosphere of the earth consisted chiefly of water and carbon dioxide; but cooling has caused the condensation of most of the water, and geological processes, more recently aided by the action of vegetation with coal and peat formation, have removed nearly all of the carbon dioxide. The latter transformations have resulted in the substitution of oxygen in the atmosphere. However, the interior of the earth continues to deliver through volcanoes large amounts of carbon dioxide, and thus the original source of atmospheric carbon dioxide persists as a diminishing supply.

To-day carbon dioxide makes up only a little more than 0.03 per cent by volume of the whole atmosphere, approximately 4.6 kilograms per square meter of the earth's surface, or about 2,300,000,000,000 metric

Water is, therefore, three fourths, carbon dioxide one fifth, of the total, and all other substances amount to but 2 to 3 per cent.

In like manner the materials ingested by an ordinary green plant are proportioned, water making up more than nine tenths, and carbon dioxide amounting to fully five times the sum of all other substances combined.

Needless to say, a large part of the water which enters and leaves plants and animals has had no real share in their organization. It is merely the bearer of dissolved substances or the means, through evaporation, of lowering the temperature of their bodies. 
tons for the whole earth. ${ }^{1}$ In the ocean the amount of carbonic acid is about 0.1 gram per liter, or approximately 0.01 per cent by weight. Here, however, much the larger part is in chemical union with bases, chiefly in the form of bicarbonates. ${ }^{2}$

There can be no doubt that the physical properties of carbon dioxide are less important to the living organism than are those of water. But indeed the characteristics of water so largely determine the nature of the environ-

${ }^{1}$ The composition of dry air is as follows :-

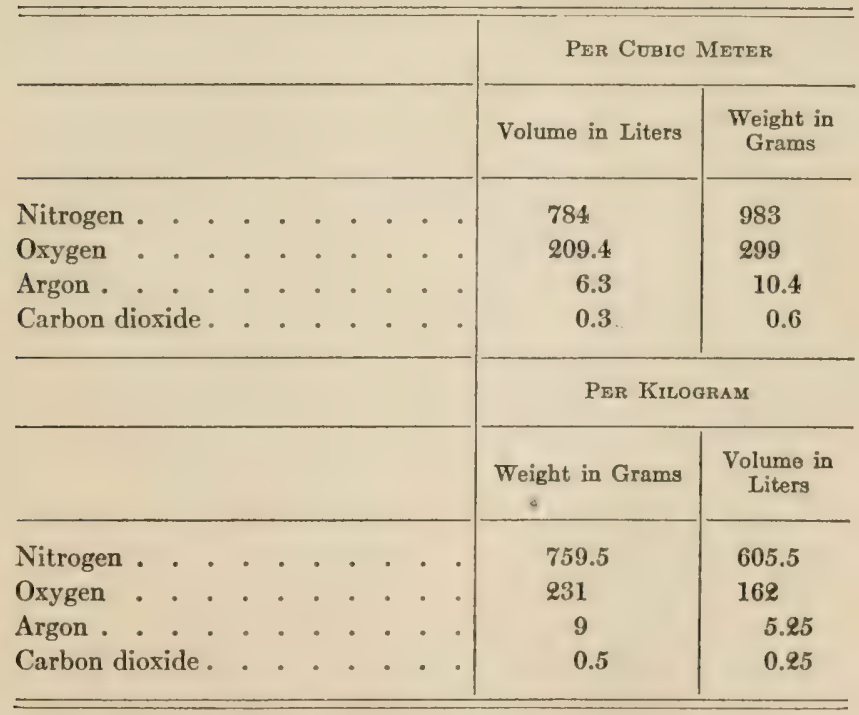

${ }^{2}$ See below in the discussion of the alkalinity of the ocean. 


\section{THE FITNESS OF THE ENVIRONMENT}

ment and the conditions within the organism alike, that this is necessarily the case. However, the less conspicuous substance is not without its physical fitnesses, and we must now turn to them.

\section{I \\ SOLUBILITY}

The most obvious of the properties of carbonic acid is its all-pervasiveness. Originally formed in vast quantities by the cosmic process, and accumulated in the atmosphere, the store has been steadily replenished there by vulcanism. It is probable that of the enormous quantities now deposited as limestone in the earth's crust, a quantity sufficient to yield an atmospheric pressure greater tenfold than the present atmospheric pressure, only a fraction was at any one time actually gaseous. For it happens that the presence of carbonic acid in the atmosphere insures the occurrence of greater, or at least nearly equal, quantities in the ocean and in all the natural waters of the earth. This is due to the solubility of carbon dioxide, to the magnitude of its absorption coefficient in water.

The absorption coefficient is the volume of gas absorbed by one liter of liquid when 
the gas pressure is one atmosphere. According to the law of Henry, however, the absorption of the gas is always proportional to its

Table of absorption Coefficients at $0^{\circ}$

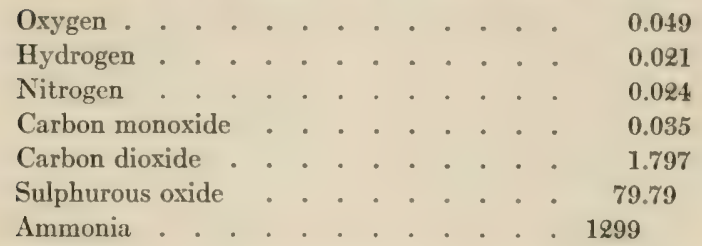

partial pressure in the atmosphere, and therefore the absorption coefficient measures the ratio, after equilibrium has been attained, between the concentration of a substance in solution and in the gaseous state, no matter what that concentration may be.

The absorption coefficient is not constant under all circumstances, and varies especially with the temperature.

$\begin{array}{cc}\text { Table of Absorption Coefficients of } \mathrm{CO}_{2} \\ \text { Temperature } & \text { Absonption Coeprticient } \\ 0^{\circ} & 1.797 \\ 10^{\circ} & 1.185 \\ 20^{\circ} & 0.901 \\ 37.29^{\circ} & 0.563 \\ 100^{\circ} & 0.244\end{array}$

It will be seen from the tables that, differing from most gases, carbon dioxide has an absorption coefficient nearly equal to one, and 
that for the ordinary temperature of the earth's waters, where they are in contact with carbonic acid gas, it is very close indeed to 1.0. Hence, when water is in contact with air, and equilibrium has been established, the amount of free carbonic acid in the water is almost exactly equal to the amount in the air. Unlike oxygen, hydrogen, and nitrogen, carbonic acid enters water freely; unlike sulphurous oxide and ammonia, it escapes freely from water. Thus the waters can never wash carbonic acid out of the air, nor the air keep it from the waters. It is the one substance which thus, in considerable quantities relative to its total amount, everywhere accompanies water. ${ }^{1}$ In earth, air, fire, and water alike these two substances are always associated.

Accordingly, if water be the first primary constituent of the environment, carbonic acid is inevitably the second, - because of its solubility possessing an equal mobility with water, because of the reservoir of the atmosphere never to be depleted by chemical

1 "Carbonic acid being more soluble than the other gases, is contained in rain water in proportions between 30 and 40 times greater than in the atmosphere." - GEIKIE, "Textbook of Geology." 4th ed., Vol. I, p. 449, 1903.

It must not be forgotten that carbonic acid in subterranean water, by which so much geological change is accomplished, originates, not in the air, but from organic matter in the soil. 
action in the oceans, lakes, and streams. In truth, so close is the association between these two substances that it is scarcely correct logically to separate them at all; together they make up the real environment and they never part company. Carbonic acid thus possesses the first great qualification of a food: its occurrence is universal and its mobility a maximum. This is due to the fact that its absorption coefficient is on the average approximately one, the most favorable value.

Needless to say the absorption coefficient of carbonic acid is also of great importance in many physiological processes, chiefly perhaps in excretion. In the course of a day a man of average size produces, as a result of his active metabolism, nearly two pounds of carbon dioxide. All this must be rapidly removed from the body. It is difficult to imagine by what elaborate chemical and physical devices the body could rid itself of such enormous quantities of material were it not for the fact that, in the blood, the acid can circulate partly free ${ }^{1}$ and, in the lungs, by a process which under ordinary circumstances has all the appearances of a simple physical phe-

${ }^{1}$ Of the total carbonic acid of the blood 5-10 per cent exists as the free acid, partly in the plasma, partly in the corpuscles. 
nomenon, ${ }^{1}$ can escape into air which is charged with but little of the gas. ${ }^{2}$ Were carbon dioxide not gaseous, its excretion would be the greatest of physiological tasks; were it not freely soluble, a host of the most universal existing physiological processes would be impossible.

\section{II}

\section{ACIDITY}

The only other property of this substance which calls for consideration at this point is its acid nature and strength. Very few minerals are freely soluble in pure water, and nearly all yield to the process of weathering far more readily because of the carbonic acid which all natural waters contain. ${ }^{3}$ The latter

${ }^{1}$ The determination of the exact nature of the process by which carbonic acid is excreted across the lung membrane is one of the standing difficulties of physiology, but we need not here enter upon its consideration.

${ }^{2}$ Expired air contains on the average more than 4 per cent by volume of carbonic acid.

3 " A few minerals (halite, for example) are readily soluble in water without chemical change, and without the aid of any intermediate element; hence the copious brine-springs of salt regions. In the great majority of cases, however, solution is effected through the medium of carbonic acid or other reagent. Limestone is soluble to the extent of about 1 part in 1000 of water saturated with carbonic acid. The solution and removal of lime from the mortar of a bridge or vault, 
constituent is probably a necessary adjuvant in the most far-reaching geological phenomena. Indeed, it is the united action of water and carbonic acid, aided in lesser degree by nitric acid, which has been formed in the atmosphere by electrical action, and by acid products of vegetation, which sets free the inorganic constituents of the earth's crust and turns them into the stream of metabolism.

But apart from the solvent action of carbonic acid, there is another group of phenomena which depend upon its acid character. These must now be explained. They are the neutrality or faint alkalinity of the ocean, and of protoplasm.

According to the modern theory of solution, water itself, like the dissolved electrolytes, is dissociated into ions, though only to a very slight degree. ${ }^{1}$ The reaction is expressed as follows:

$$
\mathrm{H}_{2} \mathrm{O}=\stackrel{+}{\mathrm{H}}+\overline{\mathrm{OH}}
$$

and the deposit of the material so removed in stalactites and stalagmites, likewise the rapid effacement of marble epitaphs in our church yards, are instances of this solution. . . . Among the sulphates, gypsum is the most important example of solution. It is dissolved in the proportion of about 1 part in 400 parts of water. Even silica is abstracted from rocks by natural waters."-Geikie, "Geology," pp. 451-452. ${ }^{1}$ For a discussion of this subject the textbook of Mellor, "Chemical Statics and Dynamics," p. 205, may be consulted. 
If the water be pure, the concentrations of hydrogen and hydroxyl ions are necessarily the same, for water is electrically neutral. A variety of independent methods of estimation have shown that at $25^{\circ}$ (centigrade) this concentration amounts almost precisely to $0.0000001 \mathrm{~N}$, in the ordinary units. ${ }^{1}$ This corresponds to 0.0000001 gram of ionized hydrogen and 0.0000017 gram of ionized hydroxyl in 1000 grams of water. Further, the theory of solution explains acidity in water by the occurrence of hydrogen ions, formed from dissolved electrolytes, in excess of hydroxyl ions; and alkalinity by a similar excess of hydroxyl over hydrogen ions. Neutrality is then the condition when, as in pure water, the two concentrations are equal. In short, expressing the concentration of ionized

${ }^{1}$ Concentrations are expressed in terms of chemical equivalents, gram-molecules, or moles. $N$ (normal) is the symbol for this unit. The values of the concentration of ionized hydrogen at neutrality as estimated by different investigators are as follows:-

$\begin{array}{lll}6 . \times 10^{-7} & \text { Kohlrausch } & 1884 \\ 1.0 \times 10^{-7} & \text { Ostwald } & 1893 \\ 1.1 \times 10^{-7} & \text { Arrhenius, Shields } & 1893 \\ 1.2 \times 10^{-7} & \text { Wijs } & 1893 \\ 0.9 \times 10^{-7} & \text { Kanolt } & 1907 \\ 1.02 \times 10^{-7} & \text { Heydweiller } & 1909 \\ 1.02 \times 10^{-7} & \text { Lundén } & 1907\end{array}$


hydrogen by $(\stackrel{+}{\mathbf{I}})$ and of ionized hydroxyl by $(\overline{\mathrm{OH}})$ :

If

$$
(\stackrel{+}{\mathrm{H}})=0.0000001 \mathrm{~N}=(\overline{\mathrm{OH}})
$$

the solution is neutral;

if

$$
(\stackrel{+}{\mathrm{H}})>0.0000001 \mathrm{~N}>(\overline{\mathrm{OH}})
$$

the solution is acid;

if

$$
(\stackrel{+}{\mathrm{H}})<0.0000001 \mathrm{~N}<(\overline{\mathrm{OH}})
$$

the solution is alkaline.

It remains to point out that implicit in these definitions is the well-founded hypothesis that in water the concentrations of hydrogen and hydroxyl ions vary inversely, so that with constant temperature under all circumstances their product is constant: ${ }^{1}$ -

$$
(\stackrel{+}{\mathrm{H}}) \times(\overline{\mathrm{OH}})=\mathbf{K}
$$

Substituting in this equation the value 0.0000001 of the concentrations at neutrality, we obtain the value

$$
K=0.00000000000001
$$

whence

$$
\stackrel{+}{\mathrm{H}})=\frac{0.00000000000001}{-}
$$

$(\mathrm{OH})$

${ }^{1}$ This corresponds with the requirements of the Mass. Law. 
Whenever a weak acid is present in aqueous solution in company with such bases as sodium, potassium, calcium, magnesium, etc., which are invariable constituents of the ocean, blood, protoplasm, etc., provided the acid be in excess, it is a simple matter to determine the reaction, which can best be measured by the values of $(\stackrel{+}{\mathrm{H}})$ and $(\overline{\mathrm{OH}})$, following the considerations above.

Now there is a certain characteristic property of an acid, its ionization constant, $k$, which measures its tendency to dissociate in aqueous solution, thereby to produce hydrogen ions, and hence to increase the intensity of acidity. Strong acids have ionization constants which are of the order of magnitude of 1.0, weak acids of the order of magnitude of 0.0001 , the weakest acids, 0.00000001 , or less.

\section{Table of Ionization Constants}

$\mathrm{HCl}, \mathrm{HNO}_{3}$, etc.

$\mathrm{H}_{3} \mathrm{PO}_{4}$

$\mathrm{H}_{3} \mathrm{AsO}_{4}$

$\mathrm{HNO}_{2}$.

$\mathrm{H}_{2} \mathrm{CO}_{3}$

$\mathrm{NaH}_{2} \mathrm{PO}_{4}$

$\mathrm{H}_{2} \mathrm{~S}$

$\mathrm{H}_{3} \mathrm{BO}_{3}$

$\mathrm{Na}_{2} \mathrm{HPO}_{4}$

1.

0.011

0.005

0.0005

0.0000003

0.0000002

0.000000091

0.0000000007

0.00000000000036

It has been discovered that in the general case above discussed the concentration of 
ionized hydrogen is always almost exactly proportional to the ratio of free acid to salt, and is equal, in very close approximation, to the product of this ratio by the ionization constant of the acid. That is to say, representing free acid by HA and salt by BA,

$$
\begin{aligned}
(\stackrel{+}{\mathrm{H}}) & =k \times \frac{\mathrm{HA}}{\mathbf{B A}} \\
k & =(\stackrel{+}{\mathrm{H}})
\end{aligned}
$$

whence, if

$$
\frac{\mathrm{HA}}{\mathrm{BA}}=1
$$

From this relationship, therefore, follows the conclusion, fully established by experiment, that whenever in such a solution the excess of acid, HA, is chemically equivalent to the quantity of salt, BA, the hydrogen ion concentration is almost exactly equal to the ionization constant of the acid. But the ionization constant of carbonic acid (first hydrogen atom) is 0.0000003 . Hence in a solution containing exactly equivalent quantities of free carbonic acid and, for example, sodium bicarbonate, the hydrogen ion concentration must be 0.0000003 N. Further, since

$$
\frac{\mathrm{HA}}{\mathrm{BA}}=\frac{(\stackrel{+}{\mathrm{H}})}{k}
$$


if the amount of acid be ten times the amount of salt $\left(\frac{\mathrm{HA}}{\mathrm{BA}}=10\right)$, the hydrogen ion concentration must be $0.000003 \mathrm{~N}$, and if the reverse be the case $\left(\frac{\mathrm{HA}}{\mathrm{BA}}=\frac{1}{10}\right)$ the value must be $0.00000003 \mathrm{~N}$.

The range of variation of concentration of hydrogen ions in the usual solutions of the chemical laboratory considerably surpasses the limits $1.0 \mathrm{~N}$ and $0.000000000000001 \mathrm{~N}$. In comparison with such enormous differences those between $0.000003 \mathrm{~N}$ and $0.00000003 \mathrm{~N}$ are almost negligible $\left(\frac{1}{100}: \frac{1}{100,000,000,000,000}\right)$.

Hence ordinarily it is quite accurate enough to speak of any solution containing both free carbonic acid and a bicarbonate, when the disparity between the concentrations of the two substances is not very great, as of constant neutral reaction. For, obviously, the neutral point, which at a temperature of $25^{\circ}$ amounts to a concentration of hydrogen and hydroxyl ions $0.0000001 \mathrm{~N}$, falls well within the narrow range of reaction of such solutions, being characterized by a ratio of carbonic acid to bicarbonate of about $1: 3$.

Thus carbonic acid, like the almost equally weak acids sulphuretted hydrogen and phos- 
phoric acid (after its first hydrogen has been neutralized by base), has the remarkable property of preserving a neutral reaction whenever it exists in solution with its salts, provided there be an excess of acid. All acids whose strength is even a little either greater or less than carbonic acid lack the property. ${ }^{1}$

This characteristic of carbonic acid is of the utmost significance, first by regulating one of the most fundamental of physicochemical conditions, and secondly by preserving throughout nature the characteristic chemical inactivity of water, which disappears whenever the reaction becomes either appreciably acid or appreciably alkaline. Almost the only case of important geological action due to acidity or alkalinity of water is the action of fresh water, containing carbonic acid itself, to weather the rocks. This process is, however, self-limited, for the dissolved material forms bicarbonates, and thus at once provides permanently inactive balanced solutions.

It is impossible to understand the efficiency with which neutrality is preserved by carbonic acid, without the actual discussion of a particular case. Let us therefore consider a solu-

${ }^{1}$ Henderson, "The Relation between the Strengths of Acids and their Capacity to Preserve Neutrality," American Journal of Physiology, XXI, 173, 1908. 
tion of 1 kilogram of carbon dioxide in 100 liters of water, to which sodium hydrate is being added. At the beginning of the experiment the hydrogen ion concentration will be approximately $0.0001 \mathrm{~N}$, almost exactly one thousand times that at neutrality, and the hydroxyl ion concentration $0.0000000001 \mathrm{~N}$, one one-thousandth that at neutrality. If, now, the sodium hydrate be added to the solution in successive portions, the change of reaction will be as indicated in the following table:-

\begin{tabular}{|c|c|c|c|c|}
\hline \multirow{2}{*}{$\begin{array}{c}\text { AMOUNT of } \\
\text { NaOH }\end{array}$} & \multirow{2}{*}{$\stackrel{+}{(H)}$} & \multirow{2}{*}{$(\overline{\mathrm{OH}})$} & \multicolumn{2}{|c|}{$\begin{array}{l}\text { INTENSITY COMPARED WITH } \\
\text { A NEUTRAL SOLUTION OF }\end{array}$} \\
\hline & & & Acidity & Alkalinity \\
\hline Grams & & & & \\
\hline 0 & $0.0001 \mathrm{~N}$ & $0.0000000001 \mathrm{~N}$ & 1000 & 0.001 \\
\hline 50 & 0.0000052 & 0.000000002 & 52 & 0.02 \\
\hline 100 & 0.0000024 & 0.000000004 & 24 & 0.04 \\
\hline 150 & 0.0000015 & 0.000000006 & 15 & 0.06 \\
\hline 200 & 0.0000011 & 0.000000009 & 11 & 0.09 \\
\hline 250 & 0.0000008 & 0.000000012 & 8 & 0.12 \\
\hline 300 & 0.0000006 & 0.000000017 & 6 & 0.17 \\
\hline 350 & 0.0000005 & 0.000000020 & 5 & 0.20 \\
\hline 400 & 0.0000004 & 0.000000025 & 4 & 0.25 \\
\hline 450 & 0.0000003 & 0.000000033 & 3 & 0.33 \\
\hline 500 & 0.00000025 & 0.00000004 & 2.5 & 0.4 \\
\hline 550 & 0.00000020 & 0.00000005 & 2.0 & 0.5 \\
\hline 600 & 0.00000015 & 0.00000007 & 1.5 & 0.7 \\
\hline 650 & 0.00000012 & 0.00000008 & 1.2 & 0.8 \\
\hline 700 & 0.00000009 & 0.00000011 & 0.9 & 1.1 \\
\hline 750 & 0.00000006 & 0.00000017 & 0.6 & 1.7 \\
\hline 800 & 0.00000004 & 0.00000025 & 0.4 & 2.5 \\
\hline 850 & 0.00000002 & 0.0000005 & 0.2 & 5.0 \\
\hline
\end{tabular}


From the table it appears that the first 50 grams of alkali reduce the hydrogen ion concentration to but 50 times that of neutral solutions, and 200 grams of alkali have made it only about 10 times that of pure water, in spite of the fact that there are more than 750 grams of free carbonic acid still present in the solution. So much acidity can at once be obtained by dissolving merely 0.004 gram of hydrochloric acid in 100 liters of water. Thereafter neither acidity nor alkalinity surpasses this intensity until 450 grams more of sodium hydrate have been added to the solution. Yet in pure water 0.005 gram of sodium hydrate would make the reaction more alkaline than that.

Such is the case when the equilibrium is homogeneous, i.e. in an isolated solution. But when, in similar cases, an atmosphere containing carbon dioxide is present, the conditions are still more striking. Suppose, for example, a solution of 100 liters containing 1 kilogram of sodium bicarbonate in equilibrium with an atmosphere containing 1 gram of carbon dioxide per liter. Let hydrochloric acid be added in successive small portions to the solution. Further let the solution be constantly stirred and shaken, and let the experiment be conducted slowly, so that there 
shall always be equilibrium between the carbonic acid in the solution and in the atmosphere. Further, let the temperature be such that the absorption coefficient of carbon dioxide shall be 1.000 . Then the successive states of the solution will be approximately as recorded in the following table:-

\begin{tabular}{|c|c|c|c|c|c|}
\hline$\underset{A D D E D}{\mathrm{HCl}}$ & $\begin{array}{l}\mathrm{H}_{2} \mathrm{CO}_{3}: \\
\mathrm{NaHCO}_{3}\end{array}$ & $\stackrel{+}{(+)}$ & $(\overline{\mathrm{OH}})$ & $\mid \begin{array}{c}\text { RELATIVE } \\
\text { ACIDITY }\end{array}$ & $\begin{array}{l}\text { Relative } \\
\text { ALKA- } \\
\text { LINITy }\end{array}$ \\
\hline Grams & & & & & \\
\hline 0 & $2.27: 11.9$ & $0.000000057 \mathrm{~N}$ & $0.000000176 \mathrm{~N}$ & 0.57 & 1.76 \\
\hline 10. & $2.27: 11.5$ & 0.000000059 & 0.000000170 & 0.59 & 1.70 \\
\hline 50 & $2.27: 10.0$ & 0.000000068 & 0.000000147 & 0.68 & 1.47 \\
\hline 100 & $2.27: 8.2$ & 0.000000083 & 0.000000120 & 0.83 & 1.20 \\
\hline 150 & $2.27: 6.3$ & 0.000000108 & 0.000000093 & 1.08 & 0.93 \\
\hline 200 & $2.27: 4.4$ & 0.000000151 & 0.000000065 & 1.54 & 0.65 \\
\hline 250 & $2.27: 2.6$ & 0.00000026 & 0.000000039 & 2.6 & 0.39 \\
\hline 300 & $2.27: 0.68$ & 0.0000010 & 0.000000010 & 10 & 0.10 \\
\hline 310 & $2.27: 0.31$ & 0.0000022 & $0.00000000 \div 5$ & 22 & 0.045 \\
\hline 318 & $\infty$ & 0.00026 & 0.00000000039 & 260 & 0.0039 \\
\hline 320 & - & 0.00045 & 0.00000000022 & 450 & 0.0022 \\
\hline 330 & — & 0.0027 & 0.000000000037 & 2700 & 0.00037 \\
\hline
\end{tabular}

From the beginning of the experiment until almost 250 grams of hydrochloric acid have been added, neither alkalinity nor acidity is double in intensity the values which obtain in a perfectly neutral solution. This amounts to a constancy of reaction which, until a few years ago, was scarcely known to the chemist at all. Such close approach to neutrality 
can be attained with pure water only after elaborate and very difficult purification, yet in the presence of carbonic acid it is the natural condition. Of course the case above discussed is an extreme one. In nature the concentrations of dissolved substances are less, the mixing less efficient, and the variations of reaction a little greater. There is also, in nature, likely to be a considerable excess of bicarbonate over free carbonic acid present.

The cause of the greater constancy of reaction in the case of the heterogeneous equilibrium is simple enough. At the beginning of the experiment the free carbonic acid of the solution is exactly in equilibrium with that of the atmosphere. Accordingly, when hydrochloric acid is poured in and reacts with sodium bicarbonate to form sodium chloride and more carbonic acid,

$$
\mathrm{NaHCO}_{3}+\mathrm{HCl}=\mathrm{NaCl}+\mathrm{H}_{2} \mathrm{O}+\mathrm{CO}_{2}
$$

every bit of the latter escapes to the atmosphere, and the total amount of acid is just what it was before. But a certain amount of carbonic acid has been replaced by the equivalent amount of hydrochloric acid. This latter substance, however, is wholly in union with sodium, as its salt. Thus the addition of the strong acid diminishes the amount of 
alkaline salt (sodium bicarbonate), but does not increase the amount of free acid. Not until the bicarbonate is entirely decomposed (318 grams $\mathrm{HCl}$ ) does the hydrochloric acid begin to exert its own action as an acid, and then 2 grams cause about as much rise in acidity as 318 grams have previously caused, or nineteen times the rise effected by the first 300 grams, or about two hundred times the rise caused by one hundred times the quantity of hydrochloric acid at the beginning of the experiment.

These statements all rest upon facts which have been accurately established by experiment and are brought forward in company with the theoretical treatment, based upon the Mass Law, only for the sake of completeness of statement and because brief exposition is otherwise scarcely possible. The extraordinary capacity of carbonic acid to preserve neutrality in aqueous solution, which is explained by its strength and solubility in water, is a well-established experimental fact, and no other known substance shares this power. ${ }^{1}$ Hydrogen sulphide might perhaps be thought of as an exception. But while its solubility

${ }^{1}$ Henderson, "The Theory of Neutrality Regulation in the Animal Organism," American Journal of Physiology, XXI, $427,1908$. 
in water is not favorable for the best results, its instability is a fatal obstacle.

Such are the physico-chemical facts regarding neutrality regulation in heterogeneous systems by means of carbonic acid and bicarbonates, and, though the exposition is difficult, it has seemed necessary to make them clear. For there is, I believe, except in celestial mechanics, no other case of such accuracy in a natural regulation of the environment. Moreover, the chemist has discovered no means of rivaling the efficiency and delicacy of adjustment of the process. Finally, acidity and alkalinity surpass all other conditions, even temperature and concentration of reacting substances, in the influence which they exert upon many chemical processes. ${ }^{1}$

Almost wholly through this mechanism the oceans are always nearly neutral. Chiefly with its aid protoplasm and blood possess an unvarying reaction. Quite recently the concentration of hydrogen ions in the ocean has been very carefully studied by Palitzsch, ${ }^{2}$

${ }^{1}$ Of all catalytic agents these ions are by far the most important. In their influence upon the stability of colloidal systems they are also unapproached by other substances.

2 "Etant donné que l'eau de mer a un contact is intime avec les organismes de la mer et que non seulement elle les entoure de ses flots, mais qu'elle traverse leurs branchies et imprègne en partie les corp des invertébrés, il semble assez 
who finds very great constancy, the extreme variations (with the exception of the Black Sea) being $0.000000011 \mathrm{~N}$ to $0.0000000045 \mathrm{~N}$. Allowing for the change of the ionization constant of water with the temperature, and the fact that in such systems the hydrogen ionization is nearly independent of the temperature, these values roughly correspond to hydroxyl ion concentrations $0.000002 \mathrm{~N}$ and $0.000005 \mathrm{~N}$ respectively at the lower temperatures and slightly higher values at the higher temperatures of sea water. This is a sufficient excess of hydroxyl ions properly to be termed faint alkalinity, though it amounts to but about 0.00005 gram per liter, or 0.000005 per cent. It is in part due to the fact that the quantity of carbonic acid in the air is now very small, while in the ocean the concentration of bicarbonates is great. Indeed, the ocean has unquestionably grown alkaline;

justifié de la placer dans la même catégorie que les autresliquides physiologiques. Des déterminations exposés dans ce qui précède il ressort que, de même que ces liquides, l'eau de mer est douée d'une grande capacité de régler sa concentration en ions hydrogène, bien que cette capacité soit moins prononcée que celle constatée par example dans le sang." - S. Palitzsch, "Sur le mesurage et la grandeur de la concentration en ions hydrogène de l'eau salée," Comptes-rendus des travaux du Laboratoire de Carlsberg, 10me Volume, 1re Livraison, 1911, p. 93. 
for its origin must have been acid from the presence of carbonic acid unbalanced by base. The present ratio betwcen bicarbonates and carbonic acid in sea water has not been accurately estimated, but it is perhaps $50: 1$ or $100: 1$. The conditions are complicated by flora and fauna, and such influences have not yet been determined.

Turning to the acid-base equilibrium of blood and protoplasm, we encounter a subject which is better understood, though not more significant in the present discussion. The alkalinity of the blood is one of the familiar subjects of physiological investigation, and its clinical importance has long been clear. Not until the introduction of the ionization hypothesis, however, was it possible to explain the conditions. The outcome of these studies has been to assign to the equilibrium between carbonic acid and bicarbonates a first place in the regulation of the reaction of blood $;^{1}$ and since such substances are invariably constituents of all protoplasm, to make evident the universal biological importance of this equi-

${ }^{1}$ Friedenthal, "Archiv für Physiologie, Verhandlungen der Physiologischen Gesellschaft Berlin," May 8, 1903. Henderson, American Journal of Physiology, XV, 257, 1906, "Ergebnisse der Physiologie," VIII, 254-325, 1909 (the last a review of the equilibrium between acids and bases in the organism). 
librium. The process is complicated by the intervention of all the other acids and bases of the body. Of these, however, only phosphates, and in lesser degree proteins, are important. Thus it is certain that in the one universal chemical equilibrium of protoplasm which has thus far been defined and quantitatively described the carbonates take a principal part.

It is not possible to explain the significance of carbonic acid in this physiological process as chiefly an adaptation; for natural selection can have nothing to do with the occurrence of carbonic acid in the living organism, or, presumably, with the nature of the original living things upon the earth. ${ }^{1}$ The presence of carbonic acid is inevitable, and whatever the first forms of terrestrial life may have been, certain it is that carbonic acid was one of the constituent substances. From that day to this it has steadily fulfilled the function of regulating the reaction of protoplasm, and of body tissues and fluids.

The recent studies of Hasselbach and Lundsgaard ${ }^{2}$ indicate that the hydrogen ion concentration of normal blood at body temperature

${ }^{1}$ It was this obvious fact which originally led me to a reconsideration of fitness.

2 "Biochemische Zeitschrift, Vol. 38, p. 77, 1912. 
is about $0.000000044 \mathrm{~N}$. This value is subject to constant slight variations, diminishing as the blood passes through the lungs, increasing during the greater circulation; but variations of this kind are certainly very slight in the healthy organism. The value corresponds to a concentration of bicarbonates about ten times as great as that of free carbonic acid. Together the acid and its salts make up the larger part of all the carbonic acid, and a very considerable fraction of all the dissolved molecules of the blood. In disease, especially diabetic coma, the hydrogen ion concentration may rise to $0.0000001 \mathrm{~N}$, or perhaps higher; when acid is injected into the blood the value may be greater still, but death speedily ensues, and it is certainly impossible during life that there should be any considerable permanent variation.

Increase in acidity of the blood can occur only in association with marked diminution in the concentration of bicarbonates, which may fall to less than one third of their normal amount, greatly impoverishing the blood in respect to carbonic acid, and interfering with its excretion. This is due to the fact that the amount of free carbonic acid in the blood is under the independent control of the respiratory center, and when acids decompose bicar- 
bonates the carbonic acid which is liberated escapes through the lungs into the air. This action is analogous to the simple heterogeneous equilibrium explained above, and calls for no special discussion.

The importance of this physiological equilibrium is to be sought in part in one of the primary characteristics of the metabolic process, - the chiefly oxidative formation of acid. In the main the foodstuffs are neutral substances, but their principal end products, except water, are almost exclusively acid compounds, - carbonic acid, phosphoric acid, sulphuric acid, uric acid. Moreover, there is a well marked tendency, at least in man and the vertebrates, under very many pathological conditions, to form other acids, such as lactic acid, $\beta$-oxybutyric acid, acetoacetic acid, etc. This tendency toward acidity of reaction and the accumulation of acid in the body is one of the inevitable characteristics of metabolism; the constant resistance of the organism one of the fundamental regulatory processes. Now it comes about through the carbonate equilibrium that the stronger acids, as soon as they are formed, and wherever they are formed, normally find an ample supply of bicarbonates at their disposal, and accordingly react as follows:- 


\section{$\mathrm{HA}+\mathrm{NaHCO}_{3}=\mathrm{NaA}+\mathrm{H}_{2} \mathrm{CO}_{3}$}

This reaction corresponds exactly to the simple case first discussed, and so causes an inconsiderable change in the concentration of ionized hydrogen. The free carbonic acid then passes out through the lungs, and the salt is excreted in the urine. Other processes are involved, including a device for final retention of a part of the alkali which has neutralized acid, ${ }^{1}$ but in the whole complex function nothing is more important than the simple reaction written above.

The hydrogen ion concentration exerts a marked influence upon the rate of progress of chemical reactions. Thus, for example, the so-called inversion of cane sugar by a process of hydrolytic cleavage into glucose and fructose,

$$
\mathrm{C}_{12} \mathrm{H}_{22} \mathrm{O}_{11}+\mathrm{H}_{2} \mathrm{O}=\mathrm{C}_{6} \mathrm{H}_{12} \mathrm{O}_{6}+\mathrm{C}_{6} \mathrm{H}_{12} \mathrm{O}_{6} \text {, }
$$

is commonly accomplished by warming a solution of sugar to which a little acid has been added. It was shown by the classical investigation of Wilhelmi that the velocity of this process depends upon the strength of the acid, or, according to the modern view, upon

${ }^{1}$ Henderson, Journal of Biological Chomistry, IX, 403, 1911. 
the concentration of hydrogen ions. Indeed, these ions are the effective agents in the process.

Reactions of this type, in which carbohydrates, fats, proteins, and other substances take part, make up a very large, if not the largest fraction of all the processes of metabolism, and there can be no doubt that for their regulation very accurate adjustment of acidity and alkalinity is essential. In the body, to be sure, such reactions are under the control of enzymes, but the concentration of hydrogen and hydroxyl ions is not less, rather more important for that reason. Beside retaining their direct influence upon the reaction, the ions also exert an influence upon the enzymes themselves. Moreover, not only enzymes, but almost all colloidal bodies, especially such unstable structures as the colloids of protoplasm, are profoundly affected by changes of reaction, and for the preservation of their stability they also are absolutely dependent upon constancy of acidity and alkalinity.

Finally, it is to be noted that glucose, which is the principal source of energy in physiological processes, is very unstable in even faintly alkaline solutions, and that its stability varies in most marked degree with the slightest change in the concentration of hydroxyl 
ions. ${ }^{1}$ Further, there is also reason to believe that the concentration of hydrogen and hydroxyl ions may sometimes be concerned in adjustments of great magnitude, which involve the distribution of water between the tissues and the body fluids, or at least between red blood corpuscles and the plasma. ${ }^{2}$ Recently, for example, a theory has been suggested which seeks to account for certain forms of œdema as the result of local or general increase in the acidity of the organism. ${ }^{3}$ In any case, whatever the fate of these latter

${ }^{1}$ Henderson, Journal of Biological Chemistry, X, 3, 1911.

2 The changing distribution of material between red blood corpuscles and plasma as the tension of carbonic acid changes has, since its discovery by Zuntz, been investigated by a series of physiologists. (See Spiro and Henderson, Biochemische Zeitschrift, 15, 114, 1908.) In each complete cycle of the circulation there occurs a complete cycle of changes between the constituents of the corpuscles and of the plasma. As the blood passes through the tissues and receives carbonic acid the volume of the red corpuscles increases from the entrance of water coming from the plasma; chlorine simultaneously passes in the same direction; and various other changes occur. In the lungs, with the escape of carbonic acid, the process is reversed. There seems to be no doubt that this process is largely dependent upon changes in reaction accompanying changes in the concentration of carbonic acid.

${ }^{3}$ M. H. Fischer, “'Edema," New York, 1910. It is impossible to judge of the correctness of many of the views set forth in this work. At present they appear to be in part illfounded. 
views may be, the common physiological processes, and the structural conditions which depend for their integrity upon constancy of the concentration of hydrogen and hydroxyl ions are certainly manifold.

The principal conditions and processes, both inorganic and organic, which rest upon the acid nature of carbonic acid and its characteristic distribution between the atmosphere and aqueous solutions have now been indicated. In their origin at least they are nowise due to the agency of organic evolution. Yet directly, because of the nature of carbon dioxide as a gas, because of its solubility in water, and on account of the precise degree of its weakness as an acid, they possess the highest possible efficiency. This conclusion might be established with rigorous accuracy by means of a mathematical analysis, but the above discussion is sufficient for the present purpose. ${ }^{1}$

In this manner carbonic acid shows itself in its physico-chemical traits variously fitted for the organic mechanism. Less various, to be sure, and less obvious than those of water, such fitnesses as it does possess are quite as

${ }^{1}$ Henderson, American Journal of Physiology, XXI, 173, 1908. 
genuine. But they are dependent upon water ; secondary in their nature; resting upon solubility and ionization; upon interactions between the two substances. So they lead us to a consideration of the most intricate of all mutual relations, to a purely chemical study of the compounds of carbon, hydrogen, and oxygen, into which water and carbonic acid can be transformed. 


\section{CHAPTER V}

\section{THE OCEAN}

T every stage of our inquiry we have seen A that the unique properties of water and carbonic acid contribute vitally important characteristics to the ocean. Such conclusions accord with the ordinary experiences of life, and they gain in significance from the undoubted fact that organic beings first existed, and for a very long time existed only in the waters. On this account it will be well to pause before attacking the problems of organic chemistry, and, in somewhat greater detail, to examine the ocean in its relation to the inhabitants of the globe. Thus we shall be able more clearly to perceive the manner in which, in one most important instance, the properties of water and carbonic acid operate to fit the world for life.

\section{I}

THE REGULATION OF PHYSICO-CHEMICAL CONDITIONS

- The most striking of all the ocean's qualities is its constancy. No doubt since its origin 
it has grown colder and more saline, and has changed its reaction from faintly acid to faintly alkaline. But a million years are little in such great slow processes, and no living thing has ever experienced appreciable change in any one of them.

Modern research in oceanography has detected surprisingly little variation in the temperature of the ocean. ${ }^{1}$ The temperature of surface water depends upon the climatic character of the locality, but it is subject to far less variation than the temperature of the atmosphere above it, and is higher than the latter. The accompanying tables $^{2}$ indicate the nature of some of the variations in the temperature of sea water.

Annual Ranges of Temperatures of Ocean Water AND OF THE AIr Over LaNd

\begin{tabular}{|c|c|c|c|c|c|c|c|c|c|c|}
\hline Latitude & . & . & . & & $0^{\circ}$ & $10^{\circ}$ & $20^{\circ}$ & $30^{\circ}$ & $40^{\circ}$ & $50^{\circ}$ \\
\hline Ocean . & . & . & . & : & 2.3 & 2.4 & 3.6 & 5.9 & 7.5 & 5.6 \\
\hline Land & . & . & . & . & - & 3.3 & 7.2 & 10.2 & 14.0 & 25.4 \\
\hline
\end{tabular}

${ }^{1}$ Nearly all the facts contained in the present chapter have been drawn from the following works: S. Günther, "Handbuch der Geophysik"; Arrhenius, "Kosmische Physik" ; and Hann's "Climatology," translated by Ward.

${ }^{2}$ See Hann's "Climatology," translated by Ward, p. 135. 
166 THE FITNESS OF THE ENVIRONMENT

Water and Air Temperatures at Lesina

\begin{tabular}{|c|c|c|c|c|c|c|}
\hline & WINTER & SpRING & SUMmer & АUTUMN & YEAR & RANGE \\
\hline Air . . & $9.2^{\circ}$ & $14.8^{\circ}$ & $24.4^{\circ}$ & $17.9^{\circ}$ & $16.6^{\circ}$ & $15.2^{\circ}$ \\
\hline Surface water . & 13.5 & 15.0 & 22.0 & 19.5 & 17.5 & 8.5 \\
\hline Water at 10 meters & 13.9 & 14.7 & 20.3 & 18.4 & 16.8 & 6.4 \\
\hline
\end{tabular}

According to Schott the variation of surface temperature of the open ocean over the whole globe is never less than $1^{\circ}$ nor more than $15^{\circ}$. Such variations are slight on the equator, larger in the region of the trade winds, less again in the northern and southern seas. ${ }^{1}$ The surface temperature extends only a short distance into the water, thus constituting a warm surface layer. It has indeed been known since the time of Aristotle that the depths of the sea are cold. In the open ocean the temperature increases steadily as the depth increases, but more rapidly near the surface, more slowly at greater depths. The bottom water at great depth varies from a temperature of $2^{\circ}$ in the tropics to about $-2^{\circ}$ in the polar waters. Such low temperature of the depths of the tropical oceans is almost certainly due to the inflow of cold water from high latitudes.

${ }^{1}$ Arrhenius, l.c. 
In the Atlantic the temperature varies approximately as follows with increasing depth:-

Depte in Meters
0
500
1000
1500
2000
2500
3000

Temperature Centigradi
$19^{\circ}$
16
9
4
3
2.5
2

In the Mediterranean, where no cold current flows in at the bottom of the ocean, the temperature sinks rapidly to $11^{\circ}$ at a short distance below the surface, and thereafter remains constant. This is due to the fact that in winter the surface water is cooled to that temperature and sinks, remaining then protected from the summer heat by the warmer layer of less density above.

The slight range of ocean temperatures, whether with changing seasons, with changing depth, or with changing latitude, depends primarily upon the latent heat of water, especially its heat of vaporization, and upon the very high freezing point, as already explained in the discussion of these physical properties.

Far more constant than the temperature is the alkalinity of sea water. It has been stated above that the extreme variation in concentra- 
tion of ionized hydrogen is from $0.000000011 \mathrm{~N}$ to $0.0000000045 \mathrm{~N}$. In his studies during a voyage of five months in the summer season of 1910 of the Danish steamship Thor, Palitzsch made the following observations: ${ }^{1}$ surface water from the Skager-Rack, from the southern portions of the North Sea, and from the west of the Baltic ranged from about $0.000000010 \mathrm{~N}$ to about $0.000000009 \mathrm{~N}$; in the North Sea the surface water varied from $0.0000000083 \mathrm{~N}$ to $0.0000000074 \mathrm{~N}$; at the latitude of Murray Firth, twenty miles from the coast, the values were between $0.0000000071 \mathrm{~N}$ and $0.0000000066 \mathrm{~N}$. In the Atlantic the surface water corresponded in the most northern portions to that of the North Sea, while in the Bay of Biscay and along the coast of Portugal the values were $0.0000000056 \mathrm{~N}$, corresponding to slightly increased alkalinity, especially if account be taken of the rising temperature. In general the waters of the Mediterranean corresponded to those of the coast of Portugal. But from the Sea of Marmora, the Bosphorus, and the Black Sea samples were obtained which gave the value $0.0000000045 \mathrm{~N}$.

In general, as the depth increased, the

${ }^{1}$ Palitzsch, "Comptes-rendus des travaux du Laboratoire de Carlsberg," 10me Volume, p. 85, 1911. 
hydrogen ion concentration increased, and the alkalinity accordingly diminished.

\begin{tabular}{|c|c|c|c|c|}
\hline \multirow{2}{*}{$\begin{array}{l}\text { Depta iN } \\
\text { Meters }\end{array}$} & \multicolumn{4}{|c|}{$\stackrel{+}{(\mathrm{H})} \times 100,000,000$} \\
\hline & MEDITERRANEAN & Atrantic & North SEa & Black Sea \\
\hline 0 & 0.59 & 0.60 & 0.74 & 0.46 \\
\hline 10 & & & & 0.56 \\
\hline 25 & & & & 0.65 \\
\hline 50 & 0.59 & 0.66 & & 0.71 \\
\hline 75 & & & & 0.93 \\
\hline 85 & & & & 1.03 \\
\hline 100 & 0.62 & 0.74 & 0.81 & 1.38 \\
\hline 200 & 0.65 & & 0.83 & 2.1 \\
\hline 300 & & & & 2.8 \\
\hline 400 & 0.65 & 0.91 & 0.93 & 3.0 \\
\hline 600 & & & 0.98 & \\
\hline 700 & & & 1.05 & \\
\hline 800 & 0.68 & 0.98 & & \\
\hline 1000 & 0.72 & 0.98 & & \\
\hline 1200 & 0.72 & 1.05 & & \\
\hline 1500 & 0.76 & 1.13 & & \\
\hline 2000 & 0.81 & 1.13 & & \\
\hline 2500 & 0.85 & & & \\
\hline 3200 & 0.85 & & & \\
\hline
\end{tabular}

The only variation from the truly remarkable constancy of reaction of the ocean, so far as we know, is in the case of the Black Sea. But this sea, at depths below 180 meters, contains sulphurous acid, which undoubtedly accounts for the slight diminution of alkalinity recorded in the table. This last obser- 
vation also provides a striking example of the efficiency with which the reaction of sea water is maintained. In spite of the unusual circumstances here the variation is inconsiderable. The only known important factor which operates to establish and to preserve the reaction of sea water is the carbonate equilibrium.

There is one consideration which must be especially noted before passing on. The most obvious effect of slight changes of temperature, and of slight changes of alkalinity as well, is upon the velocity of chemical reactions. In this respect the effect of hydroxyl ions is likely to be in proportion to their concentration, ${ }^{1}$ and the effect of temperature is usually such that a change of about ten degrees doubles the velocity of the reaction. ${ }^{2}$ Hence ordinary chemical reactions will progress about eight times as fast in the hottest as in the coldest ocean waters, and about seven times as fast in the most alkaline as in the least alkaline parts of the ocean. But in the case of any organism inhabiting a particular locality such changes in reaction velocity will be scarcely

1 The chief actions of hydroxyl ions are catalytic, and, as in the case of the catalysis of esterification, the effect is proportional to the concentration of the hydroxyl ions.

${ }^{2}$ This observation is due to van't Hoff. 
appreciable. Accordingly, the regulation is physiologically adequate.

The concentration of sea water is another nearly constant characteristic, though generally speaking the salinity is somewhat greater on the high seas than near the coasts, where fresh water is constantly diluting the salt watcr, and there are some other causes which produce slight variations. The average salt content is about 3.45 per cent. The quantities of the more important constituents, calculated from Dittmar's data, ${ }^{1}$ are as follows :-

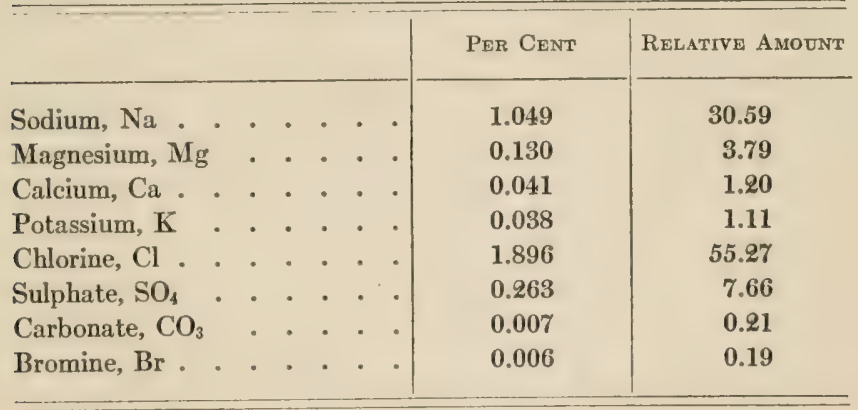

Most of the other numerous constituents are present in very small quantities. For instance, in each metric ton of sea water there

${ }^{1}$ Dittmar, Report of Voyage of the Challenger, 1884, p. 203. The original data were calculated upon the erroneous assumption that the various salts exist in solution independ- 


\section{THE FITNESS OF THE ENVIRONMENT}

are dissolved about 0.019 gram of silver and about 0.006 gram of gold, amounts which correspond to 0.0000019 per cent and 0.0000006 per cent, respectively.

It has been calculated that $166,000,000$ years have been required for the streams to carry into the sea the sodium chloride which is now present. The calcium carbonate of the rivers would however suffice to supply the present amount of that substance in 500,000 years. Accordingly, the present store of the latter substance represents but a very small fraction of what has passed through the ocean, and as a result of the intervention of life has finally been deposited as sedimentary limestone. Since the formation of the ocean, if present conditions correspond with the past, water must have carried to the dwellers of

ently of one another. Thus the composition of sea water is stated as follows :-

Relative

AMOUNT

Sodium chloride, $\mathrm{NaCl}$

Magnesium chloride, $\mathrm{MgCl}_{2}$.

77.758

Magnesium sulphate, $\mathrm{MgSO}_{4}$

10.878

Calcium sulphate, $\mathrm{CaSO}_{4}$

4.737

Potassium sulphate, $\mathrm{K}_{2} \mathrm{SO}_{4}$.

3.600

Calcium carbonate, $\mathrm{CaCO}_{3}$

2.465

Magnesium bromide, $\mathrm{MgBr}_{2}$

0.345

0.217 
the sea not less than $300,000,000,000,000,000$ tons of calcium carbonate, which they have temporarily utilized as structural material. Whether this estimate be correct or not, the process is certainly the cause of the most considerable change wrought by life upon the face of the earth.

The relative quantities of the several saline constituents of the ocean are hardly at all subject to variation. Chlorine, for example, makes up never less than 55.21 per cent and never more than 55.34 per cent of all the dissolved inorganic substances, so that the total salinity may be readily estimated with considerable accuracy by titration of the chlorides. Such constancy is due to the elaborate mixing of the waters resulting from ocean currents. There can be no doubt, however, that the relative amounts of the different acids and bases have slowly but steadily changed during the progress of geological evolution. Many substances, like calcium carbonate, have been steadily removed, a few, like sodium chloride, have steadily accumulated without loss.

The total salinity of the ocean, as stated above, is subject to slight variation. Along the North American coast, in the polar current, upon the coast of Norway, and toward the south of South America, the concentration 


\section{THE FITNESS OF THE ENVIRONMENT}

of the Atlantic is 3.2 per cent to 3.3 per cent. Areas where the concentration ranges from 3.3 per cent to 3.4 per cent are still more extensive. The greater part of the North Atlantic ranges in concentration from 3.5 per cent to 3.6 per cent. In general there is a region of maximum concentration between the Equator and the Pole.

The Mediterranean, the Red Sea, and other similar bodies of water possess a somewhat higher salt concentration, dependent upon excessive evaporation and the absence of great currents; but only in exceptional cases and small isolated bodies of water does the concentration rise above 4.1 per cent.

The salinity of ocean water varies also with the depth. In seas where there is a great influx of fresh water the surface is less concentrated than the depths; in seas where there is much evaporation the surface is more concentrated than the depths. In the latter case the higher temperature of the surface causes expansion of the more concentrated water, and enables it to remain above. When these two influences of dilution and evaporation are combined, they may bring about a yearly variation of salinity. Such variations of the environment are important to animal life, slight though they may be. Thus the 
herring in their migrations keep to a water whose concentration ranges from 3.2 per cent to 3.3 per cent.

From the constancy of the relative proportion of the salts in sea water it follows that every such constituent is subject to no greater variations than the sum of all. Interesting recent experiments have shown this fact to be of vital consequence to living organisms. Thus a host of experiments of Loeb and his pupils, and of others, have demonstrated remarkable toxicity in the action of pure salts, physiologically antagonistic actions of various pairs of salts, and peculiar advantages of media containing a variety of salts in definite relative amounts. ${ }^{1}$ Of all such balanced solutions sea water is by far the best, a condition which is almost certainly due to the processes of organic evolution. Herbst ${ }^{2}$ has shown that the development of the fertilized eggs of sea urchins can only take place in the presence of the chlorides, sulphates, and carbonates of sodium, potassium, calcium, and magnesium, and in a faintly alkaline reaction. Every one of these substances is essential,

${ }^{1}$ See the article by Loeb in Oppenheimer's "Handbuch der Biochemie."

${ }^{2}$ Herbst, Archiv. für Entwickelungsmechanik, 5, 650, 1897 ; 7, 486, 1898; 11, 617, 1901; 17, 306, 1904 . 
except that in a measure potassium may be replaced by rubidium and cæsium, and chlorine by bromine. Moreover the relative concentrations are of the highest importance. Thus it has become clear that the remarkable relative and absolute constancy of the chemical composition of sea water is biologically far more important than formerly could be surmised. This characteristic of the ocean undoubtedly fits it for living things as they exist.

It is further to be noted that the salinity of sea water is proportional to its osmotic pressure. This important property also is therefore nearly constant.

When a solution is inclosed in a membrane, a bladder, for example, and the latter is immersed in water, both water and dissolved substance pass through the wall of the membrane. Ordinarily, however, the water will move much more rapidly than the dissolved substance, hence the volume of the solution will increase, and hydrostatic pressure will be established. If a well-supported membrane of cupric ferrocyanide be substituted for the bladder, the process will be modified, in that water alone, not the dissolved substance, can pass through the membrane, which is accordingly termed semipermeable. 
Under these circumstances the pressure, called osmotic pressure by van't IIoff, may be very great.

According to the theories of van't Hoff and Arrhenius this pressure is, in the case of dilute solutions, proportional to the total number of particles (molecules plus ions) which are present in solution. In its magnitude and the laws governing its variation such pressure corresponds exactly to gaseous pressure. In fact the theory of solution consists primarily in the extension of the laws of Boyle and Gay-Lussac, of the hypothesis of Avogadro, and of the manifold theoretical developments which have been based upon them, to solutions. The great force of osmotic pressure always comes into action when solutions are in contact with permeable or semipermeable membranes. It must therefore always be reckoned with in physiology. The biological importance of the constancy of the osmotic pressure of sea water is strikingly exemplified by the precision with which every higher vertebrate preserves constant the osmotic pressure of its own body fluids, all at about seven or eight atmospheres.

It may readily be shown that the osmotic pressure of a solution is proportional to the depression of its freezing point, and accord- 
ingly osmotic pressure is commonly estimated with the help of this relationship. In the following table the facts regarding blood sera of certain animals are collected. ${ }^{1}$

Depression of the Freezing Point of Blood Serum

Man
Cow $\begin{array}{llll}\text { Degree } \\ \text { Horse } \\ \text { Pig }\end{array}$

In man the freezing point depression of the blood is, under ordinary circumstances, practically constant, and there can be no doubt that such is the case for all highest organisms. Accordingly the differences in the above table may be taken to indicate slight constant differences between the different species.

The marine animals, except a few of the vertebrates, are adjusted in their osmotic pressures to the water which surrounds them. As in the following table so in another locality where the freezing point of the water was $-1.9^{\circ}$ the body fluids of the animal were again found to agree with it. It is therefore evident that constancy of osmotic ${ }^{1}$ Höber, "Physikalische Chemie der Zelle und der Gewebe." 
pressure is for marine animals a matter of real moment.

\section{Depressions of the Freezing Point}

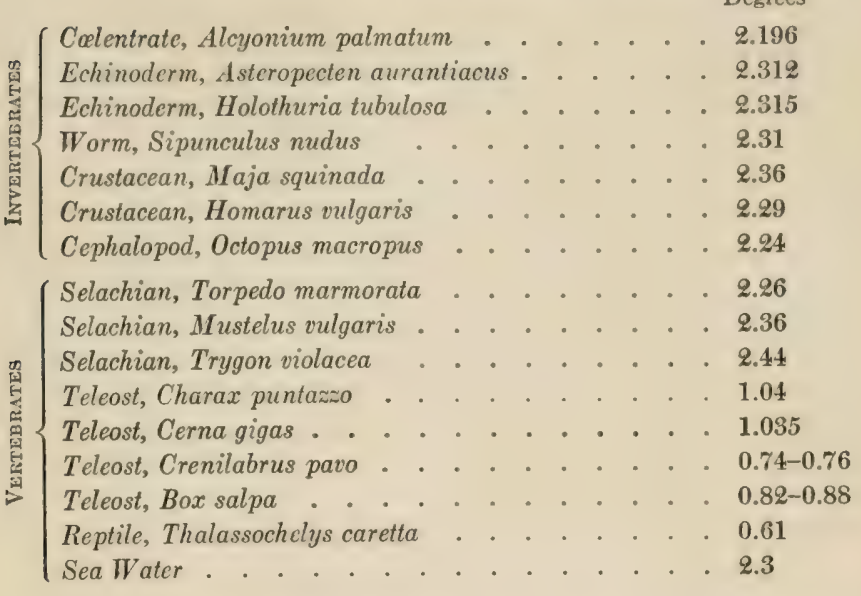

The great importance of osmotic pressure is also attested by many of the facts of physiology. The study of this subject has indeed from its origin always been closely associated with the biological sciences, and it was in great part biological experiments and wholly experiments of biologists which were employed by van't Hoff in his development, on the basis of osmotic phenomena, of the theory and laws of dilute solutions.

Absorption, secretion, excretion, and the movement of substances across membranes, 
- to say nothing of the establishment of liquid currents within the body, - are all related to osmotic pressure. The forces involved in such processes are large, and osmotic phenomena assume a special importance wherever colloidal systems occur. It appears to be certain that osmotic pressure is now securely established as one of the fundamental factors in the physico-chemical organization of the living mechanism, and one of the constant conditions, like concentration of the several constituents, alkalinity, temperature, etc., whose preservation is of vital importance.

\section{II}

\section{THE CIRCULATION OF WATER}

There are a number of causes which bring about ocean currents. In the tropics high temperature causes a far greater evaporation of water than can be offset by rainfall and the flow of rivers; near the poles this relation is reversed. Hence water must steadily flow from high to low latitudes, there to evaporate and complete the cycle in the atmosphere and on the land. In polar regions the cold water sinks and penetrates along the bottom of the sea in great deep currents to the tropics. 
The surface currents of the ocean have a different origin, for they depend upon winds, especially trade winds, etc. Such continuous action of moving air upon water has been theoretically explained by Helmholtz and Zöpperitz. Needless to say, in addition to these principal causes there are a great variety of lesser factors which assist in the formation and preservation of ocean currents.

It is impossible here to undertake an analysis of the phenomenon, but certain it is that into the processes that constantly stir the ocean, beside the rotation of the earth, the eccentricity of its orbit, and the inclination of its axis, the thermal properties of water enter as fundamentally important factors.

The magnitude and the extent of the movements which result from such influences are very considerable. The principal surface currents are oval in form, one in the North Pacific between $10^{\circ}$ and $50^{\circ}$ north latitude, one in the North Atlantic between $10^{\circ}$ and $30^{\circ}$ north latitude, one in the South Pacific between $5^{\circ}$ and $45^{\circ}$ south latitude, one in the South Atlantic between $0^{\circ}$ and $40^{\circ}$ south latitude, and one in the Indian Ocean between $0^{\circ}$ and $40^{\circ}$ south latitude. The greatest of these are the Pacific currents. In the far south is an Antarctic current flowing from 
west to east; in the north a current flows from east to west, from the Siberian coast to Northeast Greenland and thence along the east coast; another flows from Baffin's Bay along the east coast of North America.

Of all ocean currents, the Gulf Stream, a branch of the northern equatorial current, has been most carefully studied. Its maximum velocity is 220 kilometers per day, greater therefore than that of the Rhine at Coblentz; the mean about 134 kilometers a day. In the Straits of Yucatan the Gulf Stream carries 0.2 cubic kilometer (200,000,000 tons) per second. If all this water were to be cooled to the temperature of the polar ocean this would be equivalent to the transport of about 5,000,000,000,000,000 gram calories per second. The magnitude of this quantity, of course, depends upon the specific heat of water.

In this manner vast quantities of water, carrying enormous stores of heat, are constantly in motion all over the globe. The result is that homogeneity of the ocean which has been discussed above, - constancy of concentration, of composition, of temperature, of alkalinity, and of osmotic pressure. 


\section{III \\ THE OCEAN AS ENIIRONMENT}

There are, in accordance with our fundamental postulates of the characteristics of life, two principal requirements of the living organism which an environment must fulfill, - such a supply of matter and energy for food as may be suitable to a complex mechanism, and stability of conditions.

After a general review of the chief characteristics of the ocean, it is therefore necessary to examine them more particularly in relation to such requirements. In so doing it must not be forgotten, however, that these characteristics of the occan which we have just discussed are only in part due to the unique physical properties of water which have been already discussed in Chapter III, and to those of carbonic acid which have been discussed in Chapter IV. In part they depend upon the mere magnitude of the sea, on the stability of the solar system and the consequent antiquity of the geological and meteorological processes, and upon a great variety of astronomical and geophysical conditions. However, we shall only a little extend the scope of our inquiry if we now consider water not only as an indi- 


\section{THE FITNESS OF THE ENVIRONMENT}

vidual chemical substance, that is to say abstractly, but also naturally, as automatic processes of cosmic and geological evolution have fashioned it into the principal constituent of the face of the globe. Primarily, at any rate, the outcome of such processes is dependent upon the inherent properties of water and upon the quantity of it which is present on the surface of the earth, and the subject is too important to be passed completely by.

Perhaps the first desideratum in an environment as a source of food is mobility. Any organism which, like the lilies of the field, need not toil for its nourishment, is in most favorable conditions; and such conditions are the principal cause of the enormous wealth of vegetation upon the earth. Now the ocean, apart from the flora and fauna which inhabit it, is perfectly homogeneous; hence its mobility brings to an organism all that it has to offer, and even sweeps along organic nourishment as well. In the ocean not only plants but many animals may remain motionless and, like the oyster, await the food that will surely be borne to them; or they may float freely, relying on the mixing of the water to bring them into contact with their food.

After mobility, richness and variety of 
environment are important. It is certainly impossible to imagine a medium more rich and varied in elementary constituents than sea water, unless it be sea water with still other substances added to it. But, in the first place, there are few absent elements which might be added, and, in the second place, the addition of other substances would be likely to cause the escape of bodies which are present. At all events, the ocean is certainly more favorable in these three respects than if it were anything else that could occur in the course of nature. Almost ideally mobile, rich, and varied, the sea is an almost perfect source of supply for a complex mechanism. To be sure there are great difficulties in extracting its constituents from sea water, and the efficiency of physiological processes is a factor essential to their utilization, but at least there stand materials ready for the mechanism which can employ them.

The predominance of water, no doubt, forces that substance upon living beings as their chief constituent; in view of the fitness of water for the purpose that is in itself a favorable circumstance. Otherwise the organism is left free to choose from all the common elements, and from some of the rare ones, what may be most suitable to its purposes at every 
stage of the infinitely varied process of organic evolution. As a result we find here and there in the marine flora and fauna almost every element which the sea affords concentrated and put to use.

After what has gone before it will not be necessary further to discuss the second great qualification of an environment-stability of conditions in the ocean. The principal physical conditions and chemical compounds therein are constant; that is the whole case. But it is a case which cannot be bettered. Certainly nowhere else where life is possible, probably in no other place in the universe except another ocean, are so many conditions so stable and so enduring.

The regulatory devices of our modern laboratories have not yet succeeded in rivaling the ocean. Singly, certain conditions, for example, temperature, alkalinity, and concentration, may be more accurately regulated by man, though on a small scale only; but the regulation of all such properties together is not yet possible. The only known improvement upon the ocean is the body of a higher warm-blooded animal. Here, however, the processes of organic evolution have begun with the ocean, and in several respects merely perfected existing arrangements. 
This statement is far from fanciful. Not only do the body fluids of the lower forms of marine life correspond exactly with sea water in their composition, but there are at least strong indications that the fluids of the highest animals are really descended from sea water, from the sea water of an earlier epoch, to be sure, and they are not changed beyond recognition by the transformations of evolution. ${ }^{1}$ A comparison of the relative amounts of various saline constituents in sea water and in mammalian blood (roughly averaged from a variety of measurements in different species) will demonstrate this relationship.

Composition of the Salts in Per Cent

\begin{tabular}{|c|c|c|c|c|c|c|c|c|c|c|c|c|c|}
\hline & & & & & & & & & & & & SeA Water & Blood Serdu \\
\hline $\mathrm{Na}$ & . & . & . & . & . & . & . & . & . & . & . & 30.59 & 39 \\
\hline $\mathrm{Mg}$ & . & . & . & . & . & . & . & . & . & . & . & 3.79 & 0.4 \\
\hline $\mathrm{Ca}$ & . & . & . & . & . & . & . & . & . & . & . & 1.20 & 1 \\
\hline $\mathbf{K}$ & . & . & . & . & . & . & . & . & . & . & . & 1.11 & 2.7 \\
\hline $\mathrm{Cl}$ & . & . & . & . & . & . & . & . & . & . & . & 55.27 & 45 \\
\hline $\mathrm{SO}_{4}$ & . & . & . & . & . & . & . & . & . & . & . & 7.66 & \\
\hline $\mathrm{CO}_{3}$ & . & . & . & . & . & . & . & . & . & . & . & 0.21 & 12 \\
\hline $\mathrm{Br}$ & . & . & . & . & . & . & . & . & . & . & . & 0.19 & \\
\hline $\mathrm{P}_{2} \mathrm{O}_{5}$ & . & . & . & . & . & . & . & . & . & . & . & & 0.4 \\
\hline
\end{tabular}

1 See the interesting paper by Macallum, Transactions of the Royal Society of Canada, 1908, II, p. 145. 
The gaps in the table do not indicate that substances are lacking, but merely that the amounts are small. In short, the same substances are present in both cases, and in both cases sodium chloride largely predominates. The importance of carbonic acid in metabolism accounts for the large amount of sodium bicarbonate in the blood, and this raises the amounts of both sodium and carbonic acid.

It is also to be noted that the regulatory processes in the ocean and in the organism are in one or two aspects similar, e.g. temperature regulation by evaporation, and regulation of the alkalinity. Of course no importance attaches to such resemblances, beyond the fact that both regulations are highly favorable, because of the special fitness of water in one case and of carbonic acid in the other. But it is at least worthy of mention that the regulation of the ocean in general bears a striking resemblance to a physiological regulatory process, although such physiological processes are supposed to be the result of organic evolution alone. Very much this same idea occurred to Palitzsch in the course of his investigation of the alkalinity of the ocean. ${ }^{1}$ The resemblance is more obvious still when the stability of all the more 
important physical conditions of the ocean is taken into account. Indeed, however difficult it may be to make out those subtle traits of physiological processes which account for their efficiency, their adaptability, and their exactness, I feel sure that no one who is thoroughly conversant with the general characteristics of the life process can fail to see a rough counterpart in the means by which conditions in the ocean are regulated.

It is certainly a salient, and hardly a meaningless fact that the processes of inorganic and organic evolution have a similar outcome in complex, exact, and almost ideally efficient activities. Is it not possible that in the case of the organic processes some have now and then been regarded as adaptations which in reality arose automatically and quite inevitably?

The existence of efficient regulation of the ocean, establishing its most important physicochemical characteristics as constants, is of far greater importance in the sciences of nature, especially for living organisms, than could formerly have been guessed. Such natural processes were perhaps even necessary to make life possible in the birthplace of life. I cannot undertake to explain the very great importance which to-day the physical chemist 
attaches to the regulation of the conditions of a chemical process. The only way to gain an idea of this is to examine a work on physical chemistry. Certainly, however, nothing has lately arisen more essential to biology than the understanding of the influence of temperature, pressure, reaction, concentration, ionization, etc., upon all physico-chemical structures and changes, whether inorganic or vital.

Thus the fitness of the ocean appears as an embodiment of the physical fitnesses of water and carbonic acid, resulting directly and inevitably from these and other natural phenomena, and providing a lodgment for life and a medium for its earlier development upon the earth. No philosopher's or poet's fancy, no myth of a primitive people has ever exaggerated the importance, the usefulness, and above all the marvelous beneficence of the ocean for the community of living things. 


\section{CHAPTER VI}

\section{THE CHEMISTRY OF THE THREE ELEMENTS}

\section{I \\ ORGANIC CHEMISTRY}

AUNDRED years ago the firm belief A was held by all chemists that whatever substance is synthesized within the body of the living organism possesses special and peculiar characteristics of its own, which mark it off from all inorganic bodies, and divide chemistry into the two great and perfectly distinct departments of Organic Chemistry and Inorganic Chemistry. To be sure, even then many organic substances had been separated from the organism, purified, and subjected to the usual experiments of the laboratory, without at any stage manifesting unique properties. But, as Berzelius believed, a special vital force had presided over their formation, and this, therefore, he supposed to be impossible under any other circumstances. 
In the course of time, however, a long series of successful syntheses of undoubted constituents of animals and plants, among which Wöhler's preparation of urea in $\mathbf{1 8 2 8}$ is the most famous, completely destroyed the old erroneous assumption. The compounds of organic chemistry gradually came to be recognized as different from inorganic substances only in the special characteristics of the elements carbon, hydrogen, and oxygen when in chemical union with one another, just as the compounds of any other elements have their own specific characteristics. No other difference remains; every principle of chemical science applies to organic and inorganic substances alike; and accordingly life has been forever subjected to the general laws of chemistry.

As syntheses multiplied, the organic chemist found many fields for investigation where life was not concerned. The application of his new substances in the arts, as well as many fascinating theoretical problems, led him on, until, about the middle of the century or a little later, it became clear that organic substances in the original sense are but a small part of his scope. His occupation had become the study of all the compounds of carbon, wherever and however they might 
occur, and as a rule he had little to do with physiological or biological chemistry. Not that he was now ever disposed to distinguish between substances which happened to occur in living organisms and others; for at length he had completely accepted the view that, apart possibly from a few complicated substances like the proteins, such distinctions are thoroughly irrational. But the nature of the subject and the historical accidents of its development directed his attention in the main elsewhere.

Nevertheless, the distinction between organic chemistry as the science of all the compounds of carbon, and inorganic chemistry as the science of all other chemical compounds whatever has persisted, and not without sound reasons. In the course of the wonderful development of organic chemistry, which must ever be counted as one of the greatest achievements of the nineteenth century, enormous numbers of new chemical substances were discovered. In 1883 the number of carbon compounds had reached 20,000 , in $1899,74,000$, and in 1902 it exceeded $100,000 .{ }^{1}$

${ }^{1}$ See M. M. Richter, "Lexikon der Kohlenstoffverbindungen," Hamburg and Leipzig, 1900, continued in supplementary volumes. This work catalogues all the compounds of carbon as they come to light. 
This is the sufficient practical ground for preserving organic chemistry as a separate science. The subject is so vast that in fact it is impossible to incorporate it with other departments of chemistry. Even the compounds of carbon and hydrogen alone are counted by hundreds, those of carbon, hydrogen, and oxygen, by thousands, and the number of possible compounds of the three elements is almost unlimited.

The mere number of organic compounds is, however, far from constituting the only distinction between the two departments of descriptive chemistry. The unique variety of compounds containing carbon, hydrogen, and oxygen, and, in a small proportion of cases a few other elements besides, must obviously rest upon the nature of the elements themselves, especially of course upon the nature of carbon, upon the properties which are peculiar to them and which mark them off from other elements, just as the properties of argon, of the metals of the alkalies, or of the halogens determine their own chemical behavior. Moreover, such characteristics must and do contribute properties to the compounds of carbon which are theirs as a class, which distinguish them from the compounds of other elements in somewhat the same way 
that the anatomical characteristics of one class of animals distinguish such a class from other classes of animals. In short, the carbon compounds are not unique merely because they are numerous; they are uniquely numerous because they are compounds of carbon with hydrogen, oxygen, and in some cases certain other elements. They possess, moreover, other less obvious class properties as well, though of these, it must be admitted, chemistry is even yet far from a clear understanding. But unquestionably that is due to the incompleteness of the science, for the peculiar methods of organic chemistry are a sufficient guarantee of the existence of such class peculiarities. ${ }^{1}$

In our present investigation a study of the possibilities of chemical union between the elements carbon, hydrogen, and oxygen is of great importance, and accordingly we must now examine some of the results of synthetic organic chemistry.

${ }^{1}$ See the introductory chapter to Meyer and Jacobson's "Lehrbuch der Organischen Chemie," Leipzig, $190 \%$. 
A

\section{VALENCE}

The principal theoretical foundation of organic chemistry is the idea of valence. Let us consider the chemical formulas of a number of the simple compounds of hydrogen, e.g. $\mathrm{HCl}, \mathrm{H}_{2} \mathrm{O}, \mathrm{NH}_{3}, \mathrm{CH}_{4}, \mathrm{HI}, \mathrm{HBr}$. It is evident that in such formulas a single atom of hydrogen is never represented as in union with more than one atom of another element. There are, however, cases where one atom of hydrogen is in union with a single other atom, e.g. $\mathrm{HCl}, \mathrm{HBr}, \mathrm{HI}$; or two atoms of hydrogen may unite with a single other atom, e.g. $\mathrm{H}_{2} \mathrm{O}$; or three atoms of hydrogen with one other, e.g. $\mathrm{NH}_{3}$; or four hydrogens with one other, e.g. $\mathrm{CH}_{4}$. If the assumption be made that discrete bonds or forces take part in the union of atoms, hydrogen must possess but a single such bond or valence. Otherwise compounds of the type $\mathrm{X}-\mathrm{H}-\mathrm{X}, \mathrm{X}-\mathrm{H}\left\langle\frac{\mathrm{X}}{\mathrm{X}}\right.$, or of some other type in which one atom of hydrogen is in union with more than one atom of lower valence, must exist, and this is contrary to fact.

We may, therefore, employing a dash to represent valence, write the constitutional 
formulas of hydrochloric acid, water, and methane, as follows:

$$
\left.\mathrm{H}-\mathrm{Cl}, \mathrm{H}-\mathrm{O}-\mathrm{H}, \begin{array}{l}
\mathrm{H} \\
\mathrm{H}
\end{array}\right\rangle \mathrm{C}\left\langle\begin{array}{l}
\mathrm{H} \\
\mathrm{H}
\end{array}\right.
$$

Accordingly, oxygen appears to possess two valences and carbon four. These conclusions are justified by an almost inconceivable wealth of experience; they are the means of constructing the elaborate constitutional formulas which are so necessary a part of organic chemistry; and there can be no doubt that in almost all the compounds with which we shall be concerned hydrogen is invariably univalent, oxygen bivalent, and carbon quadrivalent. On this basis the construction of possible formulas of organic compounds is merely an exercise in a somewhat peculiar department of mathematics.

\section{$B$}

HYDROCARBONS

The compounds of carbon and hydrogen may first be considered. With but a single atom of carbon in the molecule one only is possible :-

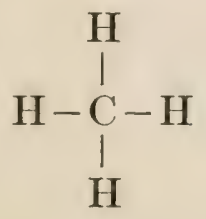


Uniting two carbon atoms by a single valence, the formula

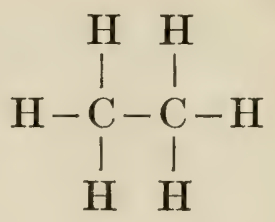

representing the compound ethane is obtained; but if the process be extended, great complexity speedily ensues. For example, the hexanes, compounds formed upon this plan containing six carbon atoms, all of one empirical formula, number five. Their constitutions are represented by the accompanying structures, every one of which corresponds to a known substance:-
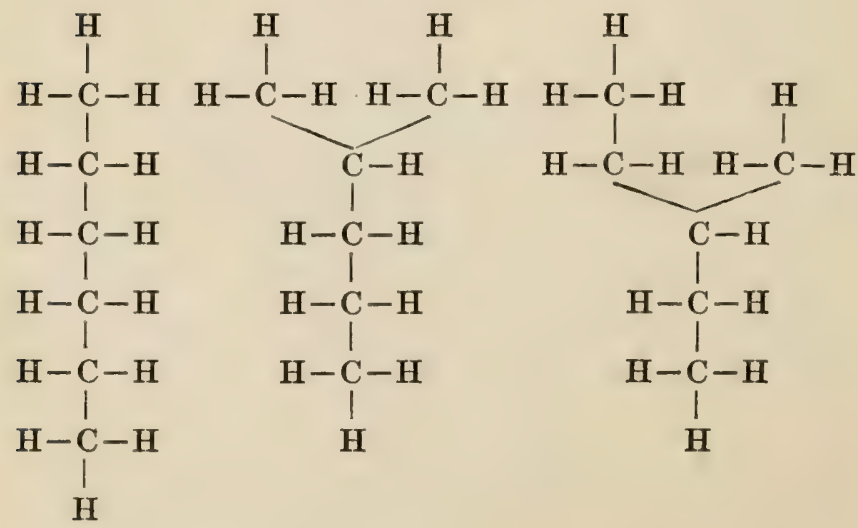

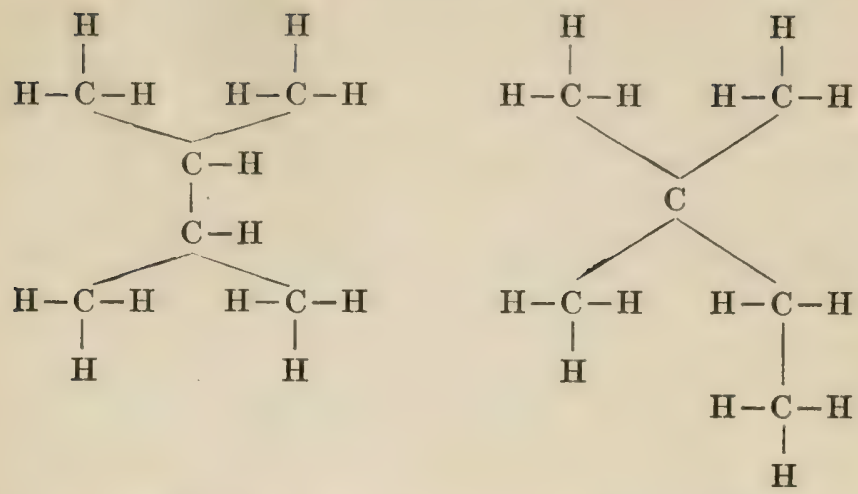

In each of the compounds represented by these formulas every carbon atom is believed to have four valences and every hydrogen atom one.

As the number of carbon atoms in the molecule increases the number of possible forms, isomers so called, multiplies with great rapidity. Of compounds $\mathrm{C}_{7} \mathrm{H}_{16}$ there are 9 forms; for $\mathrm{C}_{8} \mathrm{H}_{18}, 18$; for $\mathrm{C}_{9} \mathrm{H}_{20}, 35$; for $\mathrm{C}_{10} \mathrm{H}_{22}, 75$; for $\mathrm{C}_{11} \mathrm{H}_{24}, 159$; for $\mathrm{C}_{12} \mathrm{H}_{26}, 355$; for $\mathrm{C}_{13} \mathrm{H}_{28}$, 802; and for $\mathrm{C}_{14} \mathrm{H}_{30}, 1855$ possibilities. ${ }^{1}$ There can be no reasonable doubt that the preparation of each and all of these compounds would be possible, and that once formed they would be very stable substances. In truth, no one

${ }^{1}$ Cayley, Berichte, 8, 1056 (1875). F. Hermann, Berichte, 13, 792 (1880); 30, 2.493 (1897); 31, 91 (1898). Losanitsch, Berichte, 30, 1917, 3059 (1897). "Optical isomers" are disregarded in the estimate. 
has ever failed who has set out with skill, a good plan, and suitable starting materials, to prepare such a body.

The number and variety of hydrocarbons is further enormously extended by the possibility of double and treble unions between pairs of carbon atoms, as in ethylene,

$$
\left.\begin{array}{l}
\mathrm{H} \\
\mathrm{H}
\end{array}\right\rangle \mathrm{C}=\mathrm{C}\left\langle\begin{array}{l}
\mathrm{H} \\
\mathrm{H}
\end{array}\right.
$$

and acetylene,

$$
\mathrm{H}-\mathrm{C} \equiv \mathrm{C}-\mathrm{H}
$$

Further, more than one double or treble bond, or single, double, and treble bonds in combination, may occur, as in the well-known substances $\mathrm{CH}_{3}-\mathrm{CH}=\mathrm{CH}_{2}, \mathrm{CH}_{3}-\mathrm{C} \equiv \mathrm{CH}$, $\mathrm{CH}_{2}=\mathrm{C}=\mathrm{CH}_{2}$, etc.

Finally, the carbon atoms possess the property of uniting to form ring compounds in great variety, e.g.
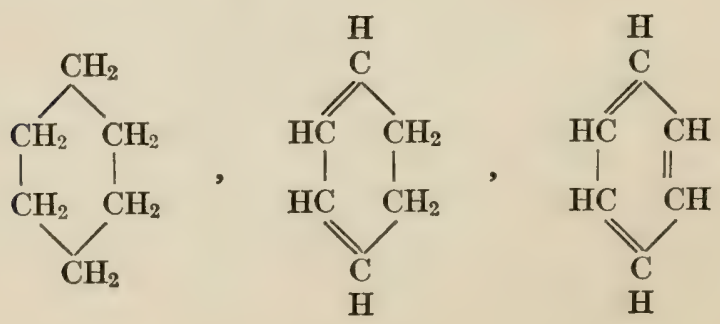


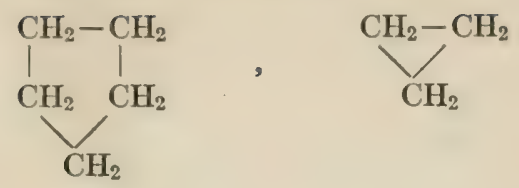

Moreover, such rings may unite with carbon chains, both those containing single bonds, and those containing double and treble bonds, whether straight or forked, in great variety; and also with other rings, e.g.

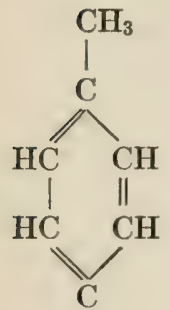

$\mathrm{H}$

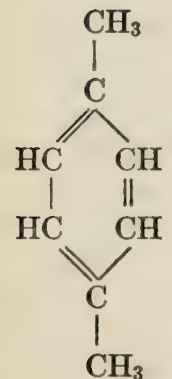

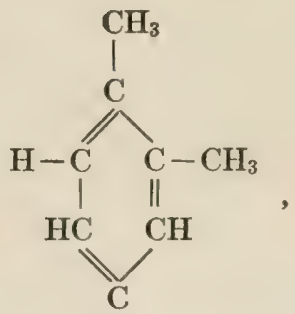

H

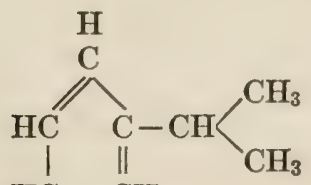

$\mathrm{HC} \quad \mathrm{CH}$

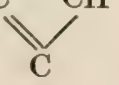

H

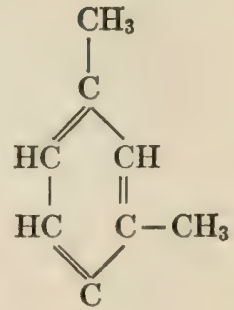

H

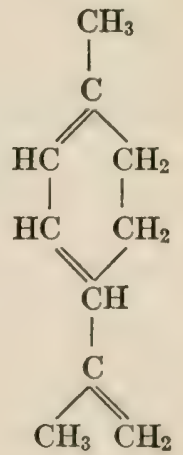




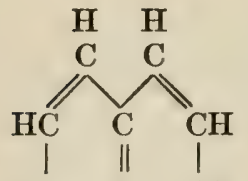

$\mathrm{HC}$ C $\mathrm{CH}$

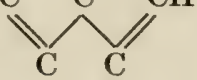

H H

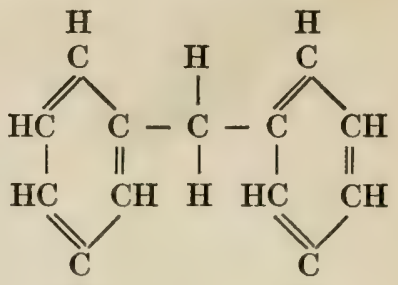

H

H

It is quite impossible briefly to indicate, still less to give an adequate idea of the bewildering diversity and complexity of the known hydrocarbons. They exist by the hundreds, and there are certainly countless thousands of possible stable bodies made up of carbon and hydrogen alone.

\section{C}

COMPOUNDS OF CARBON, HYDROGEN, AND OXYGEN

With the addition of oxygen, the variety and number of known and of possible substances is still further multiplied. Oxygen may enter into the following types of union with carbon and hydrogen in organic compounds :-

$$
\equiv \mathrm{C}-\mathrm{O}-\mathrm{H}, \quad \equiv \mathrm{C}-\mathrm{O}-\mathrm{C} \equiv, \quad=\mathrm{C}=\mathrm{O} .
$$

Alone or in combination, these groups yield a great variety of important classes of compounds. Representing a group or radical consisting of carbon and hydrogen alone by 
$\mathbf{R}$, a few of the most simple and important divisions are as follows:-
Alcohols, primary
$\mathrm{R} \cdot \mathrm{CH}_{2} \mathrm{OH}$
Alcohols, secondary
$\mathrm{R}_{2} \mathrm{CHOH}$
Alcohols, tertiary
$\mathrm{R}_{3} \mathrm{COH}$
Aldehydes
Ketones
$\mathrm{R} \cdot \mathrm{CHO}$
Acids
$\mathrm{R}_{2} \mathrm{CO}$
Esters
$\mathrm{RCOOH}$
Ethers
RCOOR
ROR

By the introduction of oxygen into the molecule any complex hydrocarbon may be converted into a great number of substances, and even in simple cases such derivatives are not few. In the accompanying formulas I have gathered together the possible hydrocarbons containing three carbon atoms (excluding ring compounds), and their possible oxygen derivatives, most of which are capable of existence as substances of varying stability, many of them being in fact wellknown common substances like lactic acid, glycerine, propionic acid, propyl alcohol, two of the simplest sugars, etc.

$\begin{array}{llll}\mathrm{CH}_{3} & \mathrm{CH}_{3} & \mathrm{CH}_{2} & \mathrm{CH}_{3} \\ \mid & ! & \| & \mid \\ \mathrm{CH}_{2} & \mathrm{CH} & \mathrm{C} & \mathrm{C} \\ \mid & \stackrel{\|}{1} \mathrm{CH}_{3} & \stackrel{\mathrm{CH}_{2}}{\mathrm{CH}_{2}} & \stackrel{\mathrm{CH}}{\mathrm{CH}}\end{array}$


204 THE FITNESS OF THE ENVIRONMENT

\begin{tabular}{|c|c|c|c|c|c|}
\hline $\mathrm{CH}_{3}$ & $\mathrm{CH}_{3}$ & $\mathrm{CH}_{3}$ & $\mathrm{CH}_{3}$ & $\mathrm{CH}_{2} \mathrm{OH}$ & $\mathrm{CH}_{2}$ \\
\hline & СHOH & $\begin{array}{l}\text { CH } \\
\|\end{array}$ & $\mathrm{COH}$ & CH & \\
\hline $\mathrm{H}_{2} \mathrm{OH}$ & $\mathrm{CH}_{3}$ & $\mathrm{CHOH}$ & $\mathrm{CH}_{2}$ & $\mathrm{CH}_{2}$ & $\mathrm{CHOH}$ \\
\hline $\mathrm{H}_{3}$ & $\mathrm{CH}_{2} \mathrm{OH}$ & $\mathrm{CH}_{3}$ & $\mathrm{CH}_{2} \mathrm{OH}$ & $\mathrm{CH}_{3}$ & $\mathrm{CH}_{2} \mathrm{OH}$ \\
\hline & C & СHOH & $\mathrm{CH}_{2}$ & $\mathrm{COH}$ & \\
\hline $\mathrm{H}$ & $\mathrm{CH}$ & $\mathrm{CH}_{2} \mathrm{OH}$ & $\mathrm{CH}_{2} \mathrm{OH}$ & $\mathrm{CHOH}$ & CHOH \\
\hline
\end{tabular}

$\mathrm{CH}_{2} \mathrm{OH} \quad \mathrm{CHOH} \quad \mathrm{CH}_{2} \mathrm{OH} \quad \mathrm{CH}_{2} \mathrm{OH} \quad \mathrm{CH}_{2} \mathrm{OH}$

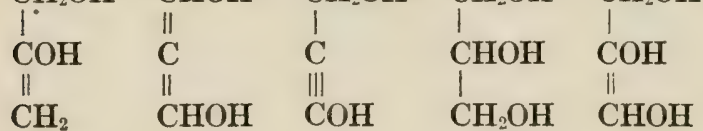

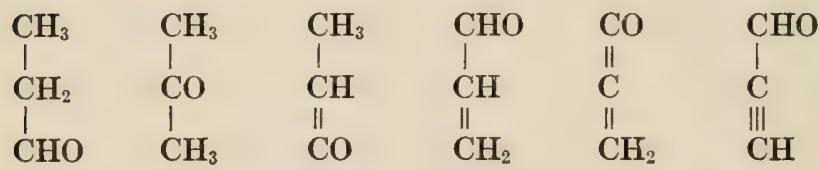

$\begin{array}{lllll}\mathrm{CH}_{3} & \mathrm{CHO} & \mathrm{CHO} & \mathrm{CO} & \mathrm{CHO} \\ 1 & 1 & 1 & \| & 1 \\ \mathrm{CO} & \mathrm{CH}_{2} & \mathrm{CH} & \mathrm{C} & \mathrm{CO} \\ 1 & 1 & \| & \| & 1 \\ \mathrm{CHO} & \mathrm{CHO} & \mathrm{CO} & \mathrm{CO} & \mathrm{CHO}\end{array}$

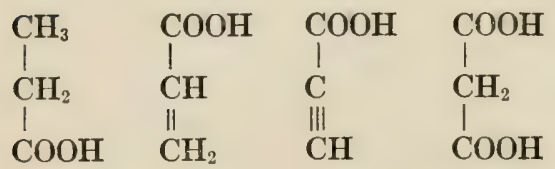

$\begin{array}{llllll}\mathrm{CH}_{3} & \mathrm{CH}_{2} \mathrm{OH} & \mathrm{CH}_{2} \mathrm{OH} & \mathrm{CH}_{3} & \mathrm{CH}_{2} \mathrm{OH} & \mathrm{CHO} \\ 1 & 1 & 1 & 1 & 1 & 1 \\ \mathrm{CHOH} & \mathrm{CH}_{2} & \mathrm{CO} & \mathrm{COH} & \mathrm{CH} & \mathrm{COH} \\ 1 & 1 & 1 & \| & \| & \| \\ \mathrm{CHO} & \mathrm{CHO} & \mathrm{CH}_{3} & \mathrm{CO} & \mathrm{CO} & \mathrm{CH}_{2}\end{array}$




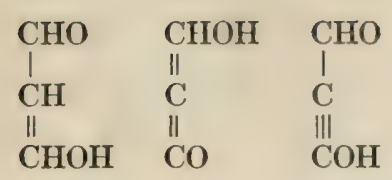

\begin{tabular}{|c|c|c|c|c|c|}
\hline $\mathrm{CH}_{2} \mathrm{OH}$ & $\mathrm{CH}_{2} \mathrm{OH}$ & $\mathrm{CH}_{2} \mathrm{OH}$ & CHO & $\mathrm{CH}_{2} \mathrm{OH}$ & CHO \\
\hline $\mathrm{CHOH}$ & $\mathrm{CO}$ & $\mathrm{COH}$ & $\mathrm{COH}$ & CO & $\mathrm{CHOH}$ \\
\hline $\mathrm{CHO}$ & $\mathrm{CH}_{2} \mathrm{OH}$ & $\mathrm{CO}$ & CHOH & CHO & CHO \\
\hline
\end{tabular}

CHO

$\stackrel{\mathrm{COH}}{ }$

$\|$

$\mathrm{CO}$

$\begin{array}{llllll}\mathrm{CH}_{3} & \mathrm{CH}_{2} \mathrm{OH} & \mathrm{COOH} & \mathrm{COOH} & \mathrm{COOH} & \mathrm{CH}_{2} \mathrm{OH}\end{array}$

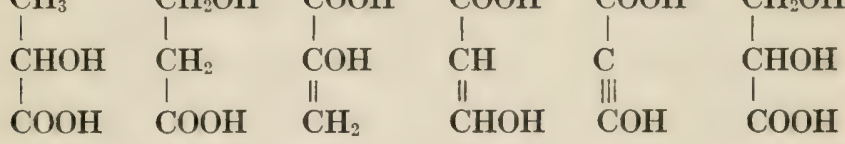

$\mathrm{COOH} \quad \mathrm{COOH}$

$\stackrel{\mathrm{COH}}{\text { ' }}$ $\stackrel{\|}{\mathrm{CHOH}} \stackrel{\text { СOOH }}{\mathrm{C}}$

$\begin{array}{llll}\mathrm{CH}_{3} & \mathrm{CHO} & \mathrm{COOH} & \mathrm{COOH} \\ 1 & 1 & 1 & 1 \\ \mathrm{CO} & \mathrm{CH}_{2} & \mathrm{CH} & \mathrm{CO} \\ 1 & 1 & \| & 1 \\ \mathrm{COOH} & \mathrm{COOH} & \mathrm{CO} & \mathrm{COOH}\end{array}$

$\mathrm{CH}_{2} \mathrm{OH} \quad \mathrm{CHO} \quad \mathrm{COOH}$ $\begin{array}{lll}\mathfrak{C O}_{2} & \stackrel{1}{\mathrm{CHOH}} & \stackrel{\mathrm{COH}}{1} \\ 1 & \stackrel{\mathrm{COH}}{\mathrm{COOH}} & \stackrel{\mathrm{C}}{\mathrm{C}=\mathrm{O}}\end{array}$ 
This is relatively a simple case. As the number of carbon atoms in the molecule increases, the number of possible oxygen derivatives multiplies in a far more rapid progression than in the case of the simplest hydrocarbons, which has been stated above. Accordingly there can be no doubt that in addition to the many thousands now known, the existence of countless millions of compounds consisting of carbon, hydrogen, and oxygen alone is possible. In a large proportion of cases the only difficulties involved in their preparation are to obtain suitable starting materials, and the enormous labor of the process. There are, for instance, hundreds of thousands of possible hydroxyl derivatives alone of the paraffine hydrocarbons of the formula $\mathrm{C}_{14} \mathrm{H}_{30}$, but only one of these is now known. ${ }^{1}$ Yet all, or at least a vast majority, would unquestionably be stable bodies if once formed.

Not less important than the number and variety of such substances is their diversity of physical and chemical characteristics. The following are, for example, individual chemical compounds of at least moderate purity, made up of the three elements alone: alcohol, formaldehyde, acetic acid, carbolic

${ }^{1}$ Methal, a constituent of spermaceti. 
acid, oxalic acid, acetone, ether, lactic acid, sugar, cotton, glycerine, olive oil, camphor, tannin, ophiotoxin (the chief poisonous constituent of cobra venom), starch, vanilline (the flavoring constituent of the vanilla bean), oil of wintergreen, salol, benzoic acid, digitaline.

Here is a variety that baffles description; but description is hardly necessary, for the facts explain themselves. In short, the compounds of the three elements which compose water and carbon dioxide exist in enormous numbers and in unparalleled diversity of chemical and physical characteristics. They include substances of the greatest stability, and others of exceeding instability ; liquids, solids, and gases; chemically active and chemically inert bodies; acids and neutral substances; substances which are readily oxidized and others which are oxidized only with great difficulty. In a very large proportion of cases these compounds are capable of entering into reactions with one another. They are, moreover, capable of forming still more complex substances, in still greater variety by entering into union with other elements, notably with nitrogen and sulphur. 


\section{$D$}

OTHER ORGANIC COMPOUNDS

The organic substances which contain nitrogen are very numerous and exceedingly diverse in their properties. A few of the principal classes of such compounds are the following : -

Amines

Nitro compounds

Nitriles

Isonitriles

Amino-acids

Azoxy compounds

Azo compounds

Hydrazo compounds $\mathrm{R}-\mathrm{NH}-\mathrm{NH}-\mathrm{R}$
$\mathrm{R}-\mathrm{NH}_{2}, \mathrm{R}_{2} \mathrm{NH}, \mathrm{R}_{3} \mathrm{~N}$

$\mathrm{R}-\mathrm{NO}_{2}$

$\mathrm{R}-\mathrm{C} \equiv \mathrm{N}$

$\mathrm{R}-\mathrm{NC}$

$\mathrm{R}-\mathrm{CH} \cdot \mathrm{NH}_{2} \cdot \mathrm{COOH}$

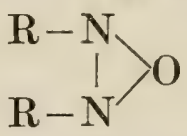

$\mathrm{R}-\mathrm{N}=\mathrm{N}-\mathrm{R}$

Derivatives of purine, pyridine, and other ring systems, etc.

The nitrogenous organic substances include classes of compounds which differ in their properties from any of the non-nitrogenous substances. Of such special properties the most conspicuous is perhaps alkalinity. Like ammonia, of which it is a derivative, the amino group $\left(-\mathrm{NH}_{2}\right)$, and various other groups containing nitrogen possess this char- 
acteristic. Such compounds, accordingly, supplement those which contain the acid carboxyl group (- $\mathrm{COOH}$ ) and make possible the fundamental relations of acid, base, and salt among organic compounds, corresponding to those of inorganic chemistry.

There exist also many compounds of sulphur, of chlorine, bromine, and iodine, as well as of various less common elements among organic substances; but in all such cases the complexity and variety of the compounds depend primarily upon the capacity of carbon, hydrogen, and oxygen, or carbon and hydrogen together, to form numerous, varied, and complex compounds on which, as it were, the further complexity is superposed.

\section{$E$}

THE CHARACTERISTICS OF ORGANIC SUBSTANCES

Thus the great diversity of organic substances depends in the first instance upon the quadrivalence of carbon, which makes of the carbon atom in the organic molecule a focus, from which chains of atoms may extend in four different directions; or, in the case of double or treble ties, in three directions ;

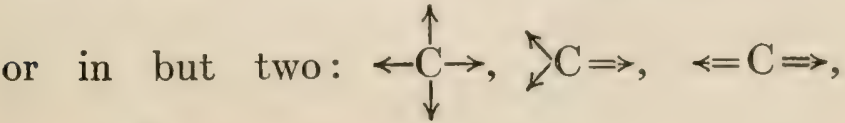


$\leftarrow \mathrm{C} \equiv$. Next comes the fact that carbon atoms, when otherwise exclusively in combination with hydrogen, and under other circumstances in lesser degree, possess an almost unlimited capacity to join together and form chains and rings in great variety. The longest carbon chain yet synthesized occurs in the compound hexakontane, ${ }^{1} \mathrm{C}_{60} \mathrm{H}_{122}$, a substance whose constitution is probably as follows :

\section{$\mathrm{CH}_{3} \cdot \mathrm{CH}_{2} \cdot \mathrm{CH}_{2} \underbrace{\ldots \ldots} \mathrm{CH}_{2} \cdot \mathrm{CH}_{2} \cdot \mathrm{CH}_{3}$. $\left(\mathrm{CH}_{2}\right)_{54}$}

The stability of this substance justifies a belief that even far longer chains of carbon atoms can exist, and, in fact, there is no known limit to the possibility of stringing carbon atoms together.

No other element is believed to share both of these characteristics, and there are various reasons to suppose that the resulting peculiarity of the system of organic compounds is really unique. Turning to the periodic classification of the elements, it will be seen that carbon is a member of the first series. Several of the elements of this series, unlike all the other elements except hydrogen, possess very definite individual properties, which

1 "Hell und Hägele," Berichte, 22, 502 (1899). 
mark them off sharply from other substances. Thus carbon bears relatively little resemblance to its neighbors silicon or titanium, nitrogen to phosphorus or ranadium, oxygen to sulpliur or chromium; while hydrogen, of course, has a place quite apart in the classification, and as an element appears to be correspondingly unique.

It is, therefore, in the highest degree probable that compounds made from elements of such positive chemical characteristics and very unusual properties will be unlike compounds formed from other elementary substances. In this manner the periodic classification confirms our confidence in the results of many decades of experience, which lead us to believe that other elements are exceedingly unlikely readily to form compounds comparable in number, variety, and complexity with those of organic chemistry as we know it.

For more evidence we may turn to certain further data of organic chemistry. I refer principally to the character of the organic radicals composed exclusively of carbon and hydrogen. In making a rational classification of the carbon compounds it has been found convenient to commence with that series of hydrocarbons, called paraffines, with which the present discussion was begun. 
From them other series may be derived by making a substitution in the molecule. Thus the substitution of a hydroxyl radical for a single hydrogen atom leads from the paraffine hydrocarbons, $\mathrm{C}_{n} \mathrm{H}_{2 n+2}$, to the alcohols $\mathrm{C}_{n} \mathrm{H}_{2 n+1} \mathrm{OH}$; the substitution of a carboxyl radical $-\mathrm{COOH}$, for the methyl group $-\mathrm{CH}_{3}$, leads from the paraffine hydrocarbons $\mathrm{C}_{n} \mathrm{H}_{2 n+1} \cdot \mathrm{CH}_{3}$ to the acids $\mathrm{C}_{n} \mathrm{H}_{2 n+1} \cdot \mathrm{COOH}$.

Moreover, the classes of compounds thus defined chemically fulfill the logical requirements of a class. They are collections of well-characterized and very similar individual things which differ greatly, and in well-marked manner, from all other things. In other words, growing complexity of the molecule, when it consists only in increase in complexity of the simple radical comprised of carbon and hydrogen, of the formula $\mathrm{C}_{n} \mathrm{H}_{2 n+1}$,

$\mathrm{CH}_{3}-, \mathrm{CH}_{3} \cdot \mathrm{CH}_{2}-, \mathrm{CH}_{3} \cdot \mathrm{CH}_{2} \cdot \mathrm{CH}_{2}-, \mathrm{CH}_{3} \cdot \mathrm{CH}_{2} \cdot \mathrm{CH}_{2} \cdot \mathrm{CH}_{2}-$
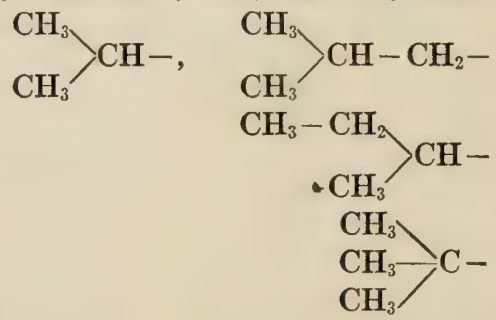

has very little effect upon the properties of the molecule. Thus the compound methane, 
$\mathrm{CH}_{4}$, very closely resembles normal butane, $\mathrm{CH}_{3} \cdot \mathrm{CII}_{2} \cdot \mathrm{CH}_{2} \cdot \mathrm{CH}_{3}$; and again propionic acid, $\mathrm{CH}_{3} \cdot \mathrm{CH}_{2} \cdot \mathrm{COOH}$, and heptylic acid, $\mathrm{CH}_{3} \cdot \mathrm{CH}_{2} \cdot \mathrm{CH}_{2} \cdot \mathrm{CH}_{2} \cdot \mathrm{CH}_{2} \cdot \mathrm{CH}_{2} \cdot \mathrm{COOH}$, are very much alike.

Quite different is the case when any other radical accumulates in the molecule. For instance, propyl alcohol, $\mathrm{CH}_{3} \cdot \mathrm{CH}_{2} \cdot \mathrm{CH}_{2} \cdot \mathrm{OH}$, which closely resembles ordinary alcohol, $\mathrm{CH}_{3} \cdot \mathrm{CH}_{2} \mathrm{OH}$, is very different in its behavior from glycerine, $\mathrm{CH}_{2} \mathrm{OH} \cdot \mathrm{CHOH} \cdot \mathrm{CH}_{2} \mathrm{OH}$, and similarly, acetic acid, $\mathrm{CH}_{3} \cdot \mathrm{COOH}$, differs materially in properties from oxalic acid $\mathrm{COOH} \cdot \mathrm{COOH}$. Even more marked are the differences when a radical accumulates upon a single carbon atom. In successive stages of oxidation ethane, $\mathrm{CH}_{3} \cdot \mathrm{CH}_{3}$, yields alcohol, $\mathrm{CH}_{3} \cdot \mathrm{CH}_{2} \mathrm{OH}$, aldehyde, $\mathrm{CH}_{3} \cdot \mathrm{CH}(\mathrm{OH})_{2}$, which by a secondary transformation goes over into the more stable form $\mathrm{CH}_{3} \cdot \mathrm{CHO}$, and acetic acid, $\mathrm{CH}_{3} \cdot \mathrm{C}(\mathrm{OH})_{3}$, which similarly becomes $\mathrm{CH}_{3} \cdot \mathrm{COOH}$. These changes correspond to the conversion of ethane, that is monomethyl methane, into dimethyl methane, trimethyl and tetramethyl methane:-

$$
\begin{aligned}
& \mathrm{CH}_{3}-\mathrm{CH}_{3} \rightarrow \mathrm{CH}_{3} \cdot \mathrm{CH}_{2} \cdot \mathrm{CH}_{3} \rightarrow \\
&{ }^{\mathrm{CH}_{3}}>\mathrm{CH}-\mathrm{CH}_{3} \rightarrow \stackrel{\mathrm{CH}_{3}}{\mathrm{CH}_{3}}>\mathrm{C}\left\langle\mathrm{CH}_{3}\right. \\
& \mathrm{CH}_{3} .
\end{aligned}
$$




\section{THE FITNESS OF THE ENVIRONMENT}

In the latter case the introduction of methyl groups in place of hydrogen produces no appreciable change in the general characteristics of the substances; in the former, the successive introduction of hydroxyl groups forms substances belonging to three different classes of compounds, - alcohols, aldehydes, and acids, which have nothing in common. In short, variation in the number and arrangement of such groups as occur in the paraffine hydrocarbon,

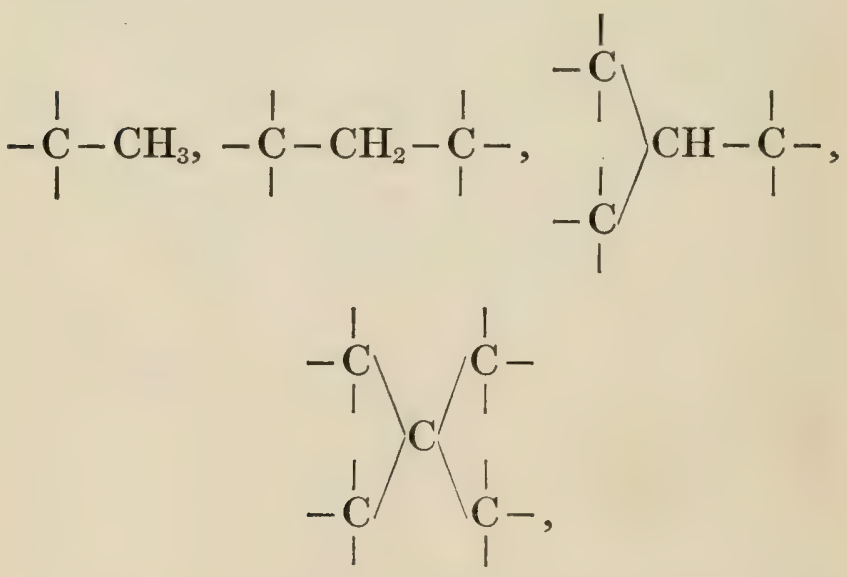

is without manifest effect upon the more important properties of the molecule, but variation in the number and arrangement of any other groups produces complete change in its characteristic properties. 
It may perhaps be urged that this argument is fallacious, in that the increase of the relative amount of hydroxyl in the above cases is larger than the relative change in radicals of the types $-\mathrm{CH}_{3}$, $=\mathrm{CH}_{2}$, $\equiv \mathrm{CH}$, and $\equiv \mathrm{C}$. But, in the first place, it is evident that the latter four radicals are actually different, and a priori there is no reason to suppose that they should not greatly differ in their effect upon the properties of a molecule, for instance, to render dissimilar the compounds normal pentane $\mathrm{CH}_{3} \cdot \mathrm{CH}_{2} \cdot \mathrm{CH}_{2}$. $\mathrm{CH}_{2} \cdot \mathrm{CH}_{3}$ and tetramethyl methane,

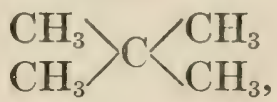

which is not the case. In the second place, the change from methane, $\mathrm{CH}_{4}$, to ethane, $\mathrm{CH}_{3} \cdot \mathrm{CH}_{3}$, is a larger proportional change in the molecule than the change from alcohol, $\mathrm{CH}_{3} \cdot \mathrm{CH}_{2} \mathrm{OH}$, to glycol, $\mathrm{CH}_{2} \mathrm{OH} \cdot \mathrm{CH}_{2} \mathrm{OH}$, or aldehyde, $\mathrm{CH}_{3} \cdot \mathrm{CHO}$, both of which produce far greater changes in the properties.

In fact, the union of carbon with hydrogen in organic compounds is a unique and peculiar chemical relationship, upon which the properties of the carbon compounds, their number, variety, and complexity largely depend. It seems to make no important difference whether 
a carbon atom is attached to four hydrogen atoms, or to one carbon and three hydrogens, or to two carbons and two hydrogens, or to three carbons and one hydrogen, or to four carbon atoms; in all such cases the effect of the radical upon the general characteristics of the molecule varies very little.

There are a great number of phenomena which might be employed further to illustrate the nature of the case, but two will suffice. The acidity of acetic acid, $\mathrm{CH}_{3} \cdot \mathrm{COOH}$, is only slightly and slowly changed by the accumulation of hydrocarbon radicals; thus the compounds propionic acid, $\mathrm{CH}_{3} \cdot \mathrm{CH}_{2}$. $\mathrm{COOH}$, and butyric acid, $\mathrm{CH}_{3} \cdot \mathrm{CH}_{2} \cdot \mathrm{CH}_{2} \cdot$ $\mathrm{COOH}$, are only a little less acid than acetic acid itself, because nearly all the effect of such larger radicals as they contain is already exerted by the methyl group.

\section{Ionization Constants of Acids}

Acetic acid,

Propionic acid,

Butyric acid,

Glycolic acid,

Chloracetic acid,

Dichloracetic acid,

Trichloracetic acid,

Glycocoll,

Oxalic acid,
$\mathrm{CH}_{3} \cdot \mathrm{COOH}$

$\mathrm{CH}_{3} \cdot \mathrm{CH}_{2} \cdot \mathrm{COOH}$

$\mathrm{CH}_{3} \cdot \mathrm{CH}_{2} \cdot \mathrm{CH}_{2} \cdot \mathrm{COOH} \quad 0.000016$

$\mathrm{CH}_{2} \mathrm{OH} \cdot \mathrm{COOH}$

$\mathrm{CH}_{2} \mathrm{Cl} \cdot \mathrm{COOH}$

$\mathrm{CHCl}_{2} \cdot \mathrm{COOH}$

$\mathrm{CCl}_{3} \cdot \mathrm{COOH}$

$\mathrm{CH}_{2} \mathrm{NH}_{2} \cdot \mathrm{COOH}$

$\mathrm{COOH} \cdot \mathrm{COOH}$
0.000018

0.000014

0.00015

0.0015

0.05

1.2

0.00000000018

0.1 
But if a hydroxyl group be substituted, as in glycolic acid, $\mathrm{CH}_{2} \mathrm{OH} \cdot \mathrm{COOH}$, or a chlorine atom, as in monochloracetic acid, $\mathrm{CH}_{2} \mathrm{Cl}$. $\mathrm{COOH}$, the acidity is greatly increased, while the compound trichloracetic acid, $\mathrm{CCl}_{3}$. $\mathrm{COOH}$, is a strong acid. On the other hand, aminoacetic acid, $\mathrm{CH}_{2} \cdot \mathrm{NH}_{2} \cdot \mathrm{COOH}$, is scarcely acid at all.

The effect of introducing a carboxyl group in place of a methyl group into any paraffine hydrocarbon, regardless of its constitution, e.g. $\mathrm{CH}_{3} \cdot \mathrm{CH}_{3} \rightarrow \mathrm{CH}_{3} \cdot \mathrm{COOH}$, is to diminish the heat of combustion of the molecule almost exactly 157 calories; but the conversion of acetic acid into oxalic acid, $\mathrm{CH}_{3} \cdot \mathrm{COOH} \rightarrow$ $\mathrm{COOH} \cdot \mathrm{COOH}$, structurally an identical change, diminishes the molecular heat of combustion only 147 calories. ${ }^{1}$ In both these instances it is certain that the nature of the influence of the radicals consisting of carbon and hydrogen exclusively is nearly independent of their size and configuration. Any other group, however, by its presence at once modifies the nature of the case, though unconcerned in the process or property. Since it can be shown that such effects, like the difference between monochloracetic acid and

${ }^{1}$ Stohmann, Zeitschrift für Physikalische Chemie. II, 29, 1888. 
trichloracetic acid, depend upon the number of such foreign groups and their arrangement, ${ }^{1}$ it is evident that the hydrocarbon radicals have a constancy of influence upon the properties of the molecule which is not shared by other radicals.

The indifference of effect of hydrogen and carbon, when linked to carbon, upon the properties of the molecule is undoubtedly a principal cause of the stability of complex organic substances. Through this peculiarity of the two elements the integrity of the valence energy of carbon is preserved, and the long carbon chains are stable. Whenever the molecule becomes overloaded with radicals of other kinds the strength of the tie between carbon atoms diminishes and the compound becomes unstable. The properties of the carbohydrates, which will be later discussed, admirably illustrate such instability. In short, organic compounds are in some respects properly to be regarded as compounds of carbon and hydrogen jointly, for it is not the properties of carbon alone, but those of carbon and hydrogen together which chiefly make them possible.

${ }^{1}$ Henderson, Journal of Physical Chemistry, IX, 40, 1905; Proceedings of the American Academy of Arts and Sciences, XLII, 639, 1907; Zeitschrift für Physikalische Chemie, LX, $413,1907$. 
In the more complex substances, such as the various ring systems of organic chemistry, it is not possible to discuss such problems of molecular mechanics. There too, however, hydrogen predominates over all other elements except carbon, and that may well be taken as a sufficient indication of its continued importance.

All of these considerations taken together suffice, I believe, to prove, or at least to make it exceedingly probable, that organic chemistry is in truth a unique field, and that no other elements can form compounds in such variety, complexity, and number as carbon, hydrogen, and oxygen. At any rate there can be no possible doubt that the compounds of organic chemistry are in these respects very remarkable indeed, and that similar cases must be extremely rare among all the possible systems of compounds made up of all the known elements.

It follows from the peculiarities just explained that the first great factor in the complexity of living organisms as we know them, the complexity and variety of their chemical constituents, depends principally upon the nature of the elements which compose such substances, and is most probably a unique, certainly a very rare characteristic of matter. 
That the very elements which make up water and carbonic acid, and apparently they alone, should possess this wonderful property is, when taken together with the physical properties of water and carbonic acid and their place in cosmic evolution as constituents of the atmosphere, a fact which cannot lightly be set aside.

Not less valuable for the organism than the multiplicity of organic substances, and the diversity of their properties, are the great variety of chemical changes which they can undergo, and that characteristic instability which renders such great complexity of chemical behavior easily attainable. In short, organic substances are uniquely fitted not only to provide complexity of structure to the organism, but also, through their instability and manifold transformations, to endow it with diverse chemical activities, with complexity of physiological function.

One factor in determining the complexity of chemical changes which organic chemical substances manifest is the enormous number of simple structural relationships which every substance bears to others. This may be readily illustrated by the formulas of some of the derivatives of propane which possess biological importance: 


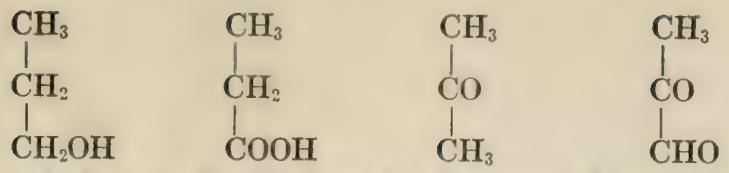

Propyl alcohol, Propionic acid, Acetone, Methyl glyoxal,

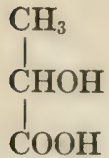

Lactic acid,

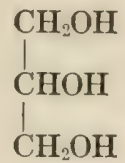

Glycerine
$\mathrm{CH}_{2} \mathrm{OH}$

$\mathrm{CHOH}$

CHO

Glycerine aldehyde,

$\mathrm{CH}_{2} \cdot \mathrm{SH}$

CH $\cdot \mathrm{NH}_{2}$

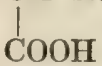

Cysteine,

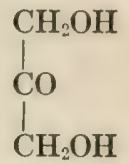

Dioxyacetone

$\mathrm{CH}_{3}$

$\mathrm{CH} \cdot \mathrm{NH}_{2}$ $\mathrm{COOH}$

Alanine,

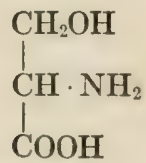

Serine,

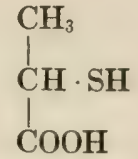

a-Thiolactic

acid

Of the above substances, acetone, lactic acid, glycerine, glycerine aldehyde, dioxyacetone, alanine, serine, and cysteine are of the greatest moment in physiological processes.

Such complexity of chemical relationships results automatically, so to speak, in a variety of chemical transformations. But the transformations are greatly facilitated by that characteristic instability of organic substances, which is perhaps the chief distinguishing feature of their behavior. For example, many inorganic substances may be subjected to very 
high temperatures without undergoing chemical change, but there are hardly any organic substances which can survive such treatment. Organic substances are also peculiarly liable to modification from the action of light and air. These are, however, but rough indications of instability, and a special case will help more clearly to define the real characteristic.

\section{F}

\section{THE SUGARS}

In accordance with the researches of Emil Fischer, the following constitution is ordinarily assigned to glucose. ${ }^{1}$

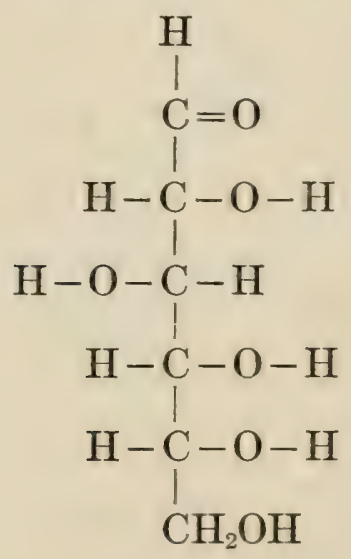

${ }^{1}$ A discussion of this formula may be found in any textbook of organic chemistry. 
It must be noted that carbon atoms to which four different groups are attached are asymmetric, that is to say, they can exist in two forms which resemble each other as the right hand resembles the left (Pasteur, LeBel, van't Hoff'). This characteristic results in further increase in the number and variety of organic compounds. It is therefore necessary, in writing the formula, to represent the form of the molecule as it exists in space (in three dimensions), and this is actually accomplished by imagining the three-dimensional formula to be projected upon the paper so that when the hydrogen atom is written to the right of the carbon atom one asymmetric form of the latter is designated, when the hydrogen atom appears to the left, the other.

It has long been known that when glucose is dissolved in water its optical activity, as the power of a substance to rotate the plane of polarization of light is loosely termed, changes slowly for some time before reaching a constant value. Recently it has been shown that this phenomenon probably depends upon the existence in solution of threc different forms of glucose, which pass freely into one another and ultimately attain a state of equilibrium. ${ }^{1}$

${ }^{1}$ This subject has been fully discussed by Hudson, Journal of the American Chemical Society, XXXII, 889, 1910. 

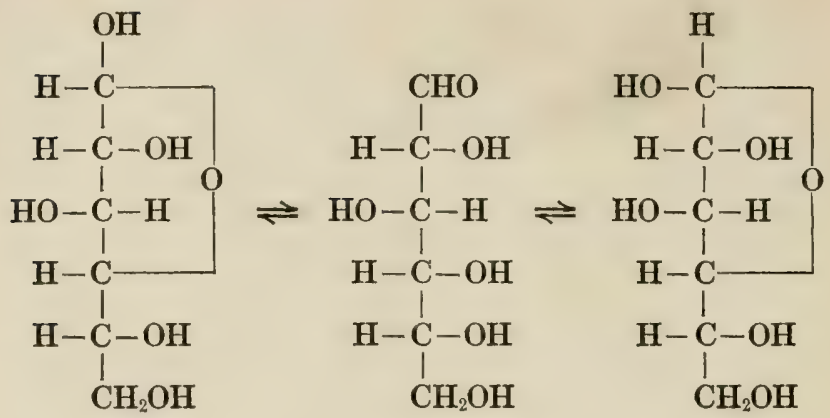

When to such a solution of glucose a small quantity of alkali is added, certain remarkable further changes occur, as was first demonstrated by Lobry de Bruyn. ${ }^{1}$ These processes result in the formation of mannose and levulose, probably according to the accompanying diagram.

Moreover, like glucose, levulose and mannose both exist in solution in three different forms, so that the resulting solution contains at least ten chemical individuals. But it is almost certain that other changes simultaneously occur and that the solution is actually still more complex, even from the outset.

Upon a continued increase of alkalinity, or even slowly under the original conditions, a multitude of other changes set in. These

${ }^{1}$ See the numerous papers by Lobry de Bruyn and Alberda van Eckenstein in Recueil des Travaux Chimiques des Pays Bas, XIV-XIX. 


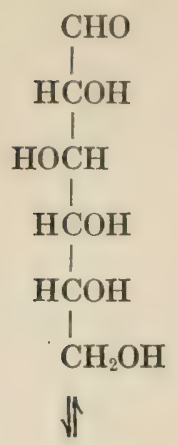

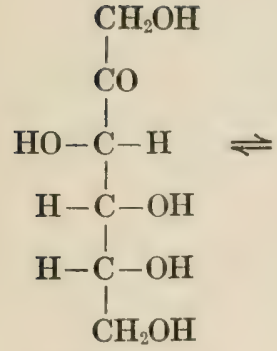

Levulose
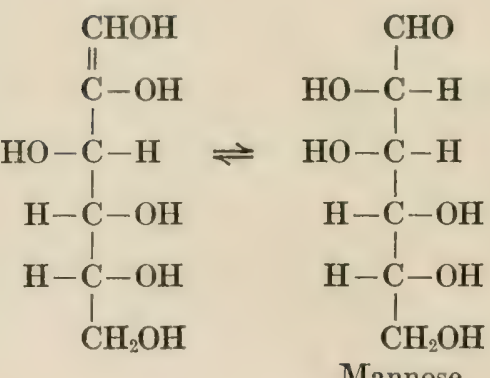

are known sometimes to lead to the formation of lactic acid, $\mathrm{CH}_{3} \cdot \mathrm{CHOH} \cdot \mathrm{COOH}$, methylglyoxal, $\mathrm{CH}_{3} \cdot \mathrm{CO} \cdot \mathrm{CHO}$, and formaldehyde, $\mathrm{H} \cdot \mathrm{CHO}$. Further, as Neff has shown, ${ }^{1}$ many other substances may also be formed. Such bodies chiefly belong to the class of oxyacids. It is also certain that a great variety of other simple sugars resembling glucose, levulose,

${ }^{1}$ Neff, "Liebig's Annallen," 376, p. 1, 1910, and 357, p. $294,1907$. 
and mannose are produced, and, all told, the constituents of such a solution probably number at least two hundred, all produced from glucose alone, under the influence of a slight excess of hydroxyl ions. Among these substances the greatest diversity of chemical behavior is to be distinguished. Alcohol, aldehyde and ketone, and acid radicals occur in great profusion and variety of combinations ; compounds possessing forked chains are present; and double bonds between carbon atoms add to the complexity. Moreover, all these substances themselves possess great chemical activity.

A single case may perhaps illustrate this point. It has been shown by Windaus and Knoop ${ }^{1}$ that in such solutions, in the presence of ammonia, one molecule of methyl glyoxal, one of formaldehyde, and two of ammonia unite to form the cyclic compound, methyl imidazol, a substance related to histidine, the latter being an important constituent of the protein molecule:-

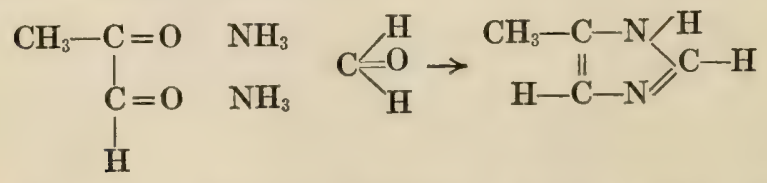

${ }^{1}$ Knoop and Windaus, Berichte, XXXVI, 1166, 1905. Hofmeister's Beiträge, VI, 392, 1905. 
The instability of glucose and of all the simple sugars is indeed exceptional in character, and the resulting processes are perhaps far more intricate and numerous than in any other similar case. However, this very case is of exceptional physiological importance, because carbohydrates are the direct result of that synthetic action of chlorophyll,

$$
6 \mathrm{CO}_{2}+6 \mathrm{H}_{2} \mathrm{O}=\mathrm{C}_{6} \mathrm{H}_{12} \mathrm{O}_{6}+6 \mathrm{O}_{2},
$$

which is the source of all organic substances and of all the energy of the organic cycle in plants and animals. Carbohydrates, moreover, are the chief constituents of plants and the chief food of animals.

Turning to this synthesis of carbohydrate in the plant, we find much that is important in the present study. The details of the chemical transformation by which waler and carbonic acid and solar cnergy are changed to sugars and oxygen still remain unknown, in spite of many careful investigations. But, at all events, it is possible to see that two things must somehow be done in order to accomplish the synthesis:

(1) Carbonic acid and water must be reduced. That is to say, oxygen must be separated from both of these compounds so that free valences may exist to unite carbon and 
hydrogen in one molecule, and so that, further, the relative proportions of the three elements may become what they are in the simple carbohydrates, $\mathrm{C}: \mathrm{H}: \mathrm{O}=1: 2: 1$.

(2) Somehow individual carbon atoms must be joined together until there are six in each molecule, where formerly there was but one.

Theoretically, it might be possible by reduction to form from carbon dioxide and water without union of carbon atoms the following substances: carbon monoxide, $\mathrm{CO}$; formic acid, $\mathrm{H} \cdot \mathrm{COOH}$; formaldehyde, $\mathrm{H} \cdot \mathrm{CHO}$; methyl alcohol, $\mathrm{CH}_{3} \mathrm{OH}$; and methane, $\mathrm{CH}_{4}$. Of such reductions the formation of formic acid, formaldehyde, and carbon monoxide has been directly realized by laboratory experiment. ${ }^{1}$

The most familiar theory of the formation of carbohydrates in the leaf is that of von Baeyer, which assumes a polymerization of one of the above substances, formaldehyde, leading directly to the formation of sugar, according to the reaction

$$
6 \mathrm{H} \cdot \mathrm{CHO}=\mathrm{C}_{6} \mathrm{H}_{12} \mathrm{O}_{6} \text {. }
$$

This process also has been carried out experimentally. Indeed, as a result of the investigations of Butlerow, O. Loew, and

${ }^{1}$ See Meyer u. Jacobson's “Lehrbuch der Organischen Chemie," Leipzig, 1907, p. 688, 693-696. 
E. Fischer, it is known that in distinctly alkaline solutions formaldehyde spontaneously goes over into a mixture of sugars which resemble glucose. Moreover, such a solution is unquestionably made up of much the same variety of substances as a glucose solution which has been subjected to the action of alkali in the same concentration.

As stated above, it is evident that if anything is to be done chemically with a mixture of carbon dioxide and water, oxygen must be split off from both carbon and hydrogen so that they may enter into the same molecule. If this chemical change, which, to be sure, is no easy one in the laboratory, be accomplished, formaldehyde among other things results; and in alkaline solution formaldehyde produces carbohydrates and leads to that amazing tangle of substances and reactions, whose nature has been briefly indicated above. In short, the one chemical process which is open, if any transformations whatever are to be accomplished with carbonic acid and water, leads directly and to all appearances necessarily to the greatest complexity that has been found in any one chemical process; to a system made up of possibly two hundred substances or more, most of which possess very great chemical activity. 
It must not be forgotten that the share of the organism in such processes is also important. If possible, the smoothness with which chemical reactions are carried out in the leaf, perhaps quite without any stop at the formaldehyde stage, and the certainty with which definite substances in large amounts instead of mixtures in very small amounts are produced, seem more remarkable than the underlying chemical facts. Needless to say, one great factor in such processes is the action of enzymes. Otherwise we are at a loss for a description of the ways and means by which the organism operates, though the brilliant studies of chlorophyll which have recently been carried out by Willstätter promise great achievements in the future. ${ }^{1}$

The underlying chemical facts, however, remain; carbohydrates are among the natural products of carbon dioxide and water; they manifest in solution, especially in such conditions as obtain in protoplasm or the ocean, ${ }^{2}$ unparalleled instability and variety of reactions; and they produce spontaneously an enormous number of very active chemical substances. It is easy to see that, given

${ }^{1}$ See his many papers of recent years in "Liebig's Annallen."

${ }^{2}$ Henderson, Journal of Biological Chemistry, X, 3, 1911. 
an enzyme possessing the power to select and catalyze any one of the reactions, the formation of any special one of the many possible products in comparative purity is an automatic result.

Such processes are in nature carried out with a perfection which to the chemist is almost inconceivable, by means of organic structures of the highest intricacy; but in the last analysis they rest upon the native properties of the three elements.

The important consideration, I repeat, is this: that reduction, the necessary first change of carbonic acid and water, can lead directly by a single continuous chemical transformation, of which the exact control is no whit more remarkable than the accurate control of the other processes of chemical physiology, ${ }^{1}$ to the full intricacy of organic chemistry; to the very most notable instance of number, variety, and activity of substances, all formed inevitably, in the nature of the case, which has yet come to light. It is of no consequence that most of the substances must be formed in mere traces by the spontaneous synthesis, for in highest degree the organism possesses the power, by enzymatic catalysis, to select

${ }^{1}$ Consult the work of Bayliss on Enzymes. London, Longmans, Green \& Company. 
any one of a group of simultaneous reactions that may serve its needs, and make that one predominant. In short, the fitness is reciprocal; the unique chemical adaptability of the process and the unique chemical powers of the living organism interlock.

Such, in brief, are the superlative advantages which the properties of the compounds of the three elements contribute to the organic mechanism. They include number of substances, variety of substances, variety of properties, variety of reactions, facility of reactions (instability), and the remarkable relationship between carbon dioxide and water and the carbohydrates. And they insure that extreme variety of chemical relationship which especially fits organic substances, once created, to be, throughout the various forms of life, the source of still other bodies, and the source of energy, by means of far-reaching chemical changes rapidly accomplished.

\section{G}

\section{HYDROLYSIS}

In the course of digestion the principal foodstuffs, carbohydrates, fats, and proteins, undergo a series of changes which are substantially the same for all. Such processes are known as hydrolytic cleavage, or more loosely 
as hydrolysis. Essentially they amount to successive splittings of the large molecules of the native substances, each cleavage being accompanied by the addition of a molecule of water, until finally from starches and like substances the simple sugars like glucose result; from the fats, fatty acids and glycerine; from the proteins, the so-called amino acids.

The cleavage of fats closely resembles the hydrolysis of a simple ester; the cleavage of proteins and carbohydrates a little more remotely resembles the same process. Accordingly, the hydrolysis of the simplest ester, methyl formate, may serve as an illustration of the nature of the reaction:-

$$
\begin{array}{c:c:c}
\mathrm{H}-\mathrm{C}-\mathrm{O} & \mathrm{CH}_{3}+\mathrm{H} \cdot \mathrm{O} & \mathrm{H}=\mathrm{H}-\mathrm{C}-\mathrm{O}-\mathrm{H}+\mathrm{H}-\mathrm{O}-\mathrm{CH}_{3} \\
\hdashline \| & \|
\end{array}
$$

This process is nothing less than the typical reaction between water and organic substances. Accordingly, it is not surprising that such reactions are by no means confined to the digestion of food. Once formed, the products of digestion are absorbed, the more readily because of their simplicity, and, also because of their simplicity, they carry into the body no trace of the organism in which they previously existed. But, if they are to 


\section{THE FITNESS OF THE ENVIRONMENT}

be built up into the tissues of the animal, they must now be turned back into such fats, carbohydrates, and proteins as are characteristic of his physical structure; into glycogen, hæmoglobin, fibrinogen, etc. Accordingly, they undergo a process which is the exact reverse of the digestive change, in the simple case: -

$$
\underset{\|}{\mathrm{H}}-\underset{\mathrm{O}}{\mathrm{C}}-\mathrm{O}-\mathrm{H}+\mathrm{H}-\mathrm{O}-\mathrm{CH}_{8}=\mathrm{H}-\underset{\|}{\mathrm{C}}-\mathrm{O}-\mathrm{CH}_{3}+\mathrm{H}-\mathrm{O}-\mathrm{H}
$$

But this is by no means the end of the matter. For example, glycogen thus formed in the liver from the glucose of the portal blood is soon torn down to glucose again. Moreover, there are a host of other special cases of the same hydrolytic cleavage, or the reverse process, in mammalian physiology. For instance, the formation of hippuric acid from benzoic acid and glycocoll, and the formation of urea itself from ammonium carbonate belong to this same class. In fact, such reactions make up a large part of all the chemical changes which take place within the organism.

It must not be imagined, however, that hydrolytic cleavages are infrequent outside the organism, or that the types of processes 
which occur within the organism are the only ones of this class. There is no more common and universally important reaction in organic chemistry, and many compounds and classes of compounds which have nothing to do with the organism undergo hydrolysis. Moreover, generally speaking, all reactions of this class are very similar in their principal characteristics, resembling one another both dynamically and statically. Spontaneously they occur not at all, or very slowly. Under the influence of enzymes, of acids, and of alkalies acting catalytically, that is to say, facilitating the process without in the end taking part in it, much as oil facilitates the action of a machine, they progress rather slowly and very smoothly. By-products are not formed; the reactions are simple, uncomplicated, and reliable. Hence they enable the organism to make all sorts of rearrangements and reconstructions of chemical substances efficiently and without loss of material.

The chief cause of such traits in hydrolysis is the fact that the energy transformation which accompanies the process is almost exactly nil. For it has been found in general that chemical reactions which liberate much energy are violent, hard to regulate, often complicated by intricate side reactions, and 
complete. In contrast, those which are without energy change generally proceed smoothly, slowly, and without complication to a state of equilibrium in which the reaction is very incomplete. ${ }^{1}$ Under the latter circumstances slight changes of conditions make possible a reversal of the delicately balanced process; the reaction can be made to run in either direction at will.

The absence of transformation of energy accompanying hydrolysis may be illustrated by a few typical cases chosen from the data of simple substances.

\begin{tabular}{|c|c|c|c|c|c|c|c|c|}
\hline & & & & & & & Calories & Per Cent \\
\hline Cane sugar & . & & . & . & . & . & +1.9 & 0.2 \\
\hline Milk sugar & - . & . & . & . & . & . & +4.3 & 0.3 \\
\hline Maltose . & - . & . & . & - & . & . & -3.7 & 0.3 \\
\hline Ethyl acetate & . & . . & • & . & . & . & +2.0 & 0.3 \\
\hline
\end{tabular}

Such measurements of heats of reaction fall well within the limits of error of the method of investigation, and there can be no doubt that in all such cases the heat of reaction is so small that it cannot be detected by the ordinary methods of measurement. ${ }^{2}$

${ }^{1}$ van't Hoff, “Acht Vorträge über Physikalische Chemie." Brunswick, 1902, Lecture 6.

${ }^{2}$ Stohmann, Zeitschrift für Physitalische Chemie, II, 29, 1888 (see also Ostwald's "Lehrbuch der Allgemeinen Che- 
Thus it is evident that the process possesses another advantage. In the course of such rearrangements no energy is lost. This conclusion is thoroughly confirmed by the studies of the energy transformations of metabolism. The body may carry on such processes as it will, in the greatest variety and complexity, rearranging and modifying its chemical structures to any extent, and there will never be an appreciable wastage of precious material or of equally precious energy in the process.

This process, as we have seen, is the characteristic reaction between water and the organic compounds. As such it is necessarily one of our chief concerns; its maximal fitness as a means of regulation, and otherwise, therefore assumes real importance in the present discussion.

\section{II}

\section{INORGANIC CHEMISTRY}

With the survey of organic chemistry we have exhausted the compounds of carbon;

mie"). These data are the most accurate now in existence which permit an estimate of the heat of hydrolysis of nonnitrogenous compounds. Numerous studies of protein derivatives from Fischer's laboratory prove that the facts are the same for these substances, and direct measurements confirm the measurements of heats of combustion. 
not so those of hydrogen and oxygen. In almost equal frequency the latter elements take part in the reactions of inorganic chemistry, and help to form its molecular structures. As an illustration of their importance in this department of the science I have counted the compounds and the classes of compounds mentioned in the table of contents of the second edition of Erdmann's "Lehrbuch der Anorganischen Chemie." In all 435 substances are referred to; of these 259, approximately 60 per cent, contain oxygen; 130 , or 30 per cent, contain hydrogen. There seems to be little doubt that this is a fair test, for the work is compendious, and all important substances and classes of substances are mentioned. Even if the acids, and the small number of bodies which are referred to in connection with their water of crystallization, be eliminated from the above count the great importance of the two elements remains clearly evident.

Only about one fourth of all the compounds mentioned contain neither hydrogen nor oxygen. A very large proportion of these consist of the chlorides, bromides, iodides, sulphides, fluorides, and other similar binary compounds, whose importance certainly does not depend upon the variety of chemical 
reactions into which they may enter, while their formation unquestionably does depend upon the intervention of both hydrogen and oxygen. All told, the chemical substances which contain neither carbon, nor hydrogen, nor oxygen make up only a few per cent of known bodies.

It is also clear that an especially large proportion of the most active inorganic compounds contain either hydrogen or oxygen. All acids contain hydrogen; most of them oxygen as well. All bases contain oxygen. Moreover, the most important classes of reactions of inorganic chemistry are probably oxidations and reductions, and the formation of salts from acids and bases. In such processes both oxygen and hydrogen are concerned.

In addition to the oxides and resulting bases and acids, a few other important substances which contain hydrogen or oxygen may be cited: ozone $\mathrm{O}_{3}$, hydrogen peroxide $\mathrm{H}_{2} \mathrm{O}_{2}$, ammonia $\mathrm{NH}_{3}$, hydrazine $\mathrm{N}_{2} \mathrm{H}_{4}$, hydroxylamine $\mathrm{NH}_{2} \mathrm{OH}$, sulphuretted hydrogen $\mathrm{H}_{2} \mathrm{~S}$, hydrochloric acid $\mathrm{HCl}$, nitrosyl chloride $\mathrm{NOCl}$, thionyl chloride $\mathrm{SOCl}_{2}$, phosgene $\mathrm{COCl}_{2}$, phosphine $\mathrm{PH}_{3}$, phosphorus oxychloride $\mathrm{POCl}_{3}$, arsine $\mathrm{AsH}_{3}$. Such compounds, and many other similar ones, are of great importance on 
account of the variety of chemical processes into which they can enter. They make up the active agents of inorganic chemistry, and it is safe to assume that their activity depends in great part upon the properties of oxygen and hydrogen.

The importance of oxygen and hydrogen in inorganic chemistry possesses a double significance in the present inquiry. In the first place it provides further confirmation of the view that the elements which make up water and carbon dioxide are unique. For the data of inorganic chemistry prove that hydrogen and oxygen are likely to confer great chemical activity wherever they are, and that they are quite unrivaled in this respect. Secondly, the occurrence of hydrogen and oxygen as primary factors of the metabolic process and as the chief constituents of the environment and of the living organism enables the latter to make use of other elements at need. Without hydrogen and oxygen, opportunities for the introduction of such other elements into the physiological processes would be necessarily much restricted, and in many cases the physiological utility of compounds containing the elements of inorganic chemistry is very great.

Chlorophyll, for example, contains mag- 
nesium, and it is thought that the process of reduction in the leaf may depend upon the characteristic properties of this element; at all events, in organic chemistry, magnesium, when employed in Grignard's reaction, is one of the most effective agents to accomplish reductions.

In like manner, hæmoglobin contains iron, and the capacity of hæmoglobin to unite with oxygen, and as oxyhæmoglobin to carry it from the lungs to the tissues is unquestionably due to the chemical behavior of that metal. Other similar metallic elements, notably copper in the class of compounds known as hæmocyanines, fulfill a similar function in lower animals.

Phosphorus in organic union is an essential constituent of a great variety of the chemical structures of living organisms, - the nucleic acids, which appear to be not less important than fats, carbohydrates, and proteids themselves in both animal and plant cells, contain phosphorus as an essential constituent. Thus phosphorus follows close upon nitrogen, after carbon, oxygen, and hydrogen, as structural material in biological chemistry. This same element also occurs in many other compounds, the simplest derivative of such bodies being glycerophosphoric acid, 


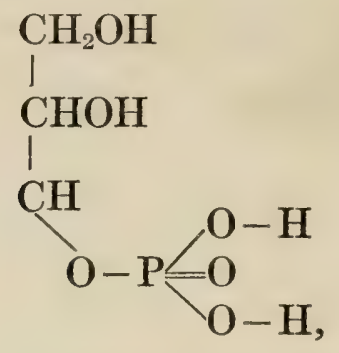

a compound of phosphorus, hydrogen, and oxygen with glycerine.

Sulphur is a constituent of the proteins, and occurs in many other important compounds. In the metabolic process of the animal sulphur is converted from a derivative of hydrogen sulphide, $\mathrm{H}_{2} \mathrm{~S}$, by oxidation, into sulphuric acid, $\mathrm{H}_{2} \mathrm{SO}_{4}$, and in the plant the process is reversed.

Iodine occurs in the thyroid and in many marine organisms. The availability of this element depends upon its existence in nature as iodides, that is to say, upon its capacity to unite with hydrogen to form hydriodic acid, HI. Finally, it is the analogous compound of chlorine with hydrogen, hydrochloric acid, which contributes acidity to the gastric juice.

This list might be much further extended, but I think that the nature of the case is now established. The conclusion seems inevitable 
that active, diverse, and important inorganic substances usually contain oxygen or hydrogen, and that it is the union of other elements with these two which renders them available and useful to the organism.

\section{III}

\section{THERMOCHEMISTRY}

Every chemical change consists in simultaneous rearrangements of matter and energy. The true nature of the chemical process is to be sought neither in the one nor in the other of these two phenomena, but in both together ; and properly energy is as much the chemist's concern as matter itself.

Thus far in the present investigation, considerations regarding energy have been avoided except in the case of hydrolytic cleavages, and these constitute a unique class of reactions. No other large and important class is characterized by inappreciable heat of reaction, for it is as heat that chemical energy commonly manifests itself when liberated. It is evident, however, in accordance with the fundamental postulates, that the organism must have energy to actuate as well as matter to form its mechanism. Therefore the nature of the energy transformations, which make up one 
aspect of the chemical reactions into which carbon, hydrogen, and oxygen enter, must be now noticed.

It has been shown above that the one possible chemical process by means of which anything can be made out of the primary constituents of the environment is reduction, the more or less complete tearing off of oxygen from carbon and hydrogen atoms in the molecules of carbon dioxide and water. As a function of the extent of the reduction the energy change involved in the process will vary. In all cases, however, the process is accompanied by large absorption of heat, as the following table of the energy absorbed per gram of the resulting substance, when reduction begins with water and carbonic acid, may indicate:-

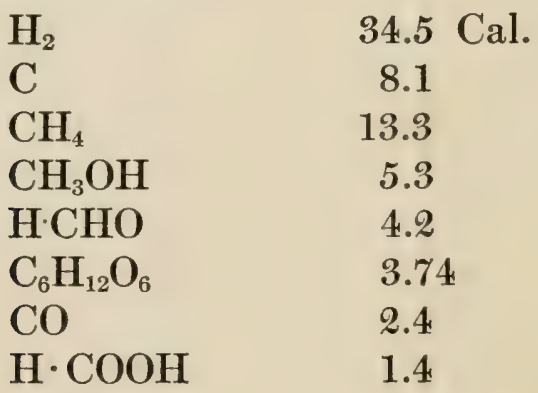

Such new compounds hold their energy only so long as they persist unchanged, and 
upon oxidation they yield it all back again, just as water vapor on condensing yields back the latent heat which it has taken up during evaporation. In this manner, every gram of glucose or other monosaccharide is necessarily a temporary depository of solar cnergy amounting to about 3.74 calories, taking up just that amount of energy when synthesized by chlorophyll, yielding it back when burned in the muscle.

Compounds of carbon and hydrogen are especially well qualified to be reservoirs of energy which may be liberated by oxidation, as the following table shows:-

HEATS OF COMBUSTION OF ELEMENTS PER GRAM

Hydrogen

Carbon

Sulphur (to $\mathrm{SO}_{2}$ )

Sulphur (to $\mathrm{SO}_{3}$ )

Nitrogen (to $\mathrm{NO}_{2}$ )

Phosphorus

Boron

Silicon

Potassium

Calcium

Aluminium
34.5 Cal.

8.1

2.3

3.2

0.2

5.9

12.3

3.3

1.3

3.3

7.0

Hydrogen, it will be seen, far exceeds any other element in the amount of heat that it 
yields upon oxidation; carbon is surpassed by but one other element, boron. Although necessarily a good deal of this heat cannot be stored in the compounds of the two elements which still contain some oxygen, yet enough remains to make the common constituents of the organism greater reservoirs of energy than most of the other elements themselves, far greater than compounds of any other elements. Thus the heat of combustion of carbohydrates ranges from about 3.7 calories to about 4.2 calories per gram, that of the proteins from about 5 calories to about 6 calories, that of the fats from about 9.2 calories to about 9.5 calories. On account of the small quantity of oxygen and the large quantity of hydrogen which they contain, the fats are a richer source of energy than carbon itself, or than any other element except hydrogen and boron.

There remains one other equally important consideration to be dealt with: the very great energy change which is involved in processes of oxidation and reduction compared with other chemical processes. The following table, showing the amount of heat liberated in the process of formation of certain binary compounds from their several elements, illustrates the case:- 
HEATS OF FORMATION

$\begin{array}{lllr}\mathrm{H}_{2} \mathrm{O} & 3.83 \mathrm{Cal} . & \mathrm{CS}_{2} & -0.25 \mathrm{Cal} . \\ \mathrm{CO}_{2} & 2.22 & \mathrm{NaCl} & 1.67 \\ \mathrm{HCl} & 0.60 & \mathrm{LiCl} & 2.20 \\ \mathrm{HF} & 1.97 & \mathrm{NaBr} & 0.87 \\ \mathrm{NH}_{3} & 1.23 & \mathrm{NaF} & 2.64 \\ \mathrm{~S}_{2} \mathrm{Cl}_{2} & 0.08 & \mathrm{Na}_{2} \mathrm{~S} & 1.14 \\ \mathrm{CCl}_{4} & 0.49 & \mathrm{SiH}_{4} & -0.21 \\ \mathrm{PI}_{3} & 0.26 & \mathrm{SiF}_{4} & 2.31 \\ \mathrm{BCl}_{3} & 0.79 & \mathrm{NS} & -0.69\end{array}$

Oxygen, as will be seen, far surpasses the other chemical elements (except fluorine) in the amount of energy liberated in the process of its chemical union with other substances.

Accordingly, it may be concluded that, on the whole, oxidations are the best chemical source of energy; reductions the best means of storing energy by chemical processes; and that among oxidations and reductions those of hydrogen especially, and then those of carbon, are associated with the largest energy transformations.

This is the last argument which I have to present, but it is one of the most potent. The very chemical changes, which for so many other reasons seem to be best fitted to become the processes of physiology, turn out to be the very ones which can divert the greatest 
flood of energy into the stream of life; and these are the reactions automatically provided for by the cosmic process.

From the materialistic and the energetic standpoint alike, carbon, hydrogen, and oxygen, each by itself, and all taken together, possess unique and preëminent chemical fitness for the organic mechanism. They alone are best fitted to form it and to set it in motion; and their stable compounds, water and carbonic acid, which make up the changeless environment, protect and renew it, forever drawing fresh energy from the sunshine. 


\section{CHAPTER VII}

\section{THE ARGUMENT}

TMHE statement of evidence for the bio1 logical fitness of the environment is at length completed. Whatever favorable properties of water, carbonic acid, and the compounds of the three elements, whatever results favorable to life, I have succeeded in finding, have been set forth.

Now, therefore, we may return to the examination of this evidence in the manner suggested in Chapter II. We may inquire into the exhaustiveness of the preceding treatment of important physical properties, seeking to discover what things have been overlooked. Thus it may be possible to decide the weighty question whether another group of elements can possess another group of equally important properties. Next, we may consider if there be other elements or compounds which rival carbon, hydrogen and oxygen, water and carbonic acid, in the qualities which make these fit for the organic mechanism, taking such properties as a whole. Unfortunately, 
in adopting this somewhat rigid logical method, tedious and perhaps unnecessary repetition is involved, but the advantages of care at this stage of the inquiry seem to be very great, for it is not easy to survey so large a field, and at best certainty that important oversights have been avoided is obviously impossible. For example, peculiarities like the anomalous expansion of water, or the relation of carbonic acid and water to the carbohydrates are not to be foreseen. On the other hand, the more general characteristics of matter are well known and, for the most part, must reveal themselves to diligent search.

\section{I}

\section{ANALYSIS OF THE EVIDENCE}

First the natural phenomena which seem to be concerned in fitness may be brought together analytically, and their effect briefly summarized.

NATURAL PHENOMENA WHICH PROMOTE FITNESS IN THE ENVIRONMENT

I. The occurrence of great quantities of water and carbon dioxide outside the solid crust of an astronomical body. 
II. Properties of Water.

a. Specific Heat.

$b$. Freezing Point.

c. Latent Heat of Fusion.

d. Latent Heat of Vaporization.

$e$. Vapor Tension.

f. (Thermal Conductivity.)

g. Expansion before Freezing.

h. (Expansion in Freezing.)

$i$. Solvent Power.

$j$. Dielectric Constant.

$k$. Ionizing Power.

l. Surface Tension.

III. Properties of Carbon Dioxide.

a. Solubility in Water.

b. Ionization Constant.

IV. Properties of the Ocean.

a. Number and Variety of Constituents.

b. Quantity of Dissolved Material.

c. Mobility.

d. Constancy of Temperature.

$e$. Constancy of Osmotic Pressure.

$f$. Constancy of Alkalinity.

g. Constancy of Composition.

V. Chemical Properties of Carbon, Hydrogen, and Oxygen.

a. Number of Compounds.

b. Variety of Compounds.

c. Complexity of Compounds. 
d. Number of Reactions.

$e$. Variety of Reactions.

$f$. Complexity of Reactions.

g. The Evenness and Lack of Energy

Change of the Process of Hydrolytic Cleavage.

$h$. The Chemical Relationship of Carbonic Acid and Water to the Sugars.

$i$. Instability of the Sugars.

j. Variety and Reactions of the Sugars.

$k$. Heats of Reaction in Organic Chemistry.

l. The Number and Variety of Compounds and Reactions of Oxygen with Other Elements.

$m$. The Number and Variety of Compounds and Reactions of Hydrogen with Other Elements.

All the properties or other phenomena noted in the above table (except II $f$, and II $h$ ) are in character or in magnitude either unique or nearly so, and are in their effect favorable to the organism as defined in the fundamental postulates. Indeed, they constitute or bring about an extraordinary set of conditions favorable to life, - ubiquity, abundance, variety, stability, mobility, constancy of composition, and invariance of physico-chemical con- 
ditions in the environment; number, rariety, complexity, adaptability, availability, activity, and richness in energy of the substances which take part in the metabolic processes and in the chemical and phrsical formation of the organism; constancy of physico-chemical conditions, such as temperature, alkalinity, colloidal disperseness, etc., within the organism; the efficiency of many physiological processes; the availability of electrical forces, etc.

In short, by many independent and united actions the above catalogued natural characteristics of the enviromment promote and favor complexity, regulation, and metabolism, the three fundamental characteristics of life upon which all our discussion has been based.

\section{II}

\section{THE ENHAUSTIVENESS OF THE TREATMENT}

One manner of judging the completeness with which different types of phenomena and properties, different elements and compounds, have been considered in the descriptive chapters preceding is to glance at the several departments of physical science, - chemistry, mechanics, heat, sound, light, magnetism, electricity, and physical chemistry. 
In setting out to consider physical and chemical properties we may perhaps begin with chemical phenomena in the narrowest sense. Such phenomena depend, according to the atomic theory, upon rearrangements of atoms within molecules. They result in the conversion of individual substances into one another, and they are accompanied by rearrangements of energy.

In the first place, it is to be noted that enormous quantitics of carbon, hydrogen, and oxygen, as water and carbonic acid, are, during a very long period of time, apparently inevitable constituents of the atmosphere of an astronomical body of sufficient size, after cooling has led to the formation of a crust. Further, it has been shown that in number, variety, complexity of forms and changes, and in the magnitude of the accompanying transformations of energy the known substances made up of carbon and hydrogen, and those made up of carbon, hydrogen, and oxygen far surpass the compounds of any other elements. Likewise the known compounds of oxygen and hydrogen with other elements are the most numerous and important among inorganic substances. Two peculiarities of the carbon compounds, the formation and properties of the carbohydrates, and the nature of the pro- 
cess known as hydrolytic cleavage, add to this list of chemical characteristics which make for fitness.

These facts appear to indicate that in general chemical behavior, in certain special characteristics as well, and in the magnitude of the quantity of energy rendered available by their chemical changes, the elements carbon, hydrogen, and oxygen are uniquely and most highly fitted to be the stuff of which life is formed and of the environment in which it exists.

Mechanics has taken a place subordinate to chemistry in the present work. Nevertheless, it has been noted that the unique properties of water are the cause of the admirable mobility of that substance and of the whole environment, and therefore of the dynamical processes of geology, meteorology, etc., including soil formation; that it is surface tension which holds water in the soil; that the efficacy of water as a means of dissolving the greatest variety of substances in the greatest amounts, makes possible high osmotic pressures, as well as mobility of all the elements; and there are a host of other considerations which have been discussed above. In all such cases the propertics of water have been found to be favorable influences for the wel- 
fare of the organism. Considering the comparative unimportance of mechanics in relation to the fundamental postulates, it seems clear that this department has not been overlooked.

Thermal processes and thermal effects are perhaps more conspicuous in the table. The thermochemical characteristics of organic compounds and the thermal properties of water are all very favorable to life. Stores of heat for the organism, constancy of temperature of both organism and environment, the permanence of bodies of water, and a multitude of other most important results flow from these properties and bear witness to their unique fitness.

Sound, light, and magnetism have not been considered, for they appear to bear only a secondary relation to the fundamental postulates.

In electricity no phenomena are more important than those of ionization in solution. To bring about ionization and thus make possible electrochemical processes, water is the very best medium, and the possibility of such processes is probably necessary to the organic mechanism.

In addition to the topics of physical chemistry already referred to under chemistry 
and the several departments of physics, the colloids and the ions of hydrogen and hydroxyl remain to be mentioned. It has been shown that the properties of water are exceptionally favorable to the existence and stability of colloidal systems; also that the properties of carbonic acid result in automatic regulation of the concentration of hydrogen and hydroxyl ions in the ocean and in the organism.

So far, then, as it is possible to judge by telling over the departments of physical science, our examination of physical and chemical properties has not been incomplete.

This conclusion may be further tested with the help of the ideas which underlie Willard Gibbs's "Phase Rule." 1 According to this rule, the condition of equilibrium in any material system depends upon the number of its components, the number of its phases, temperature, pressure, and, in general, the concentrations of all the components. Without entering upon an explanation of the exact mathematical notions which determine the meaning of the terms "component" and "phase" it will here suffice to say that in general the number of components increases as the number of separate chemical individuals increases,

${ }^{1}$ See, for instance, Findlay, "The Phase Rule and its Applications." London, 1911, 3d ed. 
and that a phase is any solid, liquid, or gaseous part of the whole system which possesses homogeneity of composition. For instance, if a system is made up of sand, salt solution, ice, and aqueous vapor, each of these separate parts, in that it is homogeneous, is a phase.

Now the properties of water have the result that more readily than other substances it exists simultaneously and in large quantities in the three phases of solid, liquid, and gas as ice, water, and aqueous vapor. This depends upon the high latent heats of fusion and vaporization, the high freezing point of water, and its vapor tension. Water enhances the complexity of the environment, and is one principal factor in the mobility of the environment as a whole. Further, it makes for stability; other things being equal, the greater the number of phases, the less the tendency to change. Among phases the disperse colloidal type is unique and of very great importance - almost the sole basis, indeed, of great physical complexity - and, as above shown, the peculiar properties of water highly favor the colloidal condition.

The solvent power of water much increases the number of components which may enter into a system of which it is a part; hence the large number of components of sea water, 
blood plasma, etc. The variety of compounds, both organic and inorganic, which contain carbon, hydrogen, or oxygen also causes enormous increase in the number of components of biological systems like protoplasm.

The effects of the properties of water above enumerated to regulate temperature are almost too numerous to mention. The specific heat of water, its latent heats of fusion and vaporization, and the high freezing point all contribute to the restriction of temperature range within the organism, in the waters, and over the whole surface of the earth. The vapor pressure of water has been shown to possess great and exceptional variability with change of temperature. This is the most important property of water meteorologically, and is the necessary condition for its ample circulation. The ratio between the gas pressure of carbonic acid and its concentration in water (absorption coefficient) has been shown to be the great factor in establishing the mobility of that substance. The total atmospheric pressure has not entered into our discussion, for it seems to have no important special relation to the properties of the three elements.

In short, the properties of water and of the carbon compounds provide for number, va- 
riety, and complexity of phases and components, and for constancy of temperature, while equally important and unique relationships between the properties of water and carbonic acid and their vapor or gas pressures exist, and exert much influence upon the meteorological cycle.

Thus, judged by the phase rule, the actual characteristics of the environment may be shown to contribute the factors which make for complexity and regulation of material systems. Now there can be no doubt that, when feasible, the ideal method - from the physicochemical point of view - to describe a material system is in the terms of the phase rule. $^{1}$ Hence the characteristics which that

1 "Ten years after the law of mass action was propounded by Guldberg and Waage, Willard Gibbs, Professor of Physics in Yale University, showed how, in a perfectly general manner, free from all hypothetical assumptions as to the molecular condition of the participating substances, all cases of equilibrium could be surveyed and grouped into classes, and how similarities in the behavior of apparently different kinds of systems, and differences in apparently similar systems, could be explained.

"As the basis of his theory of equilibria, Gibbs adopted the laws of thermodynamics, a method of treatment which had first been employed by Horstmann. In deducing the law of equilibrium, Gibbs regarded a system as possessing only three independently variable factors - temperature, pressure, and the concentration of the components of the system - and he enunciated the general theorem now usually known as the 
rule contemplates are in certain respects the most important of characteristics. Accordingly the above test is a valuable indication of the adequacy of the preceding analysis of physical and chemical properties.

In order if possible to discover the nature of such properties of matter as may have been omitted in our study of fitness, I have examined the index of Landolt and Börnstein's "Physikalisch-chemischen Tabellen," a very extensive and comprehensive work. In addition to information regarding the arbitrary units of physical science, I find mention of the following properties which have not been considered in the present discussion:-

The Mechanical Equivalent of Heat.

The Dimensions of the Angles of Crystals.

The Refraction of Light.

Compressibility.

The Dimensions of the Molecules of Gases.

Elasticity.

The Electromagnetic Rotation of the Plane of Polarization of Light.

\section{Color.}

Phasc Rule, by which he defined the conditions of equilibrium as a relationship between the number of what are called the phases and the components of the system." - FindLir, "The Phase Rule and its Applications." London, 1911, 3d ed., p. 8. 


\section{Viscosity.}

Torsion.

The Velocity of the Molecules of Gases.

Hardness.

Magnetism.

The Velocity of Light.

Optical Activity.

Friction.

The Velocity of Sound.

The Wave Length of Light.

The Length of the Path of a Gaseous Particle.

To these may be added the phenomena of radioactivity, etc.

It is clear that in the present state of knowledge the consideration of most of these properties is uncalled for. However, it may perhaps be noted in passing that the compressibility of water is remarkably small, that of protoplasm even less. ${ }^{1}$ Hence even great changes in pressure do not readily damage the organism, and, indeed, a frog's muscle appears to function normally after undergoing a pressure of 500 atmospheres. $^{2}$ Further, it is of decided consequence for many reasons that the optical properties of water are such

${ }^{1}$ Henderson and Brink, American Journal of Physiology, XXI, 248, 1908.

${ }^{2}$ Henderson, Leland, and Means, American Journal of Physiology, XXII, 48, 1908. 
that light readily penetrates it to considerable depths. As for color, landscape and modern chemical industry alike testify to the availability of carbon compounds as its source.

A final test of thoroughness may be based upon a consideration of other compounds and elements. Accepting the decision that no other properties can be so important to an active, complex, and regulated mechanism as those possessed nearly or quite as maxima by water, carbonic acid, and the compounds of the three elements, what are the possibilities of obtaining the same characteristics from other substances?

So far as chemical substances are now known, the only compound which can be even considered on this score as a substitute for water in the environment is ammonia, and in many respects, no doubt, ammonia might serve as well. ${ }^{1}$ However, chemical processes

${ }^{1}$ A full discussion of the properties of ammonia which qualify it as a substitute for water in the rôle of solvent and otherwise will be found in the article by E. C. Franklin, "The Ammonia System of Acids, Bases, and Salts," American Chemical Journal, Vol. 47, p. 285, 1919. In this paper the results of a long series of investigations are brought together. Especially important for the present purpose are the introductory remarks. "The many striking analogies between liquid ammonia and water as electrolytic solvents have been emphasized by the writer and his co-workers in papers which have appeared from time to time during the past decade. In 


\section{THE FITNESS OF THE ENVIRONMENT}

being what they are, it is impossible to imagine the presence of vast amounts of ammonia in an atmosphere, while the loss of the greater part of the energy which can be stored by tearing apart hydrogen and oxygen would be a very serious difficulty; but the loss of substantially all the incomparable chemical activity of oxygen is to all appearances an insurmountable obstacle to the substitution of ammonia for water in biological processes.

From time to time, loose discussion has arisen among chemists as to the possibility of substituting another element for carbon in the organic cycle. Such speculations have never been serious, but they have at least

all those properties which give to water its unique position among solvents, such as its abnormally high boiling point, its high specific heat, its high heat of volatilization, its high critical temperature and pressure, its high association constant,-its high dielectric constant, and its low boiling-point elevation constant, its power as an electrolytic solvent, and the facility with which it forms compounds with salts, liquid ammonia shows a remarkable similarity to water."

"While the boiling point of liquid ammonia is $33.46^{\circ}$ below zero, it still appears abnormally high when compared with the boiling temperatures of phosphine, arsine, stibine, methane, ethylene, hydrogen sulphide, hydrochloric acid, etc. The specific heat of liquid ammonia and the heat of fusion of the solid are greater than the corresponding constants for water or any other known substance, while its heat of volatilization, with the one exception of water, is the highest 
demonstrated that very few elements, probably only silicon, and perhaps boron, can even be imagined in such a rôle. It has, moreover, just been shown that there are many facts leading to the conclusion that only carbon among elements, and carbon itself only in conjunction with hydrogen, has the power to form the slieletons of compounds numerous, complex, and varied like those of organic chemistry. But, apart from this conclusion, it is certain that silicon and boron could not be mobilized like carbon. Quartz,

of any known liquid. The critical temperature of ammonia is abnormally high, and its critical pressure - the more characteristic constant - is higher than that of any other liquid excepting water. Ammonia is an associated liquid, and its dielectric constant, though much below that of water, is still high when compared with that of non-electrolytic solvents. Its boiling-point elevation constant is the lowest of any known liquid, namely 3.4 , as compared with 5.2 for water. In its tendency to unite with salts and other compounds, it probably excceds water, since salts with ammonia of crystallization are perhaps even more numerously recorded in the literature than are salts with water of crystallization. As a solvent for salts it is generally much inferior to water, though some salts, for example the iodides and bromides of mercury, lead, and silver, dissolve very much more abundantly in ammonia than they do in water, and it far surpasses the latter solvent in its ability to dissolve the compounds of carbon. Finally it exhibits conspicuous power as an ionizing solvent, the more dilute ammonia solutions at $33.5^{\circ}$ being very much better conductors of electricity than aqueous solutions of the same concentration at $18^{\circ} . "$ 
the oxide of silicon, is the most inert and immobile of rocks ; the oxide of boron is only less available as a movable constituent of the environment; and there is no other stable compound of either element which can be compared with carbonic acid for its mobility. It must be remembered that this property is the result of two independent characteristics of the latter substance, its gaseous nature, and the precise degree of its solubility in water. Finally, the regulation of the reaction of aqueous solutions by means of carbonic acid has to be taken into account.

Hence it may be concluded that hydrogen, oxygen, and carbon, water and carbonic acid, are not to be rivaled in their own qualities, even as these cannot be balanced by others which they do not possess.

On the whole, then, we may believe that the physico-chemical characteristics of material systems and material processes have been comprehensively examined in the course of the present study. Accordingly, we may finally conclude that the fitness of water, carbonic acid, and the three elements make up a unique ensemble of fitness for the organic mechanism. The search, however incomplete, has certainly not overlooked properties so important and so numerous, or compounds and elements so 
unique, as those which have been considered and set forth.

With the assurance that, in such measure as the present state of science permits, our study has been indeed exhaustive, a final argument arises. So far as we can see, all the properties of water, carbonic acid, and the three elements are fit, according to our definition of fitness. There is nothing about these substances that is really and seriously inferior to the same thing in any other substance; and in all the subjects which we have reviewed not a single disability of the primary constituents of the environment has come to light.

\section{III}

\section{SUMMARY}

For the convenience of my readers the argument which has been developed in the course of the preceding pages is here re-stated in outline.

I. Fitness is a mutual or reciprocal relationship between the organism and the environment.

II. Life is a mechanism (from the point of view of physical science). Accordingly it must be- 
a. Complex (physically, chemically, physiologically).

$b$. Durable, hence well regulated physico-chemically. This conclusion applies to -

1. The Organism.

2. The Environment.

c. Endowed with a metabolism. Hence there must be exchange with the environment of -

1. Matter.

2. Energy.

III. The primary constituents of the natural environment are -

a. Water.

b. Carbonic acid.

IV. In places where life is possible the primary constituents of the environment are necessarily and automatically formed in vast amounts by the cosmic process.

V. Water, carbonic acid, and their constituent elements manifest great fitness for their biological rôle.

a. Water possesses a great number of unique or very unusual prop- 
erties, e.g. thermal properties, solvent power, dielectric comstant, surface tension, which together result in maximal fitness in certain respects, c.g. mobility, ubiquity, constancy of temperature and richness of the environment, richness of the organism in chemical constituents, variety of chemical processes, electrical phenomena, colloidal phenomena.

b. Carbon dioxide possesses very unusual properties, e.g. magnitude of absorption coefficient, strength as acid, which together result in maximal fitness in certain respects, e.g. mobility, ubiquity, richness of the environment and organism in other elements and compounds, constancy of reaction, etc.

c. Chemical compounds containing carbon, hydrogen, and oxygen possess unique properties, e.g. number, variety, complexity, activity, variety of chemical 
relations and reactions, heats of reaction, instability, etc., which together result in maximal fitness in certain respects, e.g. as sources of matter and energy for the processes of metabolism, as sources of complex structures, as the means of establishing complex functions, etc.

VI. Oceans are formed automatically in the cosmic process.

VII. The ocean possesses unique properties, e.g. mobility, richness in dissolved substances, durability, and stability of physico-chemical conditions, depending chiefly upon the properties of water and carbonic acid, which together result in maximal fitness in certain respects, e.g. as milieu, and as source of matter for the processes of metabolism, to moderate and equalize temperature, etc.

VIII. The physical and chemical properties which have been taken into consideration include nearly all those which are known to 
be of biological importance or which appear to be related to complexity, regulation, and metabolism.

IX. There are no other compounds which share more than a small part of the qualities of fitness of water and carbonic acid; no other elements which share those of carbon, hydrogen, and oxygen.

$\mathrm{X}$. None of the characteristics of these substances is known to be unfit, or seriously inferior to the same characteristic in any other substance.

XI. Therefore the fitness of the environment is both real and unique.

In drawing this final conclusion I mean to assert the following propositions:

I. The fitness of the environment is one part of a reciprocal relationship of which the fitness of the organism is the other. This relationship is completely and perfectly reciprocal ${ }^{1}$ the one fitness is not less important

${ }^{1}$ This is not to be understood as an assertion that the relationship is symmetrical. The fact is that each organism fits its particular environment, while the environment in its most general and universal characteristies fits the most general and universal characteristics of the organic mechanism. 
than the other, nor less invariably a constituent of a particular case of biological fitness; it is not less frequently evident in the characteristics of water, carbonic acid, and the compounds of carbon, hydrogen, and oxygen than is fitness from adaptation in the characteristics of the organism.

II. The fitness of the environment results from characteristics which constitute a series of maxima - unique or nearly unique properties of water, carbonic acid, the compounds of carbon, hydrogen, and oxygen and the ocean - so numerous, so varied, so nearly complete among all things which are concerned in the problem that together they form certainly the greatest possible fitness. No other environment consisting of primary constituents made up of other known elements, or lacking water and carbonic acid, could possess a like number of fit characteristics or such highly fit characteristics, or in any manner such great fitness to promote complexity, durability, and active metabolism in the organic mechanism which we call life.

It must not be forgotten that the possibility of such conclusions depends upon the universal character of physics and chemistry. Out of the properties of universal matter and the characteristics of universal energy has arisen 
mechanism, as the expression of physicochemical activity and the instrument of physicochemical performance. Given matter, energy, and the resulting necessity that life shall be a mechanism, the conclusion follows that the atmosphere of solid bodies does actually provide the best of all possible environments for life. 


\section{CHAPTER VIII}

\section{LIFE AND THE COSMOS}

I

THE SIGNIFICANCE OF FITNESS

HALF century has passed since Darwin A wrote "The Origin of Species," and once again, but with a new aspect, the relation between life and the environment presents itself as an unexplained phenomenon. The problem is now far different from what it was before, for adaptation has won a secure position among the greatest of natural processes, a position from which we may suppose it is certainly never to be dislodged; and natural selection is its instrument, even if, as many think, not the only one. ${ }^{1}$ Yet natural selec-

${ }^{1}$ Natural selection remains still a vera causa in the origin of species; but the function ascribed to it is practically reversed. It exchanges its former supremacy as the supposed sole determinant among practically indefinite possibilities of structure and function, for the more modest position of simply accelerating, retarding, or terminating the process of otherwise determined change. It furnishes the brake rather than the steam or the rails for the journey of life; or in better 
tion does but mold the organism; the environment it changes only secondarily, without truly altering the primary quality of environmental fitness. This latter component of fitness, antecedent to adaptations, a natural result of the properties of matter and the characteristics of energy in the course of cosmic erolution, is as yet nowise accounted for. It exists, however, and must not be dismissed as gross contingency. The mind balks at such a view. Coincidences so numerous and so remarkable as those which we have met in examining the properties of matter as they are related to life, must be the

metaphor, instead of guiding the ramifications of the tree of life, it would, in Mivarl's excellent phrase, do little more than apply the pruning knife to them. In other words, its functions are mainly those of the third Fate, not the first, of Siva, not of Brahma. - Patrick Geddes and J. Artiuur Thosson, "Evolution." New York, Home University Library, 1911, p. 248.

"But as my conclusions have lately been much misrepresented, and it has been stated that I attribute the modification of species exclusively to natural selection, I may be permitted to remark that in the first edition of this work, and subsequently, I placed in a most conspicuous position namely, at the close of the Introduction - the following words: 'I am convinced that natural selection has been the main but not the exclusive means of modification." Charles Darwin, "The Origin of Species by Means of Natural Selection." New York, reprinted from the Sixth London Edition, The Home Library, pp. 495-496. 
orderly results of law, or else we shall have to turn them over to final causes ${ }^{1}$ and the philosopher.

There is, in truth, not one chance in countless millions of millions that the many unique properties of carbon, hydrogen, and oxygen, and especially of their stable compounds water and carbonic acid, which chiefly make up the atmosphere of a new planet, should simultaneously occur in the three elements otherwise than through the operation of a natural law which somehow connects them together. There is no greater probability that these unique properties should be without due cause uniquely favorable to the organic mechanism. These are no mere accidents; an explanation is to seek. It must be admitted, however, that no explanation is at hand.

For the coincidence of properties itself a rational explanation based upon known laws of nature is perhaps conceivable. Attention has already been called to the interconnection of such properties as latent heat of vaporization, thermal conductivity, molecular volume, the value of the van der Waals constant $a$,

${ }^{1}$ Bacon compared final causes to vestal virgins. "Like them," he says, "they are dedicated to God, and are barren." — "The Advancement of Learning," Book II, p. 142. 
the dielectric constant, and ionizing power. Further, it is of course most probable that numerous other properties are necessarily associated with these; and finally it is not surprising that elements of low atomic weight, which become concentrated in the atmosphere on account of the small specific gravity of their gases, should possess unusual properties, like high specific heat, or if one property leads to another, many unusual properties. Be that as it may, chemical science is still a very long way from accounting for the simultaneous occurrence of the various characteristics of water, especially if we include such things as heat of formation, solvent power, the process of hydrolytic cleavage, the degree of solubility of carbon dioxide, the anomalous expansion on cooling near the freezing point, etc.

There is, in fact, exceedingly little ground for hope that any single explanation of these coincidences can arise from current hypotheses and laws. But if to the coincidence of the unique properties of water we add that of the chemical properties of the three elements, a problem results under which the science of to-day must surely break down. If these taken as a whole are ever to be understood, it will be in the future, when research has pene- 
trated far deeper into the riddle of the properties of matter. Nevertheless an explanation cognate with known laws is conceivable, and in the light of experience it would be folly to think it impossible or even improbable. Such an explanation once attained might, however, avail the biologist little; for a further problem, apparently more difficult, remains. How does it come about that each and all of these many unique properties should be favorable to the organic mechanism, should fit the universe for life? And for the answer to this question existing knowledge provides, I believe, no clew. ${ }^{1}$

Thus regarded, our new form of the old riddle appears twofold, and, on that account, for the present the more unanswerable. There is but one immediate compensation for this complexity; a proof that somehow, beneath adaptations, peculiar and unsuspected relationships exist between the properties of matter and the phenomena of life; that the process of cosmic evolution is indissolubly linked with the fundamental characteristics of the organism; that logically, in some obscure

${ }^{1}$ The great difficulty appears to be that there is here no possibility of interaction. In our solar system, at least, the fitness of the environment far precedes the existence of the living organisms. 
manner, cosmic and biological evolution are one. In short, we appear to be led to the assumption that the genetic or evolutionary processes, both cosmic and biological, when considered in certain aspects, constitute a single orderly development that yields results not merely contingent, but resembling those which in human action we recognize as purposeful. For, undeniably, two things which are related together in a complex manner by reciprocal fitness make up in a very real sense a unit, - something quite different from the two alone, or the sum of the two, or the relationship between the two. ${ }^{1}$ In human affairs such a unit arises only from the effective operation of purpose.

Now it is most clearly evident from the experience of centuries that ordinary teleology is dangerous doctrine in science, and in the past, accidents apart, it has been invariably sterile. $^{2}$ A statement that the legs have been formed for the purpose of locomotion, no doubt possesses scientific validity, if it be properly interpreted. But the real scientific concern is for the bones and muscles, the

1 This appears logically to correspond with the "schöpferische Synthese" of Wundt.

${ }^{2}$ Interesting discussions bearing upon this subject will be found in Pearson's well-known "Grammar of Science." 
tendons and ligaments which are employed in walking, and for the evolutionary process by which they have been adapted to their use. Nevertheless, biological science has not been able to escape the recognition of a natural formative tendency, which Darwin identified as the result of natural selection. And now it appears to be necessary to postulate a like tendency in the evolution of inorganic nature. We have found that the properties of the environment, biologically considered, present the same fitness as the properties of life. In each case the fitness results, at least in part, from an evolutionary process. Through the main lines of later development these are both known, though in both cases we stop short, perhaps far short, of the origins - the origin of life and the origin of the universe if indeed they have ever originated. ${ }^{1}$ Can we then deny that in the one as in the other process there is a tendency, a bent, a direction of flow or development ? ${ }^{2}$ I think not,

${ }^{1}$ It is hardly necessary to point out that the properties of the elements are themselves quite free from variation of any sort.

2 " Alike in the external and the internal worlds, the man of science sees himself in the midst of perpetual changes of which he can discover neither the beginning nor the end. If, tracing back the evolution of things, he allows himself to entertain the hypothesis that the universe once existed in a dif- 
and it seems clear that the facts of physical science call for an explanation of the tendency to fitness of the environment in the same way that formerly the facts of biological science called for an explanation of the tendency to fitness of the organism.

To postulate such a tendency is, however, in itself rather a philosophical than a scientific act, and so, too, must be conjecture regarding the origin of fitness. It is open to any one who may be so minded speculatively to enrich this tendency with characteristics of any sort. He may follow the lead of M. Bergson and call it impetus, with all which that term now implies, or he may turn to natural theology and regard it as proof of supernatural purpose and design, or he may find a model for teleological views in many other quarters. But one thing is certain, no such discussion, be it ever so important to the philosopher or the theologian, can directly contribute to scientific knowledge and comprehension of the underlying phenomena, which are the sole positive and certain knowledge of the subject that

fused form, he finds it utterly impossible to conceive how this came to be so; and equally, if he speculates on the future, he can assign no limit to the grand succession of phenomena ever unfolding themselves before him." - IIERBert Spencer, "First Principles." New York, reprinted from the Fifth London Edition, 1880. The Home Library, p. 57. 
we possess. For these facts an explanation of a different sort would be necessary, something logically resembling natural selection, a natural process acting automatically through the properties of matter and energy, and never overstepping the limits of matter and energy, space and time; neither supernatural nor metaphysical, but purely mechanistic. Lacking any indication of what such an explanation may be, or how it is to be sought, we shall do well to turn to other considerations.

\section{II}

\section{VITALISM}

All the skill of trained biologists, multiplying and refining our knowledge of the forms of life, has even yet not availed to make clear the fundamental ideas of the science. Complexity exists here in the very nature of the case, and here, if at all, the complete subjugation of natural phenomena to physical science may be expected to fail.

In an earlier chapter the painful advance of physics and chemistry into the domain of biology has been sketched, and it was then shown how progress is beset with well-nigh insuperable obstacles. Thus it is that biological thought has never attained to that 
finality which appears, at least by contrast, to characterize the greater body of opinions in physical science.

In particular two extreme views, though often commingled, have continually striven for the mastery. The one of these, purely scientific and wholly positive, declares the phenomena of life to be, while partly unknown, ultimately knowable as manifestations of matter and energy. According to this view life is a mechanism and nothing more, in its positive scientific aspects at least. Without necessarily denying such assertions, the other view sees the unique properties of life to be dependent upon an equally unique force or tendency, operating in or through its physico-chemical organization. Either there is a peculiar vital force; or there is manifest in the organism a peculiar tendency ; or at any rate life patently follows the path into which it was propelled by an original impetus, peculiar to life, unknown in other phenomena. All such views inherently partake of metaphysics, and have, therefore, ever aroused most determined opposition among the more orthodox devotees of science.

Descartes appears to have been the first person to adopt the modern scientific attitude toward life, and from him a very large pro- 
portion of French biologists, as well as those of other nations like Huxley and Du BoisReymond, derive their philosophical views concerning their science. Descartes perceived, apparently the first among the moderns, that the scientific explanation of vital pheıumena must be a physical one, in terms of matter and motion. Far in advance of his time he applied such ideas to the nervous system, thereby establishing the nature of reflex action and invading the very citadel of animism. Outside natural science, however, Descartes was far from being a mechanist. Since the early seventeenth century the conflict between vitalism and mechanism has ranged over the whole field of biology, and its history is most complicated. After Descartes, Lavoisier, by his studies of combustion within and without the body, made the next very important step. He was then followed by Liebig, Wöhler, and a host of later chemists.

In the main the growth of exact science has steadily delivered over one vitalistic stronghold after another to the mechanists. And though in the first flush of triumph mechanism has sometimes seemed to gain more in a particular engagement than later proved to be the case, vitalism has perhaps not had a 
positive success in three centuries. Such a history no doubt depends upon the very nature of the situation; upon the inherent and inevitable weakness, within the domain of science, of vitalistic views.

Experience seems to show that the only kind of hypothesis which can find conclusive ientific support, or sound basis in the phenomena of matter and energy, is a mechanistic hypothesis. Exact and positive knowledge can demonstrate scientifically the truth of no other hypothesis with the finality which characterizes its proof of a mechanistic theory. Hence, so far as it ventures into the field of science at all, a vitalistic theory, when attacked by science, cannot effectually avail itself of the weapons of the assailant, and can never make a powerful counter attack. Its only method consists in a determined resistance, yielding little by little before the advance of positive knowledge and never gaining new territory, nor, except by accident, regaining what it has lost. Where this process is to end; in what respect and how far life is destined ever to remain a scientific riddle, can only be surmised.

The chief definitive triumphs of the mechanistic view are two: the elimination of vital force and of a belief in peculiarity of chemical 
composition from organic chemistry, through the actual successes of the laboratory in new syntheses; and the final recognition, based upon understanding of the principle of the conservation of energy, that, whatever else "vital force" may be, it is certainly not force, - a form of energy. Thus limited, vitalism has been obliged to take refuge in a more restricted belief; namely, that the organism is somehow governed by a directive tendency which, like an architect, presides over its development; but that meanwhile the manifold processes of life and evolution go on within the world of physical science just as the work of the builder conforms to the laws of mechanics, though following the plan of the architect.

This view has been well stated by another great Frenchman, Claude Bernard: "Life is the directive idea or evolutive force of the being; . . . but it would be an error to believe that this metaphysical force operates after the manner of a physical force. ... The metaphysical evolutive force by which we may characterize life is useless to science, because, existing apart from physical forces, it can exercise no influence upon them. Hence we must here separate the world of metaphysics from the world of positive phenomena 
which serves it as foundation, but which has nothing to contribute to it. . . . Summarizing, if we can define life with the help of a special metaphysical conception, it is none the less true that mechanical, physical, and chemical forces are the sole effective agents of the living organism, and that the physiologist has to take account of their action alone. We shall say with Descartes, 'One thinks metaphysically, but one lives and acts physically.", 1

Thus restricted, vitalism can apply only to formative processes and the like, though the vitalist still sees in the state of the organism

1 “Claude Bernard, 'La Science Expérimentale,' 3me ed., p. 211: 'La vie est l'idée directrice ou la force évolutive de l'être; . . . mais l'erreur serait de croire que cette force métaphysique est active à la façon d'une force physique. . . . La force métaphysique évolutive par laquelle nous pouvons caractériser la vie est inutile à la science, parce qu'étant en dehors des forces physiques elle ne peut exercer aucune influence sur elles. Il faut donc ici séparer le monde métaphysique du monde physique phénoménal qui lui sert de base, mais qui n'a rien à lui emprunter. . . . En résumé, si nous pouvons definir la vie à l'aide d'une conception métaphysique spéciale, il n'en reste pas moins vrai que les forces mécaniques, physiques, et chimiques, sont seules les agents effectifs de l'organisme vivant et que le physiologiste ne peut avoir à tenir compte que de leur action. Nous dirons avec Descartes: on pense métaphysiquement, mais on vit et on agit physiquement.," - MERz, "A History of European Thought in the Nineteenth Century." Edinburgh and London, 1903, Vol. II, pp. 379-380. 
effects of vitalistic control of its evolution, just as we perceive in a house not only the material structure, but the idea of the architect. Further, the origin of life itself remains shrouded in mystery. Meanwhile, for most men physiology has become merely biophysics and biochemistry, and mechanism is undoubtedly firmly established throughout every department of the science.

Such limitations of the vitalistic hypothesis, damaging though they may be, do not destroy its claim to consideration as a controlling factor of the processes of evolution, embryology, repair, etc., in spite of the fact that even here it has suffered serious though less complete reverses. In 1859 Darwin's natural selection offered itself as a possible substitute for vitalism in a part or the whole of this field, and soon gained very general acceptance. The survival of the fittest has now become in the judgment of all biologists an unquestioned force in the molding of life. Therefore, at best, but a restricted scope within its restricted field remains to vitalism.

From the earliest days of the new hypothesis it has been widely recognized that to accept the survival of the fittest as one factor in the adaptation of life to its environment is quite 
a different matter from proving it to be the only force which directs evolution. An early eulogy by Du Bois-Reymond upon the work of Darwin clearly discloses the nature of the situation: "Here is the knot, here the great difficulty that tortures the intellect which would understand the world. Whocver does not place all activity wholesale under the sway of Epicurean chance, whoever gives only his little finger to teleology, will inevitably arrive at Paley's discarded 'Natural Theology,' and so much the more necessarily, the more clearly he thinks and the more independent his judgment . . . the physiologist may define his science as a doctrine of the changes which take place in organisms from internal causes. .. No sooner has he, so to speak, turned his back on himself than he discovers himself talking again of functions, performances, actions, and purposes of the organs. The possibility, ever so distant, of banishing from nature its seeming purpose, and putting a blind necessity everywhere in the place of final causes, appears, therefore, as one of the greatest advances in the world of thought, from which a new era will be dated in the treatment of these problems. To have somewhat eased the torture of the intellect which ponders over the world-problem will, as long 
as philosophical naturalists exist, be Charles Darwin's greatest title to glory." 1

Recently the work of de Vries, "The Mutation Theory," has at length set forth a number of trustworthy observations of the origin of species in plants with which natural selection, in the restricted original sense at least, can have nothing to do. The origin of species by mutation consists in a sudden discontinuous variation, and selection, therefore, has no opportunity to operate upon a series of numerous minute variations which themselves display no tendency of any sort whatever, in the manner demanded by the Darwinian hypothesis. ${ }^{2}$ Hence it appears certain that natural selection cannot be regarded as completely master of the situation; apart from the origin of life there remains a lacuna in biology which for the present no existing mechanistic hypothesis can fill.

Moreover, among other things, the ordinary processes of regeneration and repair have frequently been brought forward with some success as purposeful activities inexplicable

${ }^{1}$ Du Bois-Reymond, "Darwin versus Galiani," "Reden," Vol. I, p. 211. Quoted from Merz, "History of European Thought in the Nineteenth Century," Vol. II, p. 435. To the same source I am indebted for several other quotations.

${ }^{2}$ Hugo de Vries, "The Mutation Theory." Chicago, 2 vols., 1909, 1910 (trans. Farmer and Darbishire). 
by natural selection. ${ }^{1}$ Thus $\mathrm{Du}$ Bois-Reymond: "One of the greatest difficulties presents itself in physiology in the so-called regenerative power, and - what is allied to it - the natural power of healing; this may now be seen in the healing of wounds, in the delimitation and compensation of morbid processes, or, at the farthest end of the series, in the re-formation of an entire fresh-water polyp out of one of the two halves into which it had been divided. This artifice could surely not have been learned by natural selection, and here it appears impossible to avoid the assump-

1 "Still less explicable in any way thus far proposed are certain remedial actions seen in animals. An example of them was furnished in $\S 67$, where 'false joints' were described - joints formed at places where the ends of a broken bone, failing to unite, remain movable one upon the other. According to the character of the habitual motions there results a rudely formed hinge-joint or a ball-and-socket joint, either having the various constituent parts - periosteum, fibrous tissue, capsule, ligaments. Now Darwin's hypothesis, contemplating only normal structures, fails to account for this formation of an abnormal structure. Neither can we ascribe this local development to determinants: there were no appropriate ones in the germ-plasm, since no such structure was provided for. Nor does the hypothesis of physiological units, as presented in preceding chapters, yield an interpretation. These could have no other tendency than to restore the normal form of the limb, and might be expected to oppose the genesis of these new parts." - HERBERT Spencer, "The Principles of Biology," Vol. I. New York and London, 1909, revised and enlarged edition, p. 36. 
tion of formative laws acting for a purpose. They do not become more intelligible by the fact that the regeneration of mutilated crystals, observed by Pasteur and others, points to similar processes in inanimate nature. Also the ability of organisms to perfect themselves by exercise has not found sufficient appreciation with regard to natural selection." 1

To sum up, it appears certain that at least in a few instances, and possibly quite generally, purposeful tendencies exist in the organism which seem to be inexplicable by natural selection or any other existing mechanistic hypothesis. It is not too much to hope that a scientific explanation of these phenomena in whole or in part may some day be found; but meantime they constitute the natural subject of vitalistic speculation. A field remains, though limited, where the physical scientist cannot yet successfully subdue the vitalist, however strong his conviction of the errors of vitalism. ${ }^{2}$

${ }^{1}$ Du Bois-Reymond, "Reden,” Vol. I, p. 226.

${ }^{2}$ The indeterminism which is based uniquely upon belief in freedom of the will appears to be foreign to the present discussion. It is, accordingly, entirely disregarded in the following considerations. Hence the conclusions of the present inquiry are not to be taken as cognate with such metaphysical hypotheses as the indeterminism of Kant and Lotze. 
Vitalism therefore flourishes, as the recent remarkable works of Driesch and Bergson testify. Of these two authors the former is concerned to prove that pure mechanism is insufficient in biology, and that to mechanism must be added his entelechies; ${ }^{1}$ the latter has gone beyond the vitalism of earlier authors, to give his own view of his speculations, and introduced the idea of the vital impetus.

\section{A}

\section{THE VITALISM OF BERGSON}

Upon analysis the theory of Bergson amounts to this, that there is an original creative impetus impelled upon life which, at all events in the main, is responsible for the course that organic evolution has taken. To quote his own words: "So we come back, by a somewhat roundabout way, to the idea we started from, that of an original impetus of life, passing from one generation of germs to the following generation of germs through the developed organisms which bridge the interval between the generations. This impetus, sustained right along the lines of evolution among which it gets divided, is the fundamental cause of variations, at least

${ }^{1}$ Driesch, "The Science and Philosophy of the Organism." London, 1907 and 1908, two volumes. 
of those that are regularly passed on, that accumulate and create new species. In general, when species have begun to diverge from a common stock, they accentuate their divergence as they progress in their evolution. Yet, in certain definite points, they may evolve identically; in fact, they must do so if the hypothesis of a common impetus be accepted. This is just what we shall have to show now in a more precise way, by the same example we have chosen, the formation of the eye in molluscs and vetebrates. The idea of an 'original impetus,' moreover, will thus be made clearer." 1 . . . "If life realizes a plan, it ought to manifest a greater harmony the further it advances, just as the house shows better and better the idea of the architect as stone is set upon stone. If, on the contrary, the unity of life is to be found solely in the impetus that pushes it along the road of time, the harmony is not in front, but behind. The unity is derived from a vis à tergo: it is given at the start as an impulsion, not placed at the end as an attraction. In communicating itself, the impetus splits up more and more. Life, in proportion to its progress, is scattered in manifestations which un-

${ }^{1}$ Bergson, "Creative Evolution," translated by Mitchell. New York, 1911, pp. 87, 88. 
doubtedly owe to their common origin the fact that they are complementary to each other in certain aspects, but which are none the less mutually incompatible and antagonistic." 1

The contention of Bergson may be divided into two parts: a statement of belief in an original impetus, and his biological arguments in favor of such a view. The former, in so far as it is a question exclusively of an original impetus, appears to lic outside the scope of science, in company with speculations upon the origin of the universe; the latter, because it deals with the subject-matter of science, is open to scientific criticism, and from the standpoint of the biologist is certainly far from conclusive. ${ }^{2}$

Bergson's hypothesis is, however, in essence not less vitalistic than that of Driesch. Both philosophers assume the existence of a special vital characteristic, and explain the course which evolution has taken as a result of it. In short, modern vitalism consists in postulating a directive tendency which manifests itself in or through the organism alone, and is peculiar to life.

${ }^{1}$ Ibid., p. 103.

${ }^{2}$ In fact, until the mechanistic operation of Bergson's impetus can be clearly perceived, it must remain scientifically an unsound hypothesis. 
In such speculations the properties of matter and the process of cosmic evolution have no place. ${ }^{1}$ Bergson, indeed, very definitely, and it would seem gratuitously, puts aside cosmic evolution and also, with certain slight reservations, the properties of matter as of no essential consequence in organic evolution; e.g. "This twofold result has been obtained in a particular way on our planet. But it might have been obtained by entirely different means. It was not necessary that life should fix its choice mainly upon the carbon of carbonic acid. What was essential for it was to store solar energy; but, instead of asking the sun to separate, for instance, atoms of oxygen and carbon, it might (theoretically at least, and, apart from practical difficulties

${ }^{1}$ Driesch, to be sure, has considered the problem of universal teleology, but unsuccessfully and with obvious vitalistic preconceptions such as individuality. His nearest approach to the thesis of the present work is to be found in the following lines: "I do not hesitate to confess that, apart from historical teleology relating to the sequence of one state of politics or economy upon another, and apart from phylogeny, there seems to me to be a certain sound foundation in the concept of the general harmony between organic and inorganic nature, a something which seems to show that nature is nature for a certain purpose. But I confess at the same time that I am absolutely unable to consider this purpose in any other than a purely anthropomorphic manner." - L.c., Vol. II, pp. 348-349. 
possibly insurmountable) have put forth other chemical elements, which would then have had to be associated or dissociated by entirely different physical means. And if the element characteristic of the substances that supply energy to the organism had been other than carbon, the element characteristic of the plastic substances would probably have been other than nitrogen, and the chemistry of living bodies would then have been radically different from what it is. The result would have been living forms without any analogy to those we know, whose anatomy would have been different, whose physiology also would have been different. Alone, the sensori-motor function would have been preserved, if not its mechanism, at least in its effects. It is therefore probable that life goes on in other planets, in other solar systems also, under forms of which we have no idea, in physical conditions to which it seems to us, from the point of view of our physiology, to be absolutely opposed. If its essential aim is to catch up usable energy in order to expend it in explosive actions, it probably chooses, in each solar system and on each planet, as it does on the earth, the fittest means to get this result in the circumstances with which it is confronted. That is at least what reasoning 
by analogy leads to, and we use analogy the wrong way when we declare life to be impossible wherever the circumstances with which it is confronted are other than those on the earth. The truth is that life is possible wherever energy descends the incline indicated by Carnot's law and where a cause of inverse direction can retard the descent - that is to say, probably, in all the worlds suspended from all the stars. We go further : it is not even necessary that life should be concentrated and determined in organisms properly so called, that is, in definite bodies presenting to the flow of energy ready-made though elastic canals. It can be conceived (although it can hardly be imagined) that energy might be saved up, and then expended on varying lines running across a matter not yet solidified. Every essential of life would still be there, since there would still be slow accumulation of energy and sudden release." 1

\section{$B$}

VITALISM AND TELEOLOGY

These conclusions appear to be based upon decisions regarding the essential physico-chemical conditions and characteristics of life arbi-

${ }^{1}$ Bergson, l.c., pp. 255, 256. 
trarily reached in accordance with preconceived views, and quite without scientific justification. There is certainly no reason to ascribe greater importance to energy than to matter in the vital processes, and in the light of the facts with which the preceding chapters are concerned, such views seem absurd. Indeed, whoever is disposed to speculate about biological fitness - and not even the incomparable finesse of M. Bergson's dialectic can make fitness other than the most general result of the process of organic evolution - must now weigh well the cosmic processes. For, if allowance be made for the results of natural selection in the organic world, fitness of the environment has the greater claim to be considered.

The two fitnesses are complementary; are they then single or dual in origin? The simple view would be to imagine one common impetus operating upon all matter, inorganic and organic, through all stages of its evolution, in all its states and forms, and leading to worlds like our own through paths apparently purposeful and really not yet explained. Such, it seems to me, is the natural hypothesis for the vitalist to adopt. But then vitalism vanishes, only telcology remains; for the unique characteristic of life is gone. Yet, 
putting aside mechanistic differences, is it not now lost in any case? Has not modern vitalism in accepting the limitation to entelechies or impetus destroyed itself?

The situation, briefly, seems to be as follows: two evolutionary processes independently result in two complementary fitnesses; hence they are related. In the one process the origin of fitness is in part explained by a mechanistic hypothesis. Nevertheless, many philosophers, as is their right, declare that in this process a further extraphysical influence is to be assumed. But any one who makes such an assumption for the one process must certainly now make it for the other; thus he will be led to see impetus or entelechies everywhere. Under these circumstances it may be doubted if his acquaintance with the nature of his impetus or entelechies is so intimate that he will be able to distinguish the inorganic from the organic, for he has surrendered to science all the positive physico-chemical differences between organic and inorganic bodies and processes. Hence, unless he is to make an arbitrary and unintelligible distinction, or to indulge in the spinning of cobwebs, his vitalism has ceased to be exclusively organic, in short has ceased to be vitalism at all, and has become mere universal teleology. 


\section{III}

\section{COSMIC EVOLUTION}

But, for the scientist, these are matters of little moment. He, at least, is not obliged to take any stand concerning them. This could hardly be better illustrated than by our new facts themselves. For it seems to be clear that where science is most self-sufficient, at the very basis of physical science itself, if anywhere, teleology is at work. Yet it is certain that physical science needs no teleology to explain its phenomena and processes. These are mechanisms, and since the publication of Newton's "Principia" no one has seriously doubted the fact. ${ }^{1}$

To-day there is as little room for doubt that a complete description of cosmic evolution in terms of matter and energy is possible; for it is sound scientific doctrine that what exists in the finished solar system depends upon what already existed in the nebula. The forms and states and quantities of matter and energy in the nebula determine the resulting solar system. Further, since both nebulæe and solar systems are common oc-

${ }^{1}$ Laplace's reply to a question of Napoleon's, "Why the name of God did not occur in his 'Mécanique celeste," will be recalled: "Sire, je n'ai pas besoin de cet hypothèse." 
currences, it is evident that nebulæ themselves are in a general way determined by other antecedent conditions and phenomena,

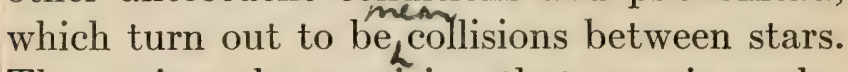
Thus arises the suspicion that cosmic evolution may be in truth a cyclic process which had no beginning and can have no end. ${ }^{1}$

An alternative hypothesis regards the pres-

${ }^{1}$ Such a view, until quite recently, was universally rejected because it appeared to conflict with the second law of thermodynamics, - that of the degradation of energy. But lately it has been put forth by no less an authority than Arrhenius, who has advanced a theory to explain away the difficulty of the second law.

"The recognition of the indestructibility of energy seemed to accentuate the difficulties of the cosmogonic problems. The theses of Mayer and of Helmholtz, on the manner in which the Sun replenished its losses of heat, have had to be abandoned. My explanation is based upon chemical reactions in the interior of the Sun in accordance with the second law of thermodynamics. The theory of the 'degradation' of energy appeared to introduce a still greater difficulty. That theory seems to lead to the inevitable conclusion that the Universe is tending towards the state which Clausius has designated as 'Würme Tod' (heat death), when all the energy of the Universe will be uniformly distributed through space in the shape of movements of the smallest particles. That would imply an absolutely inconceivable end of the development of the Universe. The way out of this difficulty which I propose comes to this: the energy is 'degraded' in bodies which are in the solar state, and the energy is 'elevated,' raised to a higher level, in bodies which are in the nebular state." - Arrhenius, "Worlds in the Making," translated by Borns. New York and London, 1908, p. xiii. 
ent form of our universe as the result of a gradual evolution from an earlicr unknown form, the development of successive solar systems being mere incidents of the larger process, the evolution as a whole directively governed by the law of the degradation of energy.

\section{A}

\section{THE PERIODIC SYSTEM}

In either hypothesis the remarkable systematic relationship between the elements which is manifest in the periodic classification has a peculiar place. If the second hypothesis be accepted, there seems to be little room for doubt that at an early period the chief cosmic process was the evolution of the elements themselves; and in the first theory the nebula, whose properties depend almost wholly upon chemical constitution and chemical and molecular energy, occupies a unique position, like the leaf in the organic cycle, or spring among the seasons. Thus, whether or not the periodic system is to be regarded as the one remaining plain result of a process by which the elements were evolved, at least it takes precedence over the other properties of matter, and lies at the very foundation of the known processes of evolution. Clearly, 
no one can doubt that upon the properties of matter as determined by the periodic system, and upon the relative amounts of the different elements, the actual process of cosmic evolution from nebula to solar system is dependent. ${ }^{1}$

Hence, in accordance with the general method of science, we must assume that the origin of environmental fitness lies at least as far back as the phenomena of the periodic system, at least as far back as the evolution of the elements, if they were ever evolved. We simply cannot doubt that the origin of a body like the earth depends exclusively upon chance plus the properties of the elements, their relative amounts, the indestructible forces of nature, and the other known factors of mechanism. The perfect induction of physical science, based upon each and all of its countless successes in every department of physics and chemistry, conclusively proves that the whole process of cosmic evolution from its earliest conceivable state to the present is pure mechanism. ${ }^{2}$

1 The same considerations apply to any other scientific hypothesis of the genesis of the solar system.

${ }^{2}$ Not only is this proved by all experience of physical science, it has also ever been the necessary working hypothesis of physicists and chemists. 


\section{TELEOLOGY}

If, then, cosmic evolution be pure mechanism and yet issue in fitness, why not organic evolution as well? Mechanism is enough in physical science, which no less than biological science appears to manifest teleology; it must therefore suffice in biology.

Thus once more we arrive at the negation of vitalism. For this conclusion we possess two arguments: the argument that in such aspects as concern physical science, and apart from differences scientifically explicable, organic and inorganic phenomena are alike, and therefore a specifically vital teleology is unnecessary; and the argument that inorganic science unquestionably has no need of nonmechanistic teleology. Hence we are obliged to conclude that all metaphysical teleology is to be banished from the whole domain of natural science. ${ }^{1}$

What then becomes of fitness? Clearly there are two logical possibilities. Either there exists an unknown mechanistic explanation of that common issue of the organic and cosmic

${ }^{1}$ Such at least is the simplest provisional hypothesis, and the only view which involves no gratuitous assumptions. It is therefore the one which must now be adopted. 
evolutionary processes, or there does not. If such an explanation be possible, at least it must be admitted that it is very hard to conceive. Yet, recalling the difficulty before the idea of natural selection arose of imagining any mechanistic explanation whatever of fitness, we shall do well not to decide against such a possibility.

On the other hand, it is conceivable that a tendency could work parallel with mechanism without interfering with it, according to a view which has been held by such thoroughgoing mechanists as Descartes, Claude Bernard, Virchow, DuBois-Reymond, and many another. Although I have no intention of here seeking a choice between these two hypotheses, being in fact convinced that now, at all events, no choice is scientifically possible, and doubting if properly speaking they are alternatives at all, ${ }^{1}$ I do feel concerned to

1 "Either the multitudinous kinds of organisms which now exist, and the far more multitudinous kinds which have existed during past geologic eras have been from time to time separately made, or they have arisen by insensible steps, through actions such as we see habitually going on. Both hypotheses imply a Cause. The last, certainly as much as the first, recognizes this Cause as inscrutable. The point at issue is, how this inscrutable Cause has worked in the production of living forms. This point, if it is to be decided at all, is to be decided only by examination of evidence. Let us inquire which of these antagonistic hypotheses is most congruous 
remove from the latter view, if I may, some of the objections which are commonly raised against it in scientific circles, conscious that in this attempt I am overstepping the boundaries of natural science.

It is evident that a perfect mechanistic description of the building of a house may be conceived. Within the world of physical science the whole process is logically complete without consideration of the architect's design and purpose. Yet such design and purpose, whether or not in themselves of mechanistic origin, are at one and the same time determining factors in the result, and nowise components of the physical process. Now it seems clear that a similar effect of a tendency working steadily through the whole process of evolution is also at least conceiveable, however small its bearing upon science, provided, like time itself, it be a perfectly independent variable, making up, therefore, with time the constant environment, so to speak, of the evolutionary process. The tendency must not be demonstrable either by weighing or by measuring, else it would amount to an interference within the mech-

with established facts." - Herbert Spencer, "The Principles of Biology." New York and London, 1909, Vol. I, revised and enlarged edition, p. 416. 


\section{THE FITNESS OF THE ENVIRONMENT}

anistic process, and it must not be itself liable to any kind of variation whose detection would directly reveal it. Where then can the origin of such a tendency be located? Why clearly, if we accept the induction in favor of mechanism, only where Bergson has shrewdly placed his vital impetus, at the very origin of things, just before mechanism begins to act. In short, our new teleology cannot have originated in or through mechanism, but it is a necessary and preëstablished associate of mechanism. Matter and energy have an original property, assuredly not by chance, which organizes the universe in space and time.

This is in very truth a metaphysical doctrine; but it has strong claims to sympathetic regard from men of science. In the first place, it leaves mechanism with the perfectly free hand which that process has undoubtedly earned in the world of phenomena. Secondly, it does but add one further riddle, and that an old and familiar one, to those two already tacitly recognized by most scientists: the existence of the universe and the existence of life. Given the universe, life, and the tendency, mechanism is inductively proved sufficient to account for all phenomena. The existence of the universe, on the other 
hand, is no concern of the scientist. Whatever clse it may achicve, mechanism can never explain, cannot eren face the problem of the existence of matter and energy. Within the world of science these are conserved; only outside that rorld can they have originated or not originated. As for the existence of life, in spite of our utter ignorance, it must be admitted that a half century has greatly diminished the number of substantial biologists who really look forward to its scientific explanation, and the greatest chemists have ever shared such a view. Liebig is reported by Lord Kelvin to have replied to the question whether he believed that a leaf or a flower could be formed or could grow by chemical forces, "I would more readily belicve that a book on chemistry or on botany could grow out of dead matter." 1 Darwin, too, once said, "It is mere rubbish thinking at present of the origin of life; one might as well think of the origin of matter." 2 Since Licbig's day the chemical organization of the cell has become in scientific knowledge vastly more complex than it was before, and I know of no biological chemist to whom the spontaneous,

${ }^{1}$ Lord Kelvin, “On the Dissipation of Energy," Popular Lectures, Vol. III, p. 464.

${ }^{2}$ Merz, Vol. II, p. 406. 
that is to say, the mechanistic, origin of a cell is scientifically imaginable, ${ }^{1}$ though all believe that once formed, cells exist as mechanisms in a mechanistic universe. ${ }^{2}$ Thus the chemist puts his mind at rest regarding the existence of life, just as the physicist calms his regarding the existence of matter, simply by turning his back on the problem. Thereby he suffers nothing in his practical task as a man of science.

Returning now to fitness, we may be sure that, whatever successes science shall in future celebrate within the domain of teleology, the philosopher will never cease to perceive the wonder of a universe which moves onward from chaos to very perfect harmonies, and, quite apart from any possible mechanistic

${ }^{1}$ This is not to express an opinion concerning the problem of abiogenesis; all admit that we cannot disprove such a theory. But while biophysicists like Professor Schäfer follow Spencer in assuming a gradual evolution of the organic from the inorganic, biochemists are more than ever unable to perceive how such a process is possible, and without taking any final stand prefer to let the riddle rest. But if life has originated by an evolutionary process from dead matter, that is surely the crowning and most wonderful instance of teleology in the whole universe.

${ }^{2}$ See, for instance, F. Hofmeister, "Die Chemische Organisation der Zelle," Vieweg, Brunswick, 1901, and Alsberg, “Mechanisms of Cell Activity," Science, pp. 97-105, July 28, 1911. 
explanation of origin and fulfilment, to feel it a worthy subject of reflection. From this point of view, however, science need expect no interference, but without any last vestige of former shackles may pursue the search after mechanistic explanations of all natural phenomena. ${ }^{1}$

At length we have reached the conclusion which I was concerned to establish. Science has finally put the old teleology to death. Its disembodied spirit, freed from vitalism and all material ties, immortal, alone lives on, and from such a ghost science has nothing to fear. The man of science is not even obliged to have an opinion concerning its reality, for it dwells in another world where he as scientist can never enter.

1 "An evolution is a series of events that in itself as series is purely physical, - a set of. necessary occurrences in the world of space and time. An egg develops into a chick; a poet grows up from infancy; a nation emerges from barbarism; a planet condenses from the fluid state, and develops the life that for millions of years makes it so wondrous a place. Look upon all these things descriptively, and you shall see nothing but matter moving instant after instant, each containing in its full description the necessity of passing over into the next. Nowhere will there be, for descriptive science, any genuine novelty or any discontinuity admissible. But look at the whole appreciatively, historically, synthetically, as a musician listens to a symphony, as a spectator watches a drama. Now you shall seem to have seen, in phenomenal form, a story." - Royce, "The Spirit of Modern Philosophy." Boston and New York, 1896, 8th ed., p. 425. 
I cannot hope to have provided more than a very imperfect illumination of certain aspects of teleology in this venture upon the foreign field of metaphysics, and I should wish to be understood as very doubtful of my success in stating what seem to me some of the philosophical conclusions to be drawn from the fitness of the environment.

There is, howerer, one scientific conclusion which I wish to put forward as a positive and, I trust, fruitful outcome of the present investigation. The properties of matter and the course of cosmic evolution are now seen to be intimately related to the structure of the living being and to its activities; they become, therefore, far more important in biology than has been previously suspected. For the whole evolutionary process, both cosmic and organic, is one, and the biologist may now rightly regard the universe in its very essence as biocentric. 


\section{INDEX}

Absorption coefficient, 136-138. tables, 137.

Acetylene, 200.

Acidity, 140, 142, 143.

Acids, 144, 157, 212, 213, 216, 217.

Adaptation, 5, 36, 66, 156, 274.

Adsorption, 128, 129, 130.

Air, 135.

tables, 135.

Alcohols, 212.

Algol, 46, 47.

Alkalinity, 142, 143, 155, 167-170, 188.

blood, 155-159.

sea water, 167-170.

table, 169.

Ammonia, 66, 110, 263, 264.

Analysis of evidence, 250-253.

Animism, 284.

Astronomy, 38-49.

Asymmetric carbon atom, 223.

Atlantic, 167, 168.

Atmosphere, 55-60, 134, 135. tables, 135.

Atomic volume, 10, 11. . curve, 11.

Atomic weights, 14.

Avogadro's Hypothesis, 177.

Balanced solutions, 175.

Baltic, 168.

Bicarbonates in blood, 157.

Biocentric point of view, 110 , 312.

Biological chemistry, 193.

Black Sea, 168, 169.

Blood, 115, 116, 153, 155-158, 161.

alkalinity, 155-158, 187.

serum, 116.

tables, 116, 187.

Boron, 265.
Bosphorus, 168.

Bottom water, 166.

Boyle's Law, 177.

Bromine, 209.

Calcium carbonate, 172, 173.

Calorie, 81.

Cane sugar, 159.

Capillary action, 78, 126, 127.

Carbohydrates, 218, 222-232.

complexity of reactions, 229 .

instability, 223-226.

mutarotation, 223.

photosynthesis, 227-229.

Carbon, 55, 56, 64, 211, 245.

constituent of environment, 64 .

in stars, 55,56 .

source of energy, 245.

unique chemical properties, 211.

Carbon chains, 210.

Carbon compounds, 66, 193, 194, 245.

Carbon dioxide, Chapter IV $(133-163), 56,61,62,63$, $64,65,66$.

absorption coefficient, 136-140.

acidity, 140-163.

atmospheric, 134, 135.

distribution, 138, 139.

excretion, 139, 140.

in sea water, 170.

metabolism, 132, 133.

necessary component of atmosphere, $56,61,62$.

regulates neutrality, 147 .

solubility, 136-140.

Carbonic acid, see Carbon dioxide.

Celestial mechanics, 153.

Characteristies of life, 30-35. incompleteness of, 34 .

Chemical properties, 206, 207, 209-222, 254, 255. 
Chemistry, Chapter VI (191-248). inorganic, 237-243. organic, 191-237.

Chlorine, 209, 242.

Chlorophyll, 230, 240, 241.

Circulation of water, $91,180-182$.

Classification of organic com-

Climate, 87. pounds, 212 .

table, 87.

Coagulation, 90.

Coal, 57.

Colloids, 77, 123, 128, 129, 130.

Color, 263.

Combustion, 25.

Complexity, 31.

Compounds of carbon, hydrogen, and oxygen, 202-207.

Compressibility, 262.

Concentration, 171.

Conditions, 31, 164-180.

Conservation of energy, 15, 18, $25,286$.

Constitutional formulas, 197-207.

Contraction, see Expansion.

Copper, 241.

Cosmic evolution, 131, 301-312.

Cosmography, 39, 60, 61 .

Cycle of matter, 26-28.

Cyclic compounds, 200, 201, 219.

Degradation of energy, 18.

Design, 85, 307.

Dew, 105.

Diabetic coma, 157.

Dielectric constant, 121, 122, 125. table, 125.

Digestion, 232.

Distribution, 128, 138.

Double bonds, 200.

Dulong and Petit's Law, 82, 83, 84 .

Durability, 31.

Dynamics, 2, 16.

Earth, 61-63.

Electricity, 256.

Electro-physiology, 124.

Elements, 72, 73.

chemical, 9-15.

figure, 11.

table, 14.
Energy, 15-19, 68, 69, 237.

Entelechy, 293, 300.

Environment, Chapter II (38-

71), 8-21, 32, 33, 183-190.

possible, 49-51.

primary constituents of, 61-63.

Enzymes, 90, 230, 231.

Ethane, 198.

Ethylene, 200.

Evaporation, 92, 97, 98, 101, 102, $103,127,174,180$.

latent heat of, 97-103.

table, 99, 100.

Evolution, 278, 279.

Excretion, 139.

Exhaustiveness of treatment, 253267.

Expansion, 106-110.

table, 107.

Fauna, 186.

Figure, the atomic volume curve, 11.

Final causes, 4, 276.

Fitness, Chapter I (1-37), 4-8, $65,66,69,131,132,266$, 267, 274-282, 305-307.

explained by Darwin, 5 .

Flora, 186.

Form, 24, 26, 32.

Formaldehyde, 225, 228, 229.

Freezing point, 93, 94, 178, 179. depression, 178, 179. tables, 178, 179. table, 94 .

Frog's muscle, 262.

Fusion, 92-94.

latent heat, 92-97. table, 95, 96.

Gastric juice, 242.

Gay-Lussac's Law, 177.

Geology, 73, 112, 173.

Geophysics, 52-55.

Germanium, 12, 13.

table, 13.

Glucose, 160, 222-227.

formation, 227.

mutarotation, 223.

reactions, 224-226.

Glycerophosphoric acid, 241, 242. 
Glycogen, 234.

Gulf Stream, 182.

Hæmocyanine, 241.

Hæmoglobin, 241.

Heat of combustion, 69, 217, 245, 246. table, 245.

Heat of formation, 244-247. tables, 244, 247.

Heat of reaction, 235, 236, 243247.

table, 236.

Helium, 41, 42, 58.

Henry's Law, 137.

Herring, 175.

Heterogeneous equilibrium, 151, 158.

Hexakontane, 210.

Hexanes, 198, 199.

Hippuric acid, 234.

Histidine, 226.

Homogeneous equilibrium, 149.

Hydrocarbons, 197-202.

Hydrogen, 55, 56, 58, 64, 211, $237-243,245$.

ions, 141-143, 169.

in sea water, table, 169.

Hydrogen sulphide, 152.

Hydrolysis, 159, 232-237.

Hydroxyl ions, 141-143.

Impetus, 281, 293-295.

Inactivity, 147.

Inorganic chemistry, 237-243.

Instability, 221.

Interstellar space, 50.

Iodine, 209, 242.

Ionization, 118-126, 155. constant, 140-163, 216. tables, 144, 216. water, 141-143.

Iron, 241.

Lactic acid, 225.

Latent heat, 92-105, 125. tables, 95, 96, 99, 100.

Lesina, 166. table, 166.

Levulose, 224-226.

Life, origin of, 288, 309, 310 .
Light, 256.

Limestone, 136.

Lobry de Bruyn's phenomenon, 224.

Magnesium, 241.

Magnetism, 256.

Mannose, 224-226.

Marmora, Sea of, 168.

Mass Law, 152.

Matter, 8-15.

Mechanics, 255, 256.

Mechanism, 282-300, 301.

Mediterranean, 167, 168, 174.

Melting, sce Fusion.

Melting point, see Freezing point.

Metabolism, 24-28, 32, 33, 35, 158.

Mcteorology, 57, 58, 73-75.

Methane, 197.

Methyl formate, 233, 234.

Methyl glyoxal, 225, 226.

Methyl imidazol, 226.

Mobility, 139, 184.

Mobilization, 115, 141.

Molecular constitution, 28, 196210.

Molecular volume, 125.

Morphology, 23.

Mutarotation, 223, 224.

Mutation, 290.

Natural selection, 4, 156, 274, $280,288$.

Natural theology, 85, 281, 289.

Nebulæ, 48-50.

Neptunism, 73.

Neutrality, 142, 143, 146. regulation, 143-162.

tables, 148, 150.

Nitrogen, 211. compounds of, 208, 209.

North Sea, 168, 169.

Nucleic acids, 241.

Ocean, Chapter V (164-190), 78, $113,114,135,136,153-$ 155.

alkalinity, 167-171.

table, 169.

as environment, 183-190. 
Ocean, concentration, 171-176. table, 171. currents, 88, 180-182. mobility, 180-182.

osmotic pressure, 176-179. tables, 178, 179.

regulation of conditions, 164180.

temperature, 165-167. tables, 165, 166, 167.

Oceanography, 165.

Edema, 161.

Optical activity, 223.

Order, 1.

Organic chemistry, 28-30, 191237.

Organism, 21-36, 63, 76.

Osmotic pressure, 176-180.

Oxidation, 25, 246, 247.

Oxygen, 64, 211, 237-243.

Paleocrystic ice, 108.

Panspermia, 50.

Paraffine hydrocarbons, 212, 214.

Partial pressure, 137.

Periodic system, 9, 11, 14, 210, $211,303,304$.

figure, 11.

table, 14.

Pharmacological action, 175.

Phase Rule, 257-261.

Phosphoric acid, 146, 147, 156.

Phosphorus, 241, 242.

Photosynthesis, 27, 227-231.

Physical chemistry, 256, 257.

Physiology, 22, 123, 124.

Planets, 46, 60.

Possible environments, 49-51.

Primary constituents of the environment, 61-63.

Propane, derivatives of, 203-205.

Properties of matter, 70 .

interconnection, 276, 277.

omitted, 261, 262.

Proteins, 156, 242.

Protoplasm, 26, 129, 130, 153, $155,156$.

Purpose, 1, 307.

Radicals, 211-218.

Rain, 105.
Red Sea, 174.

Reduction, 227, 228, 231, 244, 247.

Reflex action, 284.

Regeneration, 290-292.

Regulation, 31, 164-180, 186, 189.

Repair, 290-292.

Respiratory center, 157.

Rivers, 113, 172, 180. composition, 113. table, 113.

Salinity, 113, 114, 171-175, 187. table, 171.

Salt, 113, 114, 172, 173.

Sea urchin, 175.

Sea water, 114, 153, 154, 155, 185.

a balanced solution, 175 .

Silicon, 66, 265.

Skager-Rack, 168.

Soil, 78, 127.

Solar system, 60,61 .

Solidification, 108.

Solubility, 136-138, 140.

of carbonic acid, 136-140.

Solvent, 68, 79, 111-118, 121.

Sound, 256.

Space, 19-21.

Specific heat, 67, 68, 80-91.

Stability, 78, 150, 164, 186, 218.

Stars, 41-44, 50.

Sugars, 218, 222-232.

Sulphur, 209, 242.

Sulphureted hydrogen, 152.

Sulphurous acid, 169.

Summary, 267-273.

Sun, 44-46, 50, 60 .

Surface temperature, 166.

Surface tension, 126-130.

Survival of fittest, 288.

Synthesis, 192, 286.

Tables:

Absorption coefficients, 137.

Alkalinity and acidity, 148, 150.

Alkalinity of sea water, 169 .

Comparison of blood and sea water, 187.

Comparison of properties, 125.

Composition of air, 135 . 
Composition of blood serum, 116.

Composition of river water, 113.

Composition of sea water, 171.

Derivatives of propane, 203205.

Elements, 14.

Expansion of water, 107.

Fitness, 250-252.

Freezing point of blood serum, $178,179$.

Germanium, 13.

Heat conductivity, 106.

Heat loss of dog, 103.

Heats of combustion, 245.

Heats of formation, 247.

Heats of reaction, 236.

Heats of reduction, 244.

Ionization constants, 144, 216.

Latent heat of fusion, 95, 96.

Latent heat of vaporization, $99,100$.

Melting points, 94 .

Normal temperatures, 87.

Properties omitted, 261, 262.

Range of temperature, 165,166 , 167.

Specific heats, 81,83 .

Surface tension, 126.

Vapor tension, 105.

Teleology, 279-282, 289, 298-300, 301, 305-312.

Temperature, 67, 137, 153, 165, $166,167,170,188$.

range, $165,166,167$.

tables, $165,166,167$.

tables, 87, 165, 166, 167.

Temperature regulation, 70,86 , $87,89,91,95,98,102,103$, $109,167$.

Theory of solution, 177, 179 .

Thermal conductivity, 106, 125 . table, 106.

Thermal properties, 80-110.
Thermochemistry, 243-248.

Thermodynamics, 16, 18, 19, 128.

Time, 19-21.

Trade winds, 181.

Treble bonds, 200 .

Urea, 192, 234.

Urine, 117.

Valence, 196, 197.

Van der Waals's constant $a, 125$.

Vaporization, see Evaporization.

Vapor tension, 104, 105.

table, 105.

Variable stars, $46,47$.

Variety, 68, 207, 220.

Velocity of reaction, $90,94,159$, $170,171$.

Vital force, 191, 286.

Vitalism, 282-300, 305.

of Bergson, 293-298.

Volcanoes, 56, 134.

Water, Chapter III (72-132), 57, $61-67,131$; transparency, 100 ; as element, 72,73 ; universal importance, 7378 ; quantity and distribution, 78-79; chemical inertness, 79 ; thermal properties, $80-110$; specific heat, 80-91; effect upon temperature, 86-91; latent heat, 92-105; evaporation, 101-104; vapor tension, 104, 105; thermal conductivity, 106 ; expansion, 106-110; solvent, 111-118; ionization, 118126 ; surface tension, 126130 ; in soil, 126, 127; fitness, 131.

vapor, 101.

Weathering, 114, 140.

Winds, 88, 181. 

THE following pages contain advertisements of a few of the Macmillan books on kindred subjects. 



\title{
The Science of Human Behavior
}

\author{
By \\ MAURICE PARMELEE \\ Professor of Sociology, University of Missouri
}

Cloth, \$2.00 net; postpaid, $\$ 2.14$

This is the first book to bring together the results of the most recent work in biology, zoölogy, neurology in particular, in genetic and comparative psychology, and in anthropology, showing the significance of this work for the analysis of the fundamental factors in the determination of human behavior; namely, instinct, intelligence, feeling, and the different types of social relationships.

The book contains contributions which are vital to psychologists, anthropologists, and social scientists, and will be of great value to the general reader bringing together in convenient form the results of work which is of so much significance for the study of human behavior and human nature. To those engaged in educational work it will be of great use, and will be found valuable as a college and university text-book in certain courses in psychology and sociology.

\section{THE MACMILLAN COMPANY}




\section{An Outline of \\ the Theory of Organic Evolution}

With a Description of some of the Phenomena which it explains

By MAYNARD M. METCALF, Ph.D.

Professor of Biology in the Woman's College of Baltimore

Second Edition, Revised

Cloth, 8vo, Colored Plates, $\$ 2.50$ net

The lectures out of which this book has grown were written for the author's students at the Woman's College of Baltimore, and for others in the college not familiar with biology who had expressed a desire to attend such a course of lectures. The book is, therefore, not intended for biologists, but rather for those who would like a brief introductory outline of this important phase of biological theory.

It has been the author's endeavor to avoid technicality so far as possible, and present the subject in a way that will be intelligible to those unfamiliar with biological phenomena. The subject, however, is somewhat intricate, and cannot be presented in so simple a manner as to require no thought on the reader's part; but it is hoped that the interest of the subject will make the few hours spent in the perusal of this book a pleasure rather than a burden.

In many instances matter that might have been elaborated in the text has been treated in the pictures, which, with their appended explanations, form an essential part of the presentation of the subject. This method of treatment has been chosen both for the sake of the greater vividness thus secured and because it enables the book to be reduced to the limits desired. Many of the illustrations have been obtained from books with which the reader may wish later to become familiar.

\section{THE MACMILLAN COMPANY}




\section{THE WORKS OF HENRI BERGSON \\ Professor at the College de France}

\section{Time and Free Will}

\section{An Essay on the Immediate Data of Consciousness}

Authorized Translation by F. L. Pogson, New York

Cloth, 8vo, \$2.75 net

"The translation is faithful and readable. There are added a sympathetic preface by the translator and an admirably comprehensive bibliography of articles about Bergson's philosophy in several languages. The first presentation of this important contemporary to our public has been so well done that all readers of the book must lament the sudden death of the young Oxford scholar to whom we owe the service." - Nation.

"This is a great work, profoundly original, rigorous and keen in analysis, clear in statement; and while showing that language compels us to treat life and its problems in a symbolical manner, yet it also shows that a close analysis of experiénce clearly reveals the true concrete life. Professor Bergson does nut profess to cover the entire field of philosophy in this volume, but what he has covered is done in such an original and profound way that no one who pretends to keep abreast of philosophical thought will ignore it." - Boston Transcript.

\section{Matter and Memory}

Translated by Nancy Margaret Paul and W. Scott Palmer

$$
\text { Cloth, 8vo, } x x+339 \text { pages, index, } \$ 2.75 \text { net; by mail, } \$ 2.93
$$

This translation has been made from the fifth edition, I908, of " $\mathrm{Ma}$ tière de Mémoire," by Henri Bergson, Member of the Institute and Professor at the College de France. It has the very great advantage of being revised in proof by the author. A new introduction has also been written which supersedes that which accompanied the original work. The reader's attention is called to the fact that all the marginal notes are peculiar to the English edition; and that M. Bergson is not responsible for their insertion or character.

\section{Laughter}

Cloth, \$1.25 net; by mail, \$I.37

The work has been highly successful in France, where it is in its seventh edition. It has been translated into Russian, Polish, and Swedish. German and Hungarian translations are under preparation. Its success is due partly to the novelty of the explanation offered of the comic, and partly also to the fact that the author incidentally discusses questions of still greater interest and importance.

\section{THE MACMILLAN COMPANY}

\section{Publishers}

64-66 Fifth Avenue
Now York 





QH

541

H35

BioMed
Henderson, Lawrence Joseph The fitness of the environment 
